\title{
Papa don't preach : parenting and adolescent smoking cognitions and behavior
}

Citation for published version (APA):

Huver, R. M. E. (2006). Papa don't preach : parenting and adolescent smoking cognitions and behavior. [Doctoral Thesis, Maastricht University]. Universiteit Maastricht. https://doi.org/10.26481/dis.20060929rh

Document status and date:

Published: 01/01/2006

DOI:

10.26481/dis.20060929rh

Document Version:

Publisher's PDF, also known as Version of record

\section{Please check the document version of this publication:}

- A submitted manuscript is the version of the article upon submission and before peer-review. There can be important differences between the submitted version and the official published version of record.

People interested in the research are advised to contact the author for the final version of the publication, or visit the DOI to the publisher's website.

- The final author version and the galley proof are versions of the publication after peer review.

- The final published version features the final layout of the paper including the volume, issue and page numbers.

Link to publication

\footnotetext{
General rights rights.

- You may freely distribute the URL identifying the publication in the public portal. please follow below link for the End User Agreement:

www.umlib.nl/taverne-license

Take down policy

If you believe that this document breaches copyright please contact us at:

repository@maastrichtuniversity.nl

providing details and we will investigate your claim.
}

Copyright and moral rights for the publications made accessible in the public portal are retained by the authors and/or other copyright owners and it is a condition of accessing publications that users recognise and abide by the legal requirements associated with these

- Users may download and print one copy of any publication from the public portal for the purpose of private study or research.

- You may not further distribute the material or use it for any profit-making activity or commercial gain

If the publication is distributed under the terms of Article $25 \mathrm{fa}$ of the Dutch Copyright Act, indicated by the "Taverne" license above, 


\section{PAPA DON'T PREACH}

\section{parenting and}

adolescent smoking

cognitions and behavior 
Promotores:

Prof.dr. H. de Vries

Prof.dr. R.C.M.E. Engels (Radboud Universiteit Nijmegen)

Beoordelingscommissie:

Prof.dr. N.K. de Vries (voorzitter)

Prof.dr. T.F.M. ter Bogt (Universiteit Utrecht)

Prof.dr. L. Goossens (Katholieke Universiteit Leuven, België)

Prof.dr. R.A. Knibbe

Dr. S.P.J. Kremers

Cover design and layout by One Fish/Gouw\#

Printed by Optima Grafische Communicatie

ISBN: 90-8559-208-9

The studies presented in this thesis were conducted under the auspices of the CaRe and Public Health Research Institute (Caphri) in the Faculty of Health Sciences of Maastricht University, the Netherlands. Caphri is part of the Netherlands School of Primary Care Research (CaRe), which has been acknowledged since 1995 by the Royal Netherlands Academy of Arts en Sciences (KNAW). The studies described in Chapters 3 and 6 of this thesis were conducted with financial support from the European Commission (Tobacco Research and Information Fund; 96/IT/13-B96 Soc96201157). Publication of this thesis was financially supported by STIVORO for a smoke free future. This support is gratefully acknowledged. 


\section{PAPA DON'T PREACH}

parenting and adolescent smoking cognitions and behavior

\section{PROEFSCHRIFT}

ter verkrijging van de graad van doctor aan de Universiteit Maastricht, op gezag van de Rector Magnificus

Prof. mr. G.P.M.F. Mols, volgens het besluit van het College van Decanen, in het openbaar te verdedigen op vrijdag 29 september 2006 om 10.00 uur

door

Rosalia Maria Elisabeth Huver 

Well, Raleigh was the person who introduced tobacco in England, and since he was a favorite of the queen's - Queen Bessie he used to call her - smoking caught on as a fashion in the court. I'm sure old Bess must have shared a stogie or two with Sir Walter.

Once he made a bet with her that he could measure the weight of smoke. I admit it's strange. It's almost like weighing someone's soul, but Sir Walter was a clever guy.

First he took an unsmoked cigar and he put it on a balance and weighed it. Then he lit it up. He smoked the cigar, carefully tapping the ashes into the balance pan. When he was finished he put the butt into the pan along with the ashes and weighed what was there. Then he subtracted that number from the original weight of the unsmoked cigar. The difference was the weight of the smoke.

(from Smoke by Paul Auster and Wayne Wang) 



\section{Contents}

\section{Chapter 1}

Introduction

Part I: Integrating Parenting in the I-Change Model

Chapter 2

Parenting style and adolescent smoking cognitions

and behavior

Chapter 3

Anti-smoking parenting practices and adolescent

smoking cognitions and behavior

Chapter 4

Personality and parenting style

Part II: On Inconsistent Relations between Anti-Smoking Socialization and Adolescent Smoking

Chapter 5

Is parenting style a context for anti-smoking socialization?

Chapter 6

Bi-directional relations between anti-smoking parenting

practices and adolescent smoking

Chapter 7

General discussion

Notes

References

Samenvatting

Thanks to 

Chapter 1

Introduction 

Smoking is the most important preventable cause of death in Western society, accounting for around 25\% of premature deaths (Bonneux, Looman, \& Coebergh, 2003; Mokdad, Marks, Stroup, \& Gerberding, 2004). In the Netherlands, over 20,000 people a year die of smokingrelated diseases, such as lung cancer, chronic obstructive pulmonary disease (COPD), strokes, and coronary heart disease (STIVORO - rookvrij, 2004a). Scholars have estimated that people who died of smoking in 1990 would have lived an additional 15 years if it were not for their smoking habit. And while the economic costs of smokingrelated morbidity can be quantified, personal harm and losses cannot (Herdman, Hewitt, \& Laschober, 1993).

Smoking behavior is largely established before adulthood. Of adult daily smokers, $89 \%$ had their first cigarette before their $19^{\text {th }}$ birthday and $71 \%$ had started smoking daily by the age of 19 . Similarly, those who do not smoke in their youth are unlikely to start smoking later in life (U.S. Department of Health and Human Services, 1994). Current smoking rates among European adolescents are the highest in the world (Warren, Jones, Eriksen, \& Asma, 2006). In 2004, 46\% of Dutch adolescents aged 10 to 19 years had smoked at least once in their lives. An additional 24\% had smoked in the past four weeks, of whom 15\% indicated that they smoked on a daily basis (STIVORO - rookvrij, 2005). These figures, and the fact that a significant number of young people who smoke will eventually die from smoking (World Health Organization, 2002), underline the need to examine relevant explanatory factors for adolescent smoking behavior, in order to help prevent the smoking habit.

Researchers from various disciplines have tried to explain adolescent smoking from different perspectives. The relevance of proximal or internal cognitive factors has been emphasized, as has the importance of more distal social factors such as characteristics of parenting (Petraitis, Flay, \& Miller, 1995). In the former approach, cognitions or thoughts are assumed to intervene between external stimuli and behavioral outcomes, such as smoking. Although it is assumed that external influences, such as those of parents, are mediated by smoking-related cognitions, few studies 
have empirically tested these assumptions (e.g., Chassin, Presson, Rose, \& Sherman, 1998; Harakeh, Scholte, Vermulst, De Vries, \& Engels, 2004). In the second tradition, most studies have focused on the influence of friends, thereby ignoring parental influences (e.g., Conrad, Flay, \& Hill, 1992; Den Exter Blokland, Engels, Hale, Meeus, \& Willemsen, 2004).

The goal of the research on which this thesis is based was therefore to examine in greater depth the development of adolescent smoking cognitions and behaviors by analyzing the impact of parental influences. Specifically, these studies (a) tested how parenting can be integrated in social cognition models such as the I-Change Model and (b) further examined the relation between parenting and adolescent smoking. This chapter outlines the premises of social cognition theories, and the IChange Model in particular, and relates parenting to adolescent smoking. But first, let us briefly describe some historical trends in smoking.

\section{Historical Trends in Tobacco Use}

Tobacco use originated before 1500 BC in Native America. Thereafter, the use of tobacco was gradually adopted by other parts of the world, though it was not until 1493 that Europeans first took up smoking. The earliest European smoker was allegedly Rodrigo de Jerez, one of Christopher Columbus' fellow explorers, who took his first drag of a cigar in Cuba. After returning to Europe, Jerez was arrested and jailed by the Spanish Inquisition, who regarded the smoke leaving his mouth and nostrils as devilish. Tobacco was imported into Europe in the 1560s, probably by the English slave trader Sir John Hawkins, who brought the commodity from his expeditions to Africa and the Caribbean (Wikipedia Encyclopedia, 2006). After that, Sir Walter Raleigh and Jean Nicot, ambassador of France to Portugal, contributed to the popularization of tobacco use. The tobacco plant Nicotiana and the substance nicotine are named after the latter.

After Sir Walter Raleigh had popularized tobacco use at the court of Elizabeth I around 1600, however, King James I published his treatise 
"A Counterblaste to Tobacco" in 1604, and also around this time, the Vatican banned tobacco use. Nevertheless, smoking became ever more popular, and around 1800, the Dutch town of Gouda housed 350 pipe manufacturers on a total of 11,715 city inhabitants (Wikipedia Encyclopedia, 2006). In the $19^{\text {th }}$ century, the availability of sulfur matches further drove up smoking rates (World Health Organization, 2002), while the first serious questions on the health consequences of smoking arose. In 1828, two dissertations were written in Germany on the substance of nicotine, concluding that it was a dangerous poison (Lacqueur, 1995), and in 1857 The Lancet published several articles under the topic "The Great Tobacco Question: Is Smoking Injurious To Health?” (e.g., Eade, 1857).

During the First and Second World Wars, soldiers massively took to smoking. Cigarettes came to symbolize the camaraderie among men, as well as liberation at the end of the wars (Wikipedia Encyclopedia, 2006). Smoking rates also increased among young people. In 1916, Dutch elementary school teachers reported a $40 \%$ smoking rate among boys (Stolp, 1916). In the 1950s, scientific evidence showing detrimental health effects of smoking accumulated, stimulated by publications by Richard Doll and Bradford Hill in the British Medical Journal, linking smoking to several forms of cancer, including lung cancer (Doll \& Hill, 1954; Doll, 2000).

Public awareness of the health consequences was growing (The New York Times October 12,1958) and became even more pronounced after a study by Ernest Wynder relating smoking to lung cancer (Wynder, 1956) and publications by Larson and his team, who reviewed existing literature relating smoking to health status (Larson, Haag, \& Silvette, 1961). In the Netherlands, Lenze Meinsma led the anti-smoking lobby in this period (Meinsma, 1969). Adolescents were also becoming aware of the detrimental effects of smoking (U.S. Department of Health, Education and Welfare, 1968).

Even today, further evidence is accumulating of the harmful effects of cigarette smoke for adults and youngsters alike (U.S. Department of 
Health and Human Services, 1994; World Health Organization, 2002). Although smoking rates are gradually declining among both adults and youngsters, $30 \%$ of Dutch adults and $24 \%$ of adolescents currently smoke monthly or more (STIVORO - rookvrij, 2004b, 2004c) and it is known that in Western society, more people die from smoking than from AIDS, car accidents, alcohol, suicides, homicides, fires, and illegal drugs together (Lynch \& Bonnie, 1998).

As the harmful effects of smoking are becoming more evident, interest has also grown in factors explaining adolescent smoking. On the one hand, there are social cognition models, which explain adolescent smoking behavior from smoking-related cognitions, but do not explain how these thoughts are formed. On the other hand, social influences such as those of parents have been examined. These two approaches are discussed in more detail below, where an attempt is also made to show that they need not be mutually exclusive and may even be integrated.

\section{Social Cognition Models}

Social cognition models have been used to explain why people engage in certain behaviors, such as smoking among adolescents, posing that decisions to smoke result from internal cognitive factors or thoughts. An example of such a model is the Theory of Reasoned Action (Fishbein \& Ajzen, 1975), according to which adolescent smoking behavior is predicted by two cognitive determinants, viz. the attitude toward smoking and social normative beliefs, which in turn affect the intention to smoke. In this theory, attitude is conceptualized as the result of a weighed costbenefit analysis of the pros and cons of smoking. Hence, if the pros outweigh the cons, a positive attitude toward smoking is established, increasing the likelihood of smoking. Second, social normative beliefs encompass the adolescents' perceptions of norms of significant others. For example, the perceived approval of smoking by parents, siblings and peers is thought to lead to an increased likelihood of adolescent smoking. The Theory of Planned Behavior (Ajzen, 1991) and the ASE- 
Model (Attitude - Social influence - self-Efficacy)(De Vries, Backbier, Kok, \& Dijkstra, 1995; De Vries, Dijkstra, \& Kuhlman, 1988) later added additional cognitive components, labeled perceived behavioral control and self-efficacy, respectively, defined as the estimated ability to perform certain behavior (Bandura, 1986b). In short, adolescents are thought to be more liable to smoke if they have a positive attitude toward smoking, perceive a pro-smoking social norm and have low self-efficacy expectations to refrain from smoking (Petraitis et al., 1995).

The I-Change Model (De Vries, Mudde et al., 2003) is the successor to the ASE-Model and has further developed into an integrative model, combining aspects of various social cognitive models, such as the Health Belief Model (Janz \& Becker, 1984), the Transtheoretical Model (Prochaska, DiClemente, \& Norcross, 1992), and the Precaution Adoption Model (Weinstein, 1988). The model is presented in Figure 1 and has proven successful in predicting adolescent smoking and other health behaviors (Brug, Lechner, \& De Vries, 1995; Lechner \& De Vries, 1995, 2002; Lechner, De Vries, \& Offermans, 1997). It postulates that behavior results from various motivational phases: premotivational, motivational and post-motivational. With regard to the post-motivational phase, action plans are examples of ability factors facilitating the realization of an intention to change. Action plans are the specific plans and actions a person needs to engage in to realize a specific behavior (e.g., reading brochures about non-smoking, thinking about how to refuse cigarette offers). When these action plans are linked to external cues and become automated they are referred to as implementation intentions (e.g., Gollwitzer, 1999; Webb \& Sheeran, 2006). The intention, characteristically the main outcome parameter of the motivational stage, is most directly influenced by motivational factors or cognitions of attitude, perceived social influences and selfefficacy expectations. Additionally, a pre-motivational awareness phase is distinguished referring to the phase in which a person is not yet aware of a particular problem, in general or to the person (i.e., "smoking is not dangerous" or "this does not apply to me") and is determined by factors such as knowledge, risk perceptions and cues to action (Janz \& Becker, 
1984). These factors are in turn thought to be influenced by several information factors (message, channel, source)(McGuire, 1989). Also in the pre-motivational phase and affecting smoking behavior through smoking-related cognitions are the behavioral, psychological, biological, and social/cultural factors (De Vries \& Mudde, 1998). In this model, parenting styles and anti-smoking parenting practices can be considered as predisposing social influences.

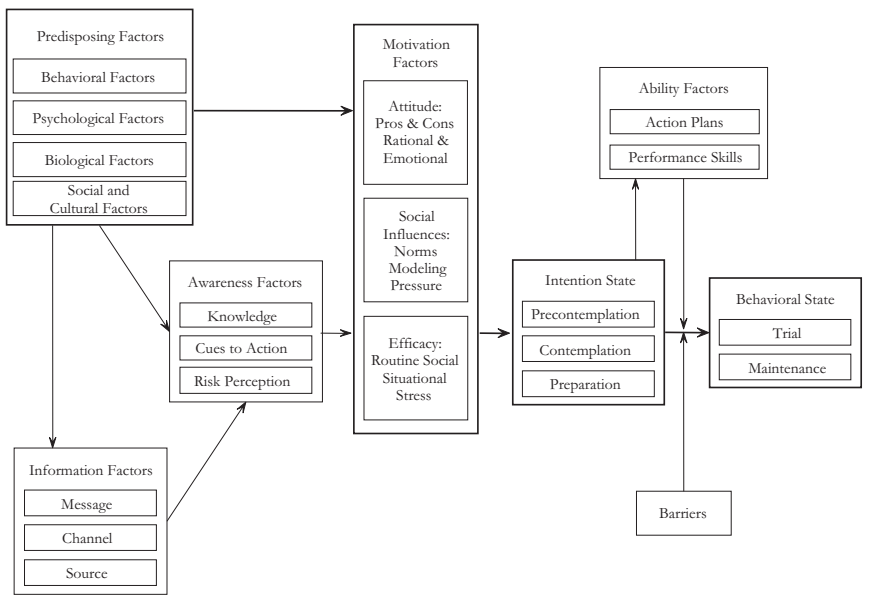

Figure 1

The I-Change Model (De Vries, Mudde et al., 2003)

\section{Parenting and Adolescent Smoking}

\section{Parental vs. Peer Influences}

Another approach to explaining adolescent smoking is to examine the direct influences of significant others. Traditionally, the smoking behavior of friends has been considered a stronger predictor of adolescent smoking than parental smoking behavior (Conrad et al., 1992; Flay, 
d'Avernas, Best, Kersell, \& Ryan, 1983), and obviously few adolescents will light their first cigarette in the presence of their parents (Engels, Harakeh, \& Scholte, 2004-2005). It has further been assumed that parental influences decline as adolescents mature, while peer influences become more prominent (Kandel, 1996; Perry, Kelder, \& Komro, 1993). However, the stability of parental influences has also been demonstrated (Brown, 1990; Chassin \& et al., 1986; De Vries, Engels, Kremers, Wetzels, \& Mudde, 2003) and research has indicated that parental influences may be at least as important as peer influences (De Vries, Candel, Engels, \& Mercken, 2006; Kandel, 1996). Longitudinal studies have confirmed that parental smoking is a strong predictor of adolescent smoking initiation and escalation (Bricker et al., 2006; Conrad et al., 1992 for a review), as have intergenerational studies (Chassin, Presson, Todd, Rose, \& Sherman, 1998) and research into hereditary effects of smoking (Vink, Willemsen, \& Boomsma, 2005). It appears that the focus on the influence of peers in adolescent smoking has meant that the role of parents has been underrated (Den Exter Blokland et al., 2004). Factors of additional importance are whether one or both parents smoke (Bricker et al., 2003; Goddard, 1992) and presumably the intensity of parental smoking (Pederson, Koval, McGrady, \& Tyas, 1998). Finally, the effects of parental smoking are incremental, in the sense that parental smoking cessation seems to be more beneficial if the child is younger (Bricker, Rajan, Andersen, \& Peterson, 2005; Den Exter Blokland et al., 2004).

Fortunately, increasing attention is being paid to parental effects on adolescent smoking (Mayhew, Flay, \& Mott, 2000). Adolescent smoking has been related to aspects of childrearing other than parental smoking, including parenting style (defined as the emotional home climate) and anti-smoking parenting practices, that is, those aspects of parent-child socialization specifically aimed at reducing adolescent smoking (Darling $\&$ Steinberg, 1993). These concepts are described in greater detail below, and related to adolescent smoking. 


\section{Parenting Styles}

Darling and Steinberg (1993) have defined parenting style as the emotional climate in which a family functions and childrearing takes place. Although the effect of parenting climate on child development has been acknowledged (Collins, Maccoby, Steinberg, Hetherington, \& Bornstein, 2000), effects of parenting style have not often been extended to the field of adolescent smoking. The following subsections describe how parenting style has been conceptualized and associated with adolescent smoking.

\section{Two parenting dimensions.}

For decades, researchers have contemplated conceptualizations of parenting climates. Heuristic researchers have broadly taken two approaches to parenting, emphasizing either the child's need for parental control or its need for parental support. Behaviorists such as John Broadus Watson adhered to the first approach and believed that all complex behaviors develop as a result of operant conditioning. Watson demonstrated this in a controversial and widely-cited experiment by conditioning 11-month-old "Little Albert" to fear all furry objects (Watson \& Rayner, 1920). In this view, children are in need of strict parental control to learn, and "too much motherly love" was thought to have detrimental effects (Watson, 1928). By contrast, researchers such as Adler and Rogers adhered to a punishment-free parenting approach, and stimulated parental warmth to achieve optimal child development (Freud, 1933; Robinson \& Green, 2004; Rogers, 1960; Torrey, 1992). In empirical research, there has been relative consensus on these two components of parenting style. The constructs of support and strict control have been frequently used, albeit under different names. For example, what Symonds referred to as the protection/rejection and submission/dominance dimensions (Symonds, 1937), were called love/ hostility and autonomy/control by Schaefer (Schaefer, 1959). Agreement was eventually reached on what good parenting encompassed, having the most beneficial effects on child outcomes: good parents were thought to show both supportive and controlling qualities (Sears, Maccoby, \& Levin, 1957). 
Diana Baumrind $(1966,1967,1971)$ provided a new impulse to parenting style research by identifying the three distinct styles of authoritative, authoritarian, and permissive parents, based on family observations. According to Baumrind, authoritative parents showed medium levels of strict control and provided a pleasant, democratic home climate in which they reasoned with their children. Authoritarian parents exerted the comparatively highest levels of control, allowed little space to their children's free will, and were considered distant. Permissive parents were non-controlling and non-demanding and behaved in an acceptant, nonpunitive, and affirmative manner, willing to give in to a child's behaviors. Authoritative parenting was thought to have the most beneficial effects on child outcomes. In the 1980s, Eleanor Maccoby and John Martin successfully merged the dimensions and styles approaches, by classifying Baumrind's styles along two underlying dimensions, as shown in Table 1, with the responsiveness and demandingness dimensions referring to the notions of support and strict control, respectively (Maccoby \& Martin, 1983). Authoritative parents expect obedience from their children but are also responsive to their children's needs in the sense that they are open to needs for autonomy. Authoritarian parents are commonly powerassertive; they attach great value to maintaining their authority, and employ punishment, including physical punishment. Permissive parents are warm, but indulgent towards their children's impulses. These parents avoid asserting authority wherever possible and do not attempt to govern their children's behavior. Finally, neglectful parents are characterized as indifferent and uninvolved. These parents are not committed to their role as parents and will minimize interaction with their children. This twodimensional classification is still considered applicable to parents today. While parenting style comprises a wide variety of parental behaviors in different situations, and one style may be more appropriate in a certain situation than another, authoritative parents are, on the whole, considered the most competent. 
Table 1

Four Parenting Styles along two Dimensions (Based on Maccoby \& Martin, 1983)

\begin{tabular}{l|ll} 
& Responsive & Unresponsive \\
\hline Demanding & Authoritative & Authoritarian \\
Undemanding & Permissive & Neglectful
\end{tabular}

Criticisms on the operationalization of strict control.

The operationalization of the strict control dimension of parenting style has been criticized. It has been questioned whether Baumrind's measure of control assesses parents' tendency to exercise control or children's willingness to obey. It was doubted whether beneficial effects of strict control were solely due to parental actions or could be the result of children's willingness to be socialized (Lewis, 1981). Similar comments have been made more recently (Kerr \& Stattin, 2000; Stattin \& Kerr, 2000). Strict parental behavioral control is often considered equivalent to parental monitoring of a child's whereabouts, and monitoring levels are usually measured by assessing parental knowledge of their children's whereabouts. Kerr and Stattin have argued that this operationalization of parental monitoring is flawed, as it does not assess how parents have gained this knowledge. Parental knowledge may be rooted in child disclosure as much as in active parental monitoring efforts. In conclusion, when measuring parental strict control, one should assess active monitoring efforts, to discriminate between parent and child actions.

\section{A third dimension.}

In the 1990s, a third parenting dimension was proposed, labeled psychological control. Whereas strict control reflects behavioral monitoring, psychological control reflects parental attempts to control their offspring's psychological world, intruding into and manipulating thoughts, feelings, and attachment bonds (Barber \& Harmon, 2002; Gray \& Steinberg, 1999; Steinberg, Lamborn, Darling, Mounts, \& Dornbusch, 1994). Based on premises and supported by data, five common styles can be derived, namely the authoritative style (high support, high strict control, low psychological control), the authoritarian style (low support, 
high strict control, low psychological control), the permissive style (high support, low strict control, low psychological control), the rejecting style (low support, low strict control, high psychological control), and the neglectful style (low support, low strict control, low psychological control)(Den Exter Blokland, Engels, \& Finkenauer, 2001; Goossens \& Beyers, 1999, 2000).

\section{Parenting style and adolescent health.}

Research has shown beneficial effects of authoritative parenting. Authoritative parenting has been found predictive of better psychosocial development, greater academic competence, less delinquent behavior, and fewer somatic symptoms in adolescents over time (e.g., Steinberg et al., 1994). With respect to health behaviors, adolescents of authoritative parents tend to eat more fruit and drink less alcohol, and to be less likely to use marihuana (e.g., Beck, Shattuck, Haynie, Crump, \& Simons Morton, 1999; Jackson, Henriksen, \& Foshee, 1998; Kremers, Brug, De Vries, \& Engels, 2003; Radziszewska, Richardson, Dent, \& Flay, 1996). Similarly, prospective effects of authoritative parenting, as measured by combinations of the three underlying aforementioned dimensions, have been found on adolescent smoking, indicating that children of authoritative parents are less likely to initiate smoking (Chassin et al., 2005; O’Byrne, Haddock, \& Poston, 2002; Simons Morton, 2002). In brief, the global family climate affects children's development, and adolescent smoking in particular.

\section{Determinants of parenting style.}

If parenting style affects adolescent smoking, then determinants of parenting may be of indirect relevance (Belsky \& Barends, 2002; Prinzie et al., 2004). Hence, from an interventionist perspective, it would be interesting to find out why some parents are more capable than others (O'Connor, 2002). To date, most studies have focused on high-risk samples, relating parental psychopathology, such as depression, to parenting or examining determinants of maladaptive parenting (Kendler, Sham, \& MacLean, 1997; McGroder, 2000; McLoyd, Jayaratne, Ceballo, \& Borquez, 1994; Simons, Beaman, Conger, \& Chao, 1993). 
Furthermore, most research has focused on teenage parents (Hardy, Astone, Brooks Gunn, Shapiro, \& Miller, 1998; Kessler et al., 1997) or parents of toddlers (Downey \& Coyne, 1990), so there is a lack of insight into factors associated with parenting styles among "normal" parents of adolescents. Parental personality is thought to influence a wide range of other possible individual determinants of parenting, such as marital quality, occupational aspects, and social support (Belsky \& Barends, 2002), making the relation between parental personality and parenting qualities especially interesting. Relative consensus on a five-factor structure of personality has been reached, comprising five personality dimensions commonly labeled extraversion, conscientiousness, agreeableness, emotional stability, and openness (Costa \& McCrae, 1992; Digman, 1990; Saucier \& Goldberg, 1998). Although facets of personality have been related to aspects of parenting (e.g., Kendler et al., 1997; Kochanska, Clark, \& Goldman, 1997; Prinzie et al., 2004), comprehensive insight into the relation between the Big Five personality dimensions and parenting style as described above is still lacking for parents of adolescents.

\section{Anti-Smoking Parenting Practices or Parental Preaching}

It is argued above that parental influences on adolescent smoking have been ignored, and the effects of global parenting styles have been discussed. More recently, it has been proposed that parents can also socialize their children in a more subject-specific manner. Anti-smoking parenting practices are aspects of parent-child socialization aimed at discouraging adolescent smoking (Darling \& Steinberg, 1993), and research has begun to identify several forms of anti-smoking parenting practices. For instance, the presence of anti-smoking rules in the house and more frequent parent-child communication about smoking can lead to reduced levels of adolescent smoking (Andersen, Leroux, Bricker, Rajan, \& Peterson, 2004; Chassin, Presson, Todd et al., 1998; Jackson \& Henriksen, 1997), and parents can also reduce the availability of tobacco products at home (Engels \& Willemsen, 2004; Engels, Finkenauer, 
Kerr, \& Stattin, 2005; Jackson, 1997; Ma, Shive, Legos, \& Tan, 2003). In addition, parental reactions to adolescent smoking are considered to be important (Ma et al., 2003). Parents may react to adolescent smoking by punishing a child (Henriksen \& Jackson, 1998; Jackson, 1997; Jackson \& Henriksen, 1997). On the other hand, parents may also reward children for not smoking. An example of such a reward is the non-smoking agreement that is common in the Netherlands, where parents try to get their children to enter into agreements by offering them the prospect of rewards for non-smoking. In 2004, 27\% of Dutch youths aged 10 to 19 engaged in some form of a non-smoking agreement (STIVORO - rookvrij, 2005).

Although these findings sound promising, research into the effects of antismoking parenting practices on adolescent smoking has been sparse and its findings are inconclusive. The seemingly favorable findings reported above are often based on cross-sectional research, and not all crosssectional studies have found similar positive effects (Engels \& Willemsen, 2004; Harakeh, Scholte, De Vries, \& Engels, 2005). Furthermore, the few available longitudinal studies have failed to find prospective effects of anti-smoking socialization (Den Exter Blokland, Hale, Meeus, \& Engels, 2006; Engels et al., 2005; Ennett, Bauman, Foshee, Pemberton, \& Hicks, 2001). Hence, parental anti-smoking practices could be beneficial, but additional research is needed to examine the circumstances under which preaching anti-smoking messages can be effective.

Several explanations for the inconsistent findings are possible. First, the effectiveness of anti-smoking parenting strategies could depend on parental smoking status. Parents who smoke themselves may be less capable or willing to influence the smoking behavior of their children (Clark, Scarisbrick Hauser, Gautam, \& Wirk, 1999). However, studies have indicated that effects of anti-smoking practices are not moderated by parental smoking status (Bricker, Leroux, Andersen, Rajan, \& Peterson, 2005; Jackson \& Henriksen, 1997). Second, Darling and Steinberg (1993) have suggested that parenting style is a context in which smokingspecific parenting practices are expressed. Hence, parenting practices 
may produce different effects on children in different parenting climates. Finally, parenting is generally considered a determinant of adolescent problem behavior, whereas the way in which children influence their parents has seldom been examined. The few studies that have measured bi-directional effects indicate that parents do indeed react to adolescent problem behavior (Kerr \& Stattin, 2003; Stice \& Barrera, 1995; Van der Vorst, Engels, Meeus, Dekovic, \& Vermulst, in press). Although this idea has not yet been tested for adolescent smoking, it is conceivable that cross-sectional findings are being misinterpreted and previous longitudinal designs are inadequate in that they disregard effects of children on their parents.

\section{Mind the Gaps}

Above, two approaches to explaining adolescent smoking behavior have been distinguished. First, social cognition models explain adolescent smoking as the result of internal cognitive processes and propose that external influences are mediated by these cognitions (Petraitis et al., 1995). Specifically, the I-Change Model regards aspects of parenting as distal social factors (De Vries, Mudde et al., 2003). Second, although parental influences have traditionally been overlooked as research focused on peer influences (Conrad et al., 1992; Den Exter Blokland et al., 2004), parents can influence adolescent smoking by their own smoking behavior, their parenting style and their anti-smoking parenting practices (Darling \& Steinberg, 1993). However, research on these aspects has been scarce and inconsistent, leaving several questions unanswered, which are addressed in this thesis:

1. How is parenting style related to adolescent smoking cognitions and behavior?

2. How are anti-smoking parenting practices related to adolescent smoking cognitions and behavior?

3. Is parental personality associated with parenting style? 
4. Are effects of parenting on adolescent smoking cognitions and behavior moderated by parental smoking status?

5. Does parenting style serve as a context for anti-smoking socialization?

6. Is the relation between parental anti-smoking socialization and adolescent smoking of a bi-directional nature?

To answer these questions, data were collected among adolescents and parents in two projects, as can be seen from Table 2. First, data were gathered in the context of the Study of Medical Information and Lifestyles in Eindhoven (SMILE). SMILE is an ongoing joint project of Maastricht University and 23 family physicians from seven medical practices located in Eindhoven, a city of approximately 200,000 inhabitants situated in the southern part of the Netherlands. The family physicians provided addresses of approximately 2900 adolescents between the ages of 12 and 19 and over 4000 parents, who were then invited to participate. Adolescents were only included in the study if informed consent was received from themselves and their parents. Second, data from the European Smoking prevention Framework Approach (ESFA) were analyzed (De Vries, Mudde et al., 2003; Kremers, De Vries, \& Mudde, 2000). This program was primarily designed to develop and test the efficacy of a comprehensive smoking prevention program, whereby high school students from six European countries were asked to fill out questionnaires in class at the beginning of each school year for four

Table 2

Overview of Studies

\begin{tabular}{lllll}
\hline & $\begin{array}{l}\text { Research } \\
\text { Questions }\end{array}$ & Study & Data Collection & Sample \\
\hline & & & & \\
Chapter 2 & 1,4 & SMILE & May 2003 & 48212 to 19-year-olds \\
Chapter 3 & 2,4 & ESFA & September 1998, 2000 & 2312 13-year-olds at Time 1 \\
Chapter 4 & 3 & SMILE & May 2003 & 688 parents of adolescents \\
Chapter 5 & 5 & SMILE & May 2003 & 48212 to 19-year-olds \\
Chapter 6 & 4,6 & ESFA & September 1998, 1999, 2000 & 1721 13-year-olds at Time 1 \\
\hline
\end{tabular}


consecutive years, starting in the first year of high school. The present research used data from Dutch adolescents in the control condition.

\section{Outline of this Thesis}

While researchers have explained adolescent smoking from social cognition models and by examining parental influences, these two approaches have rarely been integrated. This is addressed in Part I of this thesis. The first two studies of the present project examined whether aspects of parenting can be considered distal social factors in the I-Change Model, as can be seen from Figure 1. More specifically, Chapters 2 and 3 describe whether the I-Change Model can be extended with parenting style and anti-smoking parenting practices, respectively. In addition, direct associations between these aspects of parenting and adolescent smoking behavior are examined, parental smoking status is taken into account and gender differences are considered. Chapter 4 outlines the relationship between parental personality and parenting style, as parental personality may be of indirect relevance to children's development.

Part II of this thesis reports on two studies addressing inconsistencies in research relating anti-smoking parenting practices to adolescent smoking. Chapter 5 examines whether parenting style can be regarded as a context in which anti-smoking socialization takes place (Darling \& Steinberg, 1993). Chapter 6 attempts to explain previously reported inconsistent effects of anti-smoking socialization, proposing that parentchild relations are of a bi-directional nature, in which parents not only influence their children's smoking, but the children's smoking behavior also drives the anti-smoking practices that parents engage in.

Findings of these studies are summarized in Chapter 7, which also addresses limitations of the study designs, implications of the results and provides some concluding thoughts. 




\section{PART I}

integrating parenting in

the I-Change Model 



\section{Chapter 2}

\section{Parenting style and adolescent smoking cognitions and behavior}

Based on: Huver, R. M. E., Engels, R. C. M. E., Van Breukelen, G., \& De Vries, $\mathrm{H}$. (in press). Parenting style and adolescent smoking cognitions and behavior.

Psychology and Health. 



\begin{abstract}
Parenting style and smoking-related cognitions have both successfully predicted adolescent smoking behavior. Data were collected among 482 Dutch adolescents to examine whether effects of parenting styles (authoritative, permissive, authoritarian, rejecting, neglectful, measured by underlying dimensions support, strict control, and psychological control) on adolescent lifetime smoking were mediated by cognitions (pro-smoking attitude, social norm, self-efficacy, intention) and to study the role of gender in this process. Support was not significantly associated with smoking behavior. The inverse relation between strict control and smoking was partly mediated by attitude and intention, both associated with increased smoking. Psychological control related directly to increased lifetime smoking. Combinations of dimensions creating the specific styles were not associated with cognitions or behavior. Maternal and paternal parenting were equally associated with smoking cognitions and behavior. Nor were effects moderated by adolescent gender. Interventions to prevent adolescent smoking initiation should aim at increasing strict control and reducing psychological control.
\end{abstract}




\section{Introduction}

Even though the harmful effects of tobacco use are well known (U.S. Department of Health and Human Services, 1994), a 2003 survey found that $46 \%$ of Dutch adolescents aged 10 to 19 indicated to have smoked at least once in their lives, while $24 \%$ had smoked in the past month and $15 \%$ smoked on a daily basis (STIVORO - rookvrij, 2004b). Researchers have tried to explain adolescent smoking behavior in many ways, for instance by applying social cognition models and by accounting for parenting style (Petraitis et al., 1995). According to social cognitions theories, smoking behavior is the result of social cognitive factors, namely attitudes, social influence perceptions, self-efficacy expectations and intentions (Ajzen, 1991; Conrad et al., 1992; De Vries, Mudde et al., 2003). Others (e.g., Jackson, Bee Gates, \& Henriksen, 1994; O’Byrne et al., 2002) have studied the relation between adolescent smoking behavior and parenting styles, which are defined as "a constellation of attitudes toward the child that are communicated to the child and that, taken together, create an emotional climate in which the parent's behaviors are expressed" (Darling \& Steinberg, 1993). We tried to integrate these two research lines by studying whether the effects of parenting style on adolescent smoking behavior are mediated by smoking-related cognitions.

The theoretical framework applied in this study is the I-Change Model (Integrated Model for Change), a successor to the ASE model (Attitude - Social influence - self-Efficacy)(De Vries, Mudde et al., 2003; Huver, Engels, \& De Vries, 2006). This model of motivational and behavioral change combines aspects of several health psychology theories, such as social learning theory (Bandura, 1977), the Theory of Planned Behavior (Ajzen, 1991), and the Transtheoretical Model (Prochaska et al., 1992). A set of motivational factors, namely attitude, perceived social influences, and self-efficacy expectations, is assumed to influence the intention to smoke, which in turn predicts smoking behavior together with specific goal setting strategies to bridge the intention-behavior gap, referred to as action plans. The advantages and disadvantages of smoking that a person 
perceives together constitute their attitude toward smoking. An example of social influence is social norm, referring to approval of smoking by people in the social climate. Self-efficacy has been described as the estimated ability to engage in a certain behavior, for instance refraining from smoking (Bandura, 1986a). According to the I-Change Model, the cognitions are influenced by several predisposing factors, including social factors. Consequently, parenting style can be viewed as a social predisposing factor within the I-Change Model.

Traditionally, parenting style has been seen as a constellation of two underlying dimensions. The first is parental support (responsiveness), which refers to the affective component of parenting. The second is strict control (demandingness), which denotes monitoring, supervision, and rule-setting (Baumrind, 1966, 1971; Maccoby \& Martin, 1983). While strict control is usually measured by parental knowledge about children's whereabouts, Stattin and Kerr (2000) have argued that parental knowledge is not only the result of parental monitoring, but also of child disclosure, and that a measure of strict control should not only assess parental knowledge, but also active monitoring efforts by the parents. More recently, psychological control has been proposed as a third parenting dimension. Whereas strict control refers to control over a child's behavior, psychological control refers to parental attempts to control offspring's psychological world, such as thoughts, feelings, and attachment bonds. These attempts are often intrusive and manipulative (Barber \& Harmon, 2002; Gray \& Steinberg, 1999; Steinberg et al., 1994). Previous research has established five commonly occurring styles based on scores on these dimensions, viz., the authoritative (high support, high strict control, low psychological control), permissive (high support, low strict control, low psychological control), authoritarian (low support, high strict control, low psychological control), rejecting (low support, low strict control, high psychological control), and neglectful styles (low support, low strict control, low psychological control)(e.g., Den Exter Blokland et al., 2001; Goossens \& Beyers, 1999, 2000).

Beneficial effects of authoritative parenting have been found on several 
adolescent health behaviors, such as alcohol use (Beck et al., 1999), drug use (Jackson et al., 1998), and fruit intake (Kremers et al., 2003). Likewise, authoritative parenting has been inversely related to adolescent smoking (Jackson et al., 1994; Jackson et al., 1998; Pierce, Distefan, Jackson, White, \& Gilpin, 2002), whereas children of parents providing low acceptance and low strict control have been found to be more likely to start smoking (Chassin et al., 2005) and to smoke more regularly (Glendinning, Shucksmith, \& Hendry, 1997). Favorable effects of authoritative parenting on smoking have also been found in a study where authoritative parenting was defined as a climate in which decision-making is a joint process between parent and adolescent, but the parent decides (Radziszewska et al., 1996). In another study, parents' involvement, expectations, and monitoring were negatively associated with smoking initiation (Simons Morton, 2002) and smoking in the past 30 days (Simons Morton, Haynie, Crump, Eitel, \& Saylor, 2001). Furthermore, a nonpermissive parenting style has been found to reduce the likelihood of cigarette use (Mott, Crowe, Richardson, \& Flay, 1999). O'Byrne et al. (2002) found parental intimacy and autonomy granting - the opposite of psychological control - to be associated with reduced chances of smoking initiation and with a greater readiness to quit and more quit attempts when adolescents had already taken up smoking. Finally, psychological control has been found to be correlated with increased current and future smoking behavior (Harakeh et al., 2004). Overall, it is evident that authoritative parenting has favorable effects on adolescent smoking behavior, as do its underlying dimensions.

Few studies, however, have investigated whether parenting can be viewed as a distal factor operating on adolescent smoking behavior through cognitions. In a study among Dutch high-school students, anti-smoking socialization - measured by parental reactions to smoking, house rules on smoking, and communication about smoking - was associated with smoking-related cognitions, which in turn related to lifetime smoking (Huver et al., 2006). Effects of anti-smoking practices on smoking were partly mediated by smoking-related cognitions. As regards general parenting styles, adolescents experiencing maternal support had more 
negative beliefs about smoking (Chassin, Presson, Rose et al., 1998). Another study (Harakeh et al., 2004) found that the effects of the quality of the parent-child relationship on smoking initiation were mediated by attitude toward smoking, self-efficacy, social norm, and intention to smoke. Parental knowledge about their offspring's whereabouts also predicted smoking initiation through self-efficacy and social norm. The effects of the latter two factors on smoking were in turn mediated by the intention to smoke. Although previous work in this field has been limited, these studies suggest that the effects of parenting on adolescent smoking may indeed be mediated by smoking-related cognitions.

Previous research also provides reasons to assume that parental and adolescent gender may moderate the effects of parenting. In one of the few studies distinguishing between maternal and paternal parenting, low levels of paternal support increased the likelihood of smoking, whereas this was not found for maternal support (Piko, 2000). As regards adolescent gender, it has been shown that boys and girls report different experienced parenting strategies (Dornbusch, Ritter, Leiderman, Roberts, \& Fraleigh, 1987), with girls reporting higher levels of both maternal and paternal demandingness (Shek, 1998). In another study, which found parental monitoring to be inversely related to cigarette use, girls experienced closer monitoring than boys (Raboteg Saric, Rijavec, \& Brajsa Zganec, 2001). Engels et al. (2005) found higher levels of psychological control to be associated with increased levels of smoking onset for boys, but not for girls.

In brief, both parenting style and smoking-related cognitions have been found to be associated with adolescent smoking behavior. Earlier work suggests that it is reasonable to assume that effects of parenting operate through these cognitions and that effects differ with parental and adolescent gender. We hypothesized that authoritative parenting and its underlying dimensions (high support, high strict control, low psychological control) would be favorably related to adolescent smoking behavior and that this effect would be mediated by smoking-related cognitions. We also explored the moderating effects of parental and adolescent gender. 


\section{Methods}

\section{Participants and Procedures}

In May 2003, 2,905 Dutch adolescents between the ages of 12 and 19 were sent 16-page questionnaires, along with pre-stamped envelopes, in the context of the SMILE project (Study of Medical Information and Lifestyles in Eindhoven). SMILE is a joint project of Maastricht University and 23 family physicians from seven medical practices located in Eindhoven, a city of approximately 200,000 inhabitants situated in the southern part of the Netherlands. Completing the questionnaire took 30 to 45 minutes, and a telephone helpline and website were available for questions. Anonymity was guaranteed and respondents were informed that whether they participated or not would not be disclosed to their family physicians. Participants were eligible to win a CD voucher. A reminder was sent to those who had failed to respond two weeks after the questionnaire had been mailed. The response rate was $16.6 \%(N=482)$, and while responders did not differ from non-responders in terms of age, girls were slightly more likely to respond than boys $(\mathrm{OR}=1.26, p<.05)$. The adolescents had a mean age of 15.35 years $(S D=2.02)$ and less than $1 \%$ lived on their own. Most respondents were of Dutch origin (76.4\%), and $54.4 \%$ indicated to be religious, which both is representative of the Netherlands (Statistics Netherlands, 2006). Never-smokers made up $60.8 \%$ of the sample, in line with national figures (STIVORO - rookvrij, 2004b).

\section{Measures}

\section{Parenting style.}

Maternal and paternal parenting style were assessed separately, using an instrument based on work by Steinberg and colleagues (Steinberg, Elmen, \& Mounts, 1989; Steinberg, Lamborn, Dornbusch, \& Darling, 1992), which had been translated into Dutch (Beyers \& Goossens, 1999). This 22-item measure assessed the three dimensions of parenting style: support, strict control, and psychological control. Factor analysis with 
Oblimin rotation supported this three-dimension structure. Support was measured by seven statements, such as "I can count on my mother to help me out, if I have some kind of a problem" ( $\alpha=.76$ mother; .83 father; $r=.48, p<.001)$. Six statements such as "My mother REALLY knows what I do with my free time" and "My mother TRIES to know where I go at night" assessed not only parental knowledge but also behavioral monitoring, as has been recommended (Stattin \& Kerr, 2000), together forming the strict control measure $(\alpha=.71$ mother; .82 father; $r=.58, p$ $<.001)$. Nine statements such as "My mother acts cold and unfriendly if I do something she doesn't like" assessed psychological control $(\alpha=.66$ mother; .77 father; $r=.67, p<.001)$. Answers were rated on five-point Likert scales ranging from "completely untrue" to "completely true".

\section{Attitude.}

Four attitude questions measured the degree to which respondents found smoking unhealthy/healthy, bad/good, tasting bad/good, and unpleasant/ pleasant. Answers ranged from 1 to 7 . A mean attitude score was obtained, with higher scores indicating a more positive attitude toward smoking $(\alpha$ $=.85)$ (Huver, Engels, Vermulst, \& De Vries, resubmitted-a).

\section{Social norm.}

Adolescents were asked to what extent they felt that their mother, father, brother(s), sister(s), friends, best friend, and girlfriend/boyfriend thought they should smoke. Answers ranged from 1 "I definitely should not smoke" to 7 "I definitely should smoke" (Kremers, Mudde, \& De Vries, 2001b). A mean score was calculated, with higher scores indicating a higher perceived pro-smoking norm $(\alpha=.96)$.

\section{Self-efficacy.}

Perceived ability to refrain from smoking was assessed with an instrument based on work by Lawrance (De Vries et al., 1988; Kremers et al., 2001b; Lawrance, 1988). A mean score was computed from 10 questions such as "When you feel depressed, are you able to refrain from smoking?" with answers ranging from 1 "I am sure I will smoke" to 7 "I am sure I won't smoke" $(\alpha=.97)$. 


\section{Intention to smoke.}

Respondents were asked which of eight statements described them best, in terms of their intention to smoke in the future. Answers ranged from 1 "I am sure I will never start smoking" to 7 "I think I will start smoking within the next month" and 8 "I smoke already" (Kremers, De Vries, Mudde, \& Candel, 2004).

\section{Adolescent smoking behavior.}

Participants were asked to indicate which of nine statements described them best, ranging from 0 "I have never smoked, not even one puff" to 8 "I smoke at least once a day" (Flay, 1993; Kremers, Mudde, \& De Vries, 2001a; U.S. Department of Health and Human Services, 1994). Since prevention of smoking uptake in adolescence is especially relevant to prevent smoking in later life (Chassin, Presson, Rose, \& Sherman, 1996; Fergusson \& Horwood, 1995), participants were classified as either never-smokers $(0)$ if they indicated never to have smoked, "not even one puff", or as ever-smokers (1) for the remainder of the respondents.

\section{Background variables.}

Several background variables were included as covariates in the regression analyses. We assessed adolescent gender (0 "boy", 1 "girl"), age, religiousness (0 "not religious", 1 "religious"), and ethnicity, based on parental origin ( 0 "not of Dutch origin", 1 "of Dutch origin"). Parental smoking behavior was measured as the number of parents who were perceived as smokers, so scores ranged from 0 to 2 .

\section{Statistical Analyses}

Multiple linear and logistic regression analyses were used to test the hypothesis that effects of parenting style on adolescent smoking behavior were mediated by cognitions. According to Baron and Kenny (1986), three conditions must be met for mediation. First, parenting must be associated with smoking-related cognitions. Second, cognitions should be associated with smoking behavior, after parenting has been corrected for. Third, parenting has to be related to smoking behavior, and the 
inclusion of smoking-related cognitions in the model should result in decreased effects of parenting on smoking. Not only is the $p$-value of the effect expected to inflate, there should also be a decrease in the magnitude of the coefficients. In order to test Baron and Kenny's first criterion, we regressed smoking-related cognitions on parenting variables, after correcting for background variables. The other criteria were tested by means of a stepwise regression analysis in which lifetime smoking was regressed on background variables and parenting dimensions (step 1), attitude, social norm, and self-efficacy (step 2), and intention (step 3). The second mediation criterion means that smoking-related cognitions must be associated with adolescent smoking in step 2 . The third criterion implies that support, strict control, and psychological control must be related to smoking in the first step, and that their effects must decrease in the second and third steps relative to the first.

In addition to these mediation tests, we tested whether maternal parenting was associated with smoking cognitions and behavior in a way that differed from paternal parenting. This was examined for parental smoking behavior and the three parenting dimensions by computing two new predictors for each of these variables: the average $(A)$ and the difference (D) of the maternal and paternal scores, which were included in the linear regression and in step 1 of the logistic regression analysis. It can be shown by writing out a regression equation that if $A$ and $D$ are included as predictors instead of the maternal and paternal scores, then $\mathrm{D}$ is predictive if and only if maternal and paternal parenting have different effects on the outcome of interest. If $\mathrm{D}$ is not significantly predictive, it can be dropped from the model and the regression weight of A gives the effect of maternal as well as paternal parenting. If $\mathrm{D}$ is predictive, then $\mathrm{A}$ and $\mathrm{D}$ must be replaced with the original maternal and paternal scores to test the effect of each.

To see if combinations of dimensions creating specific parenting styles (e.g., authoritative, measured by high support/high strict control and high support/high strict control/low psychological control) helped predict adolescent smoking-related cognitions and behavior, given the inclusion 
of the three dimensions as main effects in the regression model, two-way (e.g., support x strict control) and three-way interactions (support x strict control x psychological control) between parenting dimensions were examined. If the main effects of the dimensions were equal for mothers and fathers (viz., the $\mathrm{D}$ variables as described above were not significant), then interactions were computed between the averaged scores of mothers and fathers on each dimension.

Finally, to determine whether associations of parenting with smoking cognitions and behavior differed for boys and girls, we tested whether adolescent gender interacted with parental smoking and parenting dimensions and styles. We tested the significance of adolescent gender*A and gender* $\mathrm{D}$ in a model with main terms $\mathrm{A}, \mathrm{D}$, and gender. This was done for parental smoking status, as well as each parenting dimension. Non-significant interaction terms were sequentially removed from the model, respecting assumptions of hierarchy, using $\alpha=.01$ instead of .05 to reduce the risk of type I errors due to multiple testing. Predictors were centered before computing interaction terms to prevent multicollinearity (Aiken \& West, 1991; Tabachnick \& Fidell, 2001).

The residuals of all regression analyses were checked for non-normality, outliers, and influential cases (Cook's distance $>1$ ). No serious deviations were found. In view of the nested nature of our sample, with respondents nested within seven practices, we tested the presence of differences between practices with respect to smoking cognitions and behavior by including dummy indicators for practice into the regression models. We found no such effects (all $p>.06$ ). Additional analyses were carried out to correct for socio-economic status (SES), indicated by parental educational level and household income. This hardly affected the results of the regression analyses. The results presented here do not include these two variables because of the large percentage of missing values on both variables (> 43.3\%). 


\section{Results}

\section{Correlations}

Table 1 presents Pearson's correlations between the variables used in our study. Strict control correlated positively with support, and psychological control did so inversely. Gender was only related to psychological control, indicating that girls reported less psychological control. Age was associated with parenting in the sense that older adolescents perceived less support and strict control. Children of religious parents experienced more psychological control. In addition, respondents of Dutch origin were more likely to report higher levels of psychological control. Perceived parental smoking status correlated negatively with strict control. Of the smoking-related cognitions, a positive attitude toward smoking correlated negatively with support and strict control, as did a higher perceived pro-smoking norm. Higher levels of self-efficacy were related to a climate of strict control. By contrast, a higher intention to smoke was associated with less strict control. Lifetime smoking behavior correlated with less support and strict control.

Are Effects of Parenting Style on Smoking Behavior Mediated by Cognitions?

\section{Associations between parenting and cognitions.}

Table 2 present the results of the four linear regression analyses of adolescents' attitude toward smoking, perceived pro-smoking social norm, self-efficacy, and intention to smoke on parenting dimensions, after controlling for adolescent gender, age, religiousness, ethnicity, and parental smoking status. Support was only associated with a less positive perceived social norm toward smoking. Strict control was predictive of all four supposed mediators. More specifically, adolescents under strict control had a less positive attitude toward smoking, perceived less a positive social norm toward smoking, had a higher self-efficacy toward refraining from smoking, and had a lower intention to smoke. Psychological control was only associated with self-efficacy, in the sense 


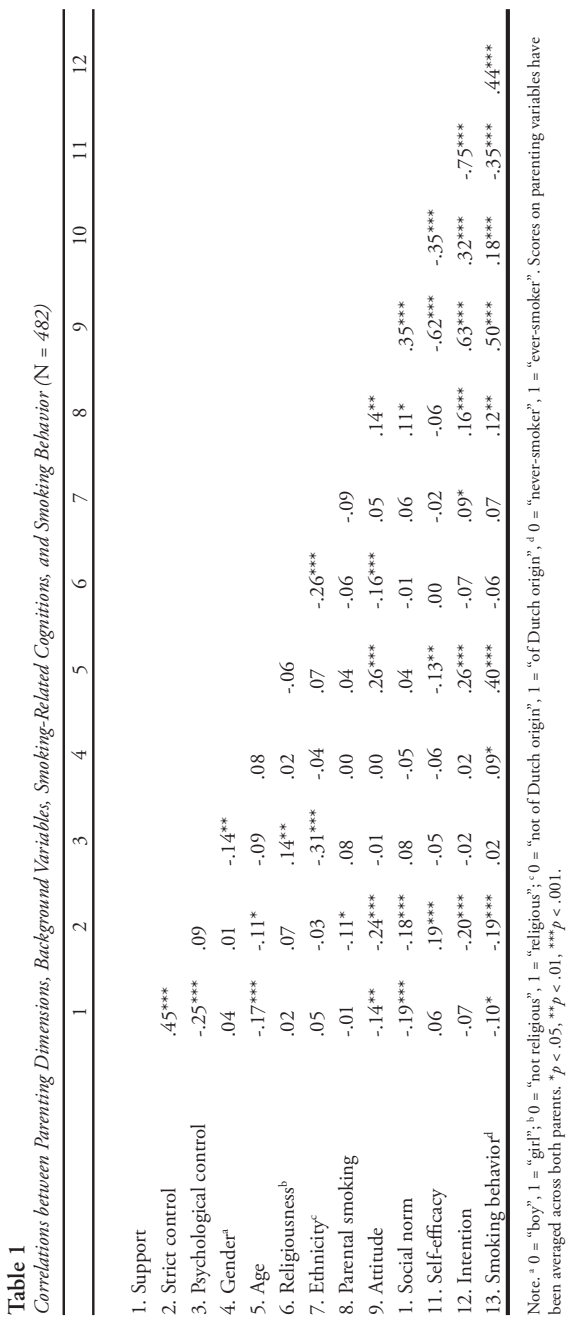

44 
that adolescents reporting a high psychological control climate had lower self-efficacy. We have indicated that the combination of the three parenting dimensions yields the specific parenting styles. We therefore tested whether the combinations of dimensions added to the prediction of smoking-related cognitions. There were no significant interactions between parenting dimensions in their relation to smoking-related cognitions (all $p>0.08$ ), indicating that the specific styles did not contribute to the prediction of smoking cognitions, given the inclusion of the three parenting dimensions as predictors in the model.

Table 2

Results (Standard $\beta$ values) of Linear Regression Analyses of Smoking-Related Cognitions on Mothers' and Father' Parenting Dimensions $(\mathrm{N}=482)$

\begin{tabular}{|c|c|c|c|c|}
\hline Variable (scale range) & $\begin{array}{l}\text { Attitude toward } \\
\text { smoking }\end{array}$ & $\begin{array}{l}\text { Perceived } \\
\text { pro-smoking } \\
\text { social norm }\end{array}$ & Self-efficacy & $\begin{array}{l}\text { Intention } \\
\text { to smoke }\end{array}$ \\
\hline Gender $^{a}$ & -0.03 & -0.06 & -0.07 & 0.02 \\
\hline Age & $0.24^{* * *}$ & -0.03 & -0.09 & $0.22^{* * *}$ \\
\hline Religiousness $^{\mathrm{b}}$ & $-0.10^{*}$ & 0.06 & -0.06 & 0.00 \\
\hline Ethnicity $^{c}$ & 0.04 & 0.10 & -0.05 & $0.11^{*}$ \\
\hline Parental smoking & $0.11^{*}$ & 0.08 & 0.03 & 0.08 \\
\hline Support (1-5) & -0.02 & $-0.14^{*}$ & -0.06 & 0.04 \\
\hline Strict control (1-5) & $-0.19^{* * *}$ & $-0.12^{*}$ & $0.22^{* * *}$ & $-0.17^{* *}$ \\
\hline Psychological control (1-5) & 0.03 & 0.05 & $-0.13^{*}$ & 0.07 \\
\hline Adjusted $R^{2}$ & 0.12 & 0.05 & 0.04 & 0.08 \\
\hline
\end{tabular}

Note. ${ }^{2} 0=$ "boy", 1 = "girl"; ${ }^{\mathrm{b}} 0=$ "not religious", 1 = "religious"; ${ }^{\mathrm{c}} 0=$ "not of Dutch origin", $1=$ "of Dutch origin". Scores on parenting variables have been averaged across both parents. ${ }^{*} p<.05,{ }^{* *} p<.01,{ }^{* * *} p<.001$.

\section{Associations between cognitions and lifetime smoking.}

Table 3 present the results of the stepwise logistic regression analyses of lifetime smoking on background variables and parenting dimensions (step 1), attitude, social norm, self-efficacy (step 2), and intention (step 3). After controlling for background variables and parenting, respondents with a pro-smoking attitude were more likely to have smoked. Social 
norms and self-efficacy were not associated with smoking behavior. A higher intention to smoke was related to an increased probability of having smoked. Effects of attitude on smoking remained significant and almost unchanged after intention had been included in the model, ruling out complete mediation of attitude by intention, notwithstanding their association in the univariate analyses.

\section{Associations between parenting and lifetime smoking.}

Total effects of support, strict control, and psychological control on adolescent never/ever smoking, after correction for background variables, are listed under step 1 in Table 3. We did not find a significant association between support and smoking. By contrast, adolescents under strict control were less likely to have smoked. Adolescents reporting higher levels of psychological control had a higher probability of lifetime smoking. Accounting for cognitions in the model (steps 2 and 3) caused strict control to become less significant. Psychological control remained a significant variable in the model after attitude, social norm, self-efficacy, and intention had been accounted for. Interactions of dimensions were not significantly related to smoking. As such, creating specific parenting styles (e.g., authoritative) out of two or three underlying dimensions did not add to the prediction of adolescent smoking (all $p>.13$ ).

Considering that (1) strict control was associated with attitude toward smoking and intention to smoke, (2) attitude and intention were related to lifetime smoking, and (3) strict control was associated with smoking behavior and effects decreased after inclusion of smokingrelated cognitions in the model, we conclude that the protective effects of strict control on lifetime smoking were partly mediated by attitude toward smoking and intention to smoke. With respect to the other two parenting dimensions, the effects of support and psychological control on lifetime smoking were not mediated by cognitions, since these effects failed to meet the Baron and Kenny criteria for mediation and the deteriorating effects of psychological control thus operated directly on smoking behavior. 
Table 3

Results of Logistic Regression Analyses of Lifetime Smoking Behavior ( $O=$ Never, $1=$ Ever) on Background Variables and Mothers' and Father' Parenting Dimensions (Step 1), Attitude, Social Norm, Self-Efficacy (Step 2), and Intention (Step 3)

\begin{tabular}{|c|c|c|c|c|c|c|}
\hline \multirow[b]{2}{*}{ Variables entered (scale range) } & \multicolumn{2}{|c|}{ Step 1} & \multicolumn{2}{|c|}{ Step 2} & \multicolumn{2}{|c|}{ Step 3} \\
\hline & $\overline{\mathrm{OR}}$ & $\bar{p}$ & OR & $\bar{p}$ & OR & $\bar{p}$ \\
\hline Gender $^{a}$ & 1.54 & .086 & 1.68 & .066 & 1.66 & .075 \\
\hline Age & 1.56 & $<.001$ & 1.51 & $<.001$ & 1.52 & $<.001$ \\
\hline Religiousness $^{b}$ & 0.94 & .790 & 1.10 & .730 & 1.12 & .695 \\
\hline Ethnicity ${ }^{c}$ & 2.38 & .014 & 2.65 & .013 & 2.42 & .023 \\
\hline Parental smoking & 1.37 & .073 & 1.26 & .236 & 1.26 & .241 \\
\hline Support $(1-5)$ & 1.72 & .055 & 1.81 & .059 & 1.78 & .071 \\
\hline Strict control (1-5) & 0.53 & .003 & 0.66 & .084 & 0.68 & .107 \\
\hline Psychological control (1-5) & 1.96 & .017 & 1.94 & .031 & 2.00 & .024 \\
\hline Attitude (1-7) & & & 2.22 & $<.001$ & 1.93 & $<.001$ \\
\hline Social norm (1-7) & & & 0.94 & .719 & 0.94 & .719 \\
\hline Self-efficacy (1-7) & & & 0.81 & .247 & 0.96 & .848 \\
\hline Intention & & & & & 1.71 & .026 \\
\hline Nagelkerke's $R^{2}$ & & 0.26 & & 0.42 & & 0.44 \\
\hline
\end{tabular}

Note. ${ }^{2} 0$ = "boy", 1 = "girl"; ${ }^{\mathrm{b}} 0=$ "not religious", 1 = "religious"; ' 0 = "not of Dutch origin", 1 = "of Dutch origin". Scores on parenting variables have been averaged across both parents. For quantitative predictors the OR reflects the effect of one unit increase of the predictor on lifetime smoking. The effect of $k$ units increase is equal to $\mathrm{OR}^{* *} k$.

\section{Are Effects of Parenting Moderated by Gender?}

We tested whether maternal smoking behavior differed significantly from paternal smoking behavior in relation to adolescent smoking cognitions and behavior (see the Methods section for a more detailed explanation of this procedure). The difference scores (maternal smoking minus paternal smoking) did not add to the prediction of smoking related-cognitions or lifetime smoking (all $p>.14$ ), indicating that maternal and paternal smoking behavior were similarly associated with adolescent smoking cognitions and behaviors. In addition, we examined whether maternal and paternal parenting dimensions differently influenced adolescents. Again, the difference scores (maternal minus paternal score on each dimension) were not significant (all $p>.07$ ). Thus, associations of support, strict control, and psychological control with adolescent smoking-related cognitions and behavior were the same for both parents. 
To study moderation by the adolescents' gender, we computed interaction terms of gender with parental smoking and parenting dimensions and styles. These were all not significant using the more stringent significance level (adjusted $\alpha$ of .01, all $p>.04$ ), indicating that the effects of parenting on adolescent smoking-related cognitions and lifetime smoking behavior were equal for boys and girls.

\section{Additional Analyses}

To examine whether results depended on the age of the adolescent, we computed interaction terms of all parenting and smoking-related cognition variables with age. None of the interaction terms proved significant (all $p>.05$ ). The associations of parenting with cognitions and of parenting and cognitions with smoking were thus independent of the age of the adolescent.

\section{Discussion}

The first goal of our study was to examine whether parenting style (measured by the underlying dimensions of support, strict control, and psychological control) affected adolescent lifetime smoking behavior through the smoking-related cognitions in the I-Change Model, namely attitude toward smoking, perceived pro-smoking social norm, selfefficacy expectations, and intention to smoke. Secondly, we examined whether maternal parenting differed from paternal parenting in its relations with smoking-specific cognitions and behavior, and whether associations between parenting and smoking cognitions and behavior were moderated by the gender of the adolescent. We found that the inverse relation between strict control and adolescent lifetime smoking was partly mediated by attitude toward smoking and intention to smoke, both related to increased lifetime smoking. Psychological control, however, did not operate through cognitions and was directly associated with increased smoking. Specific parenting styles (e.g., authoritative) created out of scores on two or three underlying dimensions were not 
associated with smoking cognitions or behavior. Effects of maternal parenting did not differ from those of paternal parenting, and the relations between parenting and cognitions and smoking behavior were similar for boys and girls.

With respect to the associations between parenting and lifetime smoking, strict control was related to reduced adolescent smoking, which was as hypothesized and in agreement with previously published results (Gray \& Steinberg, 1999; Otten, Engels, \& Van den Eijnden, in press-a; Simons Morton et al., 2001; Simons Morton, 2002). The finding that psychological control had unfavorable effects on smoking is also in line with our expectations and previous findings (O'Byrne et al., 2002), possibly the result of reactance processes (Mott et al., 1999). Unlike previous studies, we failed to find a beneficial association between support and adolescent smoking (Glendinning et al., 1997; Gray \& Steinberg, 1999). It has been shown, however, that strict control is a stronger predictor of adolescent problem behaviors than support (Gray \& Steinberg, 1999), and a lack of effect of support on smoking initiation among Dutch adolescents has been reported (Den Exter Blokland, Hale, Meeus, \& Engels, submitted). Clearly, cultural differences in the effects of parenting on smoking need to be studied further. We did not even find interaction between support and strict control, so the absence of a significant effect of support holds for adolescents reporting a high level of strict parental control just as well as for those reporting a low level. This contrasts with previous research, which found authoritative parenting to have favorable effects on adolescent smoking behavior (e.g., Jackson et al., 1994; Jackson et al., 1998; Pierce et al., 2002). In our study, specific parenting styles were not related to smoking cognitions or behavior, since including interactions of support, strict control, and psychological control did not improve the prediction, given that the model already included the three main effects. Effects of parenting style thus appear to be the sum of the effects of the three parenting dimensions of which each style is composed. It is reasonable to assume that dimensions operate independently (Gray \& Steinberg, 1999), and our findings support this assumption. 
We hypothesized that the authoritative parenting style and its underlying dimensions would be positively associated with smoking-related cognitions. If effects of parenting on smoking are explained by mediating effects of cognitions, then we expect parenting to be associated with these cognitions, as was indeed found in earlier studies (Chassin, Presson, Rose et al., 1998; Harakeh et al., 2004). Our results show, first, that parental support was not related to adolescent smoking-related cognitions, with the exception of perceived social norm. The absence of relations between support and cognitions is in agreement with the finding that support was not significantly associated with smoking behavior. A similar lack of significant cross-sectional and longitudinal effects of parental involvement was also reported elsewhere (Bush et al., 2005). The fact that support was associated with perceived social norm is not surprising; both constructs relate to perceptions of parenting. Second, those of our adolescents who reported being raised in a climate of strict control had a less positive attitude toward smoking, perceived a lower pro-smoking social norm, had greater self-efficacy about refraining from smoking, and a lower intention to smoke. This is consistent with our expectations and earlier findings (Harakeh et al., 2004). In a strict control climate, characterized by parental rule-setting and monitoring, social norms toward smoking are likely to be more explicitly stated by parents. Interestingly, the associations between strict control by parents and cognitions suggest that these norms are indeed privately accepted and internalized (Kelman, 1958). Third, it has been argued that behavior problems in teenagers, such as smoking, are associated more with parental behavioral monitoring than with psychological control (Barber, Olsen, \& Shagle, 1994; Galambos, Barker, \& Almeida, 2003; Gray \& Steinberg, 1999) and that psychological control corresponds more to internalized than externalized problems in adolescents (Barber \& Harmon, 2002). Psychological control was not related to adolescent attitude, perceived social norm, or intention, but only showed a negative relation with self-efficacy. As parental manipulation is likely to result in low self-esteem in adolescents, this finding fits in with our expectations. The fact that psychological control is directly associated with adolescent 
smoking behavior, without being mediated by cognitions, implies that psychological control directly affects adolescents' smoking behavior.

Attitude and intention were related to increased chances of lifetime smoking. Social norm and self-efficacy were not associated with smoking behavior, and this lack of effect could not be attributed to the mediating role of intention. One could argue that the roles of social norm and selfefficacy need to be re-evaluated (Huver et al., 2006), or that smoking is less of a cognitive process than we assumed (Kremers, De Vries et al., 2004) and that less reasoned pathways to smoking should be examined (e.g., Gibbons, Gerrard, \& Lane, 2003). On the other hand, most adolescents in the age group we studied did not smoke on a regular basis, implying that we primarily studied the difference between never having smoked and experimental or occasional smoking. There is indication that whether youngsters experiment with smoking is less likely to be the result of fully reasoned action than of further progression through smoking stages (Engels, Knibbe, \& Drop, 1999; Kremers, Mudde, De Vries, Brug, \& De Vries, 2004). For example, the I-Change model has been successfully applied to predict adolescent smoking continuation (Ausems, 2003) and cessation (Panday, Reddy, Ruiter, Bergstrom, \& De Vries, 2005). Additional research is needed into the way in which parenting style and smoking-related cognitions operate on progression in smoking stages.

In this study, parenting effects on adolescent smoking-related cognitions and behavior did not significantly depend on either parent gender or adolescent gender. Publications reporting differences in parenting between mothers and fathers are scarce (e.g., Piko, 2000). In our study, maternal parenting was associated with smoking-related cognitions and behavior in the same way as parental parenting, suggesting similar influences of mothers and fathers. In modern-day Western society, parents tend to discuss parenting strategies, resulting in considerable agreement and similarity. Perhaps a more precise instrument of parenting style could differentiate maternal from paternal parenting. Contrary to earlier findings (e.g., Engels et al., 2005; Raboteg Saric et al., 2001), the 
relation between parenting and smoking cognitions or behavior was not moderated by adolescent gender. Apparently, boys and girls are affected by their parents in the same way, as has been previously found in another Dutch sample (Huver et al., 2006).

This study was subject to certain limitations and provides directions for future research. First, we solely used data reported by the adolescents in our assessment of parenting style and parental smoking behavior, which is prone to bias. However, we feel confident about using such data, since there are indications that reports of parenting style by adolescents are more reliable indicators of parents' actions than the parents' own reports (e.g., Engels, Finkenauer, Meeus, \& Dekovic, 2001). Data collected amongst parents might be biased as well, and social desirability strongly affects parental responses to questions on child rearing (Brown, Mounts, Lamborn, \& Steinberg, 1993; Van der Vorst, Engels, Meeus, Dekovic, \& Van Leeuwe, 2005). In any case, it is not so much what parents do that influences their children as how the children experience it (Engels, 2000). Second, autonomy granting has been proposed as the opposite of psychological control (Steinberg et al., 1989) and is defined as the extent to which parents encourage offspring to think for themselves. Recently, however, it has been demonstrated that psychological control and autonomy granting might not be at opposite ends of a continuum, but might be distinct constructs leading to different behaviors in children (Silk, Morris, Kanaya, \& Steinberg, 2003). Future research into these constructs is needed to examine whether autonomy granting may be an additional construct associated with adolescent smoking cognitions and behavior. Third, due to the cross-sectional nature of this study, no conclusions about causality can be drawn. Parenting styles are not necessarily stable over time (Goossens \& Beyers, 1999, 2000; Juang \& Silbereisen, 1999) and it is conceivable that some parents will adopt a different parenting strategy as a consequence of their offspring's smoking. For instance, parents might exert more strict control if they get the idea their son or daughter has started smoking, in which case it is not the parents influencing the adolescents' smoking behavior but the adolescents' smoking habits influencing parenting behavior. 
It is important to stress, however, that previous research has shown prospective effects of parenting (Chassin et al., 2005; Harakeh et al., 2004). Furthermore, smoking-related cognitions are usually seen as predictors of smoking behavior, but may also change in synchrony with the behavior, as a result of cognitive dissonance processes (Stacy, Bentler, \& Flay, 1994). With respect to future research, we strongly emphasize the need for collecting data in multiple waves in family or school settings, allowing for cross-lagged panel analyses, in order to fully comprehend the process by which parents influence adolescent smoking cognitions and behavior.

We conclude that (a) parental support was not significantly associated with adolescent smoking-related cognitions or behavior, (b) protective effects of strict control on adolescent smoking were partly mediated by attitude and intention to smoke and were thus internalized, and (c) psychological control was directly related to increased smoking behavior. With respect to health promotion practice, this implies that interventions trying to achieve favorable changes in adolescent smoking-related cognitions and to prevent smoking onset should focus on increasing strict control by the parents. In addition, reducing levels of psychological control in the child-rearing climate may have favorable effects on adolescent smoking. Such interventions do not need to be tailored to parental or adolescent gender. 



\section{Chapter 3}

\section{Anti-smoking parenting practices and adolescent smoking cognitions and behavior}

Published as: Huver, R. M. E., Engels, R. C. M. E., \& De Vries, H. (2006). Are anti-smoking parenting practices related to adolescent smoking cognitions and behavior? Health Education Research, 21, 66-77. 



\begin{abstract}
The aim of this study was to explain effects of anti-smoking parenting practices on adolescent smoking cognitions and behavior by showing mediating effects of cognitions. Data were gathered among Dutch high school students in the control condition of the European Smoking prevention Framework Approach (ESFA). Anti-smoking parenting practices were measured by parental reactions to smoking, house rules, frequency and content of communication about smoking. Attitudes, perceived social influences, and self-efficacy made up for smoking cognitions. Additionally, intention to smoke was measured. Relations between practices and cognitions were mostly significant. While some practices were associated with less smoking (communication about health risks of smoking, health risks of breathing in smoke, addictive qualities of smoking, attention for smoking in school), others were related to increased chances of smoking (rewards for not smoking; frequency of communication about smoking; communication about being allowed to smoke, price of cigarettes, friends smoking). Effects of parenting hardly varied by parental smoking status or adolescent gender. Several practices operated through cognitions, which was more pronounced in older adolescents. Counter productive effects of practices and the few effects in the longitudinal analyses indicate that the order in which parents and adolescents influence each other should be examined more closely.
\end{abstract}




\section{Introduction}

Early adolescence is a particularly important period in which efforts to prevent smoking uptake and to delay smoking initiation can be effective (Bush \& Iannotti, 1993; Glynn, 1993; Kelder, Perry, Klepp, \& Lytle, 1994). Early adolescence and the transition from primary to secondary school are characterized by a sharp increase in the percentage of youths that have ever tried a cigarette (STIVORO - rookvrij, 2004b; U.S. Department of Health and Human Services, 1994). Of adult daily smokers, $89 \%$ has had their first cigarette before their $19^{\text {th }}$ birthday and $71 \%$ has started daily smoking by age 19 (U.S. Department of Health and Human Services, 1994). By the age of $18,71 \%$ of Dutch adolescents has smoked at least once (DEFACTO-rookvrij, 2001). In addition, 28\% of adolescents aged 10 to 19 , of which $11 \%$ of $10-14$-year-olds, has smoked in the past four weeks (STIVORO, 2003).

The I-Change Model (Integrated Model for Change) proposed by De Vries (De Vries, Mudde et al., 2003) and earlier versions of this model, then called the ASE model (Attitude - Social influence - self-Efficacy), have been successful in predicting smoking and other health behaviors (Brug et al., 1995; De Vries \& Mudde, 1998; Lechner \& De Vries, 1995, 2002; Lechner et al., 1997). As can be seen from Figure 1, this model of motivational and behavioral change combines aspects of several theories, such as Bandura's Social Learning Theory (Bandura, Adams, \& Beyer, 1977), the Theory of Planned Behavior (Ajzen, 1991), the Health Belief Model (Janz \& Becker, 1984), and the Transtheoretical Model (Prochaska et al., 1992). According to the I-Change Model, smoking intention and behavior can be predicted from a set of motivation factors or cognitions, namely attitude, perceived social influences and self-efficacy expectations. Attitudes consist of the advantages and disadvantages a person perceives concerning a certain health behavior. Social influence is a constellation of three types of perceived influence of others, consisting of perceived social norms, behavior and pressure. Finally, self-efficacy is defined as the estimated ability to engage in a certain behavior. These cognitive factors are influenced by several predisposing factors, among which are 
social factors. Behavior is then predicted by intention as well as by ability factors and barriers.

One of the predisposing social factors relates to anti-smoking parenting practices that can be described as content specific acts of parenting (Darling \& Steinberg, 1993). Associations between parenting practices and smoking have been found for parental reactions to adolescent smoking (Ma et al., 2003), such as punishments (Fearnow, Chassin, Presson, \& Sherman, 1998; Henriksen \& Jackson, 1998; Jackson, 1997; Jackson \& Henriksen, 1997), house rules about smoking (Henriksen \& Jackson, 1998; Jackson \& Henriksen, 1997), and communication about smoking (Engels \& Willemsen, 2004; Fearnow et al., 1998; Jackson, 1997; Jackson \& Henriksen, 1997). However, of papers published on this subject, only very few made use of longitudinal data (e.g., Engels et al., 2005; Ennett, Bauman, Foshee et al., 2001).

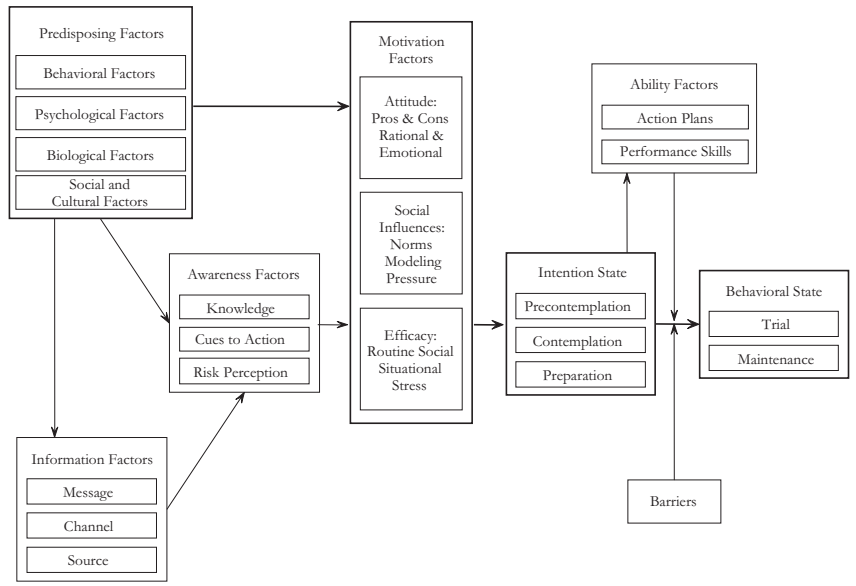

Figure 1

The I-Change Model (De Vries, Mudde et al., 2003) 
While effects of cognitions and anti-smoking parenting practices on adolescent smoking have been established, this study aims to explain effects of anti-smoking practices by taking mediating effects of cognitions into account. In this line of reasoning, parenting practices are considered distal predisposing social factors in the I-Change Model. It is hypothesized that anti-smoking parenting practices are associated with adolescent's smoking cognitions, namely attitude, social influence and self-efficacy. In addition, a model is tested to analyze the effects of antismoking parenting practices on lifetime smoking and the mediating role of smoking-specific cognitions. In addition to proposing this mediating model, the current study goes beyond previous work in terms of three features. This study is set in a representative sample of youngsters. Moreover, this study measures several forms of anti-smoking parenting practices. Finally, effects of anti-smoking practices on smoking behavior were investigated for students in the first year of high school and two years later, as well as longitudinally.

\section{Method}

\section{Participants and Procedures}

Data were gathered in two waves among Dutch students at thirty high schools in the control condition of the ESFA project (European Smoking prevention Framework Approach)(De Vries, Mudde et al., 2003; Kremers et al., 2000). In 1998, all $7^{\text {th }}$ grade students were asked to fill in self-administered questionnaires at the beginning of the school year (T1), with $7^{\text {th }}$ grade being the first year of high school in the Netherlands. This procedure was repeated two years later (T2). The questionnaires had been qualitatively pre-tested (Vroom, 1994) in a representative sample of youngsters. Filled-in questionnaires were put in envelopes and individually sealed, after which the teacher put all the envelopes in a larger one that was sealed in front of the class. Analyses were carried out with $23127^{\text {th }}$ graders $(M=12.71 ; S D=0.54)$ and $24219^{\text {th }}$ graders, the marginal difference in sample sizes being caused by a change in student 
population, due to absenteeism at one measurement point. Respondents that participated in both waves and were never smokers at T1 were included in the longitudinal analyses $(N=1072 ; M=13.02 ; S D=0.73$ at T1). The sample was $51.0 \%$ male and mostly native $(82.0 \%), 4.5 \%$ was from Turkey, $1.9 \%$ from Morocco, $1.1 \%$ from Surinam, $1.0 \%$ from Indonesia, 3.5\% from elsewhere, and $6.0 \%$ had a mixed background. Of the $47.3 \%$ of religious respondents, $31.2 \%$ was Roman Catholic, 6.9\% Islamic, 4.5\% Protestant, 0.3\% Buddhist, and 4.4\% had another religion. At T1, 40.1\% of respondents had ever smoked. Two years later, this percentage was $62.2 \%$. In the longitudinal analyses, $36.7 \%$ of the never smokers at T1 had smoked at T2.

\section{Measures}

Adolescent smoking behavior was assessed by classifying participants in one of two categories. Never smokers were defined as never having smoked a cigarette, not even one puff. Respondents that did not fit into the category of never smokers were classified as ever smokers (Kremers et al., 2001a). Answers were cross-validated using a four-item algorithm assessing current and lifetime smoking status (De Vries et al., 1994; De Vries, Mudde et al., 2003).

Demographical variables taken into account were respondents' age and gender $(0$ = male, 1 = female $)$.

Parental reactions were measured by three questions on five-point scales. Respondents were asked whether their parents would get angry if they found out they smoked. Secondly, they were asked if they would be punished for smoking. Thirdly, participants were asked if they would receive a reward for not smoking.

House rules were measured by seven questions. The adolescents could indicate whether they were allowed to in their own room; the living room; the kitchen; bathrooms and toilets; the hall, corridor and staircases; outside, specifically in the garden, yard, garage or shed. A score of 1 
indicated presence of a house rule of not being allowed to smoke and 0 indicated the absence of such a rule.

Communication about smoking was measured by eleven questions. First, participants were asked to indicate the frequency with which they had discussed the subject of smoking with their parents. Answers ranged from 0 "no/talked about it, but not in the last year" to 4 "yes, often". Subsequently, respondents were asked to indicate whether their parents had discussed the following topics with them: health risks of smoking, health risks of breathing in smoke, non-smoking agreements, being allowed to smoke, places where the adolescent could or could not smoke, prices of cigarettes, addiction, attention paid to smoking in school, friends who smoke, and others offering cigarettes.

Attitudes were measured by 12 smoking-related beliefs on seven-point scales. Factor analysis revealed that variables loaded on one of two unique factors, namely the pros or cons of smoking, which were summed to form two scales of six questions each $(\alpha=.62 ; .72)$ (Kremers et al., 2001b).

Parental social influences were measured with three constructs. Parental social norms were assessed by asking the participants what their mother or father would expect them to do (-3 "I definitely should not smoke" to 3 "I definitely should smoke" $)(r=.67, p<.001)$. Perceived parental smoking behavior was addressed by two dichotomous questions asking respondents about their parents' smoking behavior $(r=.31, p<.001)$. Respondents could indicate the amount of perceived parental pressure by answering whether they had ever felt pressure not to smoke from their mother or father. Answers ranged from 0 "never" to 4 "very often" ( $r=$ $.60, p<.001)$. Maternal and paternal answers were summed.

Self-efficacy was assessed with an instrument based on earlier work by Lawrance (1988). Twelve questions were presented such as "When you are with others who smoke, are you able not to smoke?" and answers ranged from -3 "I am sure I won't smoke" to 3 "I am sure I will smoke". Answers were summed to form a self-efficacy score, ranging from -36 to $36(\alpha=.95)$. 
Intention to smoke was measured by the question "Do you intend to smoke in the future?" with answers from -3 "definitely not" to 3 "definitely".

\section{Statistical Analyses}

Regression analyses were carried out to determine the associations between anti-smoking parenting practices, adolescent smoking cognitions and behavior. Attitude, social influence and self-efficacy were regressed on parenting practices to test the relationship between smoking cognitions and smoking-related parenting practices. In addition, a model was tested using logistic regression to predict lifetime smoking status by parenting practices, adolescent smoking-related cognitions, and intention to smoke. In the first step of the model, age and gender were included as covariates. In its second step, the model tested the direct relations between parenting practices and smoking behavior. In the third step, attitudes, perceived social influences and self-efficacy were entered into to the model. Intention to smoke in the next year was included in the final step. The first two steps were carried out according to the Backward Likelihood Ratio method. By contrast, the cognitions and intention were entered into the model by means of "forced entry" (Tabachnick \& Fidell, 2001). These multiple and logistic regressions were carried out crosssectionally at two points in time to compare the models with children when at different ages, as well as longitudinally, where $\mathrm{T} 1$ variables were used to predict T2 outcomes. Effect sizes $\left(f^{2}\right)$ were calculated. Sizes over .02 were considered small, over .15 medium and over .35 large (Cohen, 1988, 1992).

\section{Results}

Effects of Anti-Smoking Parenting Practices on Smoking-related Cognitions

Results of the backward multiple regressions predicting smokingrelated cognitions by anti-smoking parenting practices at $\mathrm{T} 1, \mathrm{~T} 2$, and longitudinally are shown in Tables 1, 2, and 3, respectively. 
As can be seen from the effect sizes in Table 1, at T1, anti-smoking practices were associated mostly with the cons of smoking, perceived social norm, and perceived behavior, though effect sizes were small. House rules about smoking in the adolescent's own room, and communication about the price of cigarettes or friends smoking were not significantly related to cognitions.

At T2 (Table 2), parenting practices were more often related to cognitions, and standardized beta's and effect sizes increased in comparison to T1. Most associations were found of practices with cons and self-efficacy. Medium effect sizes were found for cons of smoking, perceived social norms, perceived behavior and self-efficacy. Where communication about being allowed to smoke was most frequently associated with cognitions at $\mathrm{T} 1$, no significant relations were found at $\mathrm{T} 2$.

Longitudinally (Table 3), practices were still significantly associated with all smoking-related cognitions, though fewer associations were found and effect sizes were non-existent or small. Perception of parental behavior was influenced most. House rules about smoking in the own room and bathroom or toilets, frequency of communication about smoking, and communication about the health risks of breathing in smoke, being allowed to smoke, places where smoking is allowed, the price of cigarettes, addictive qualities of smoking, and friends smoking were not associated with cognitions. 


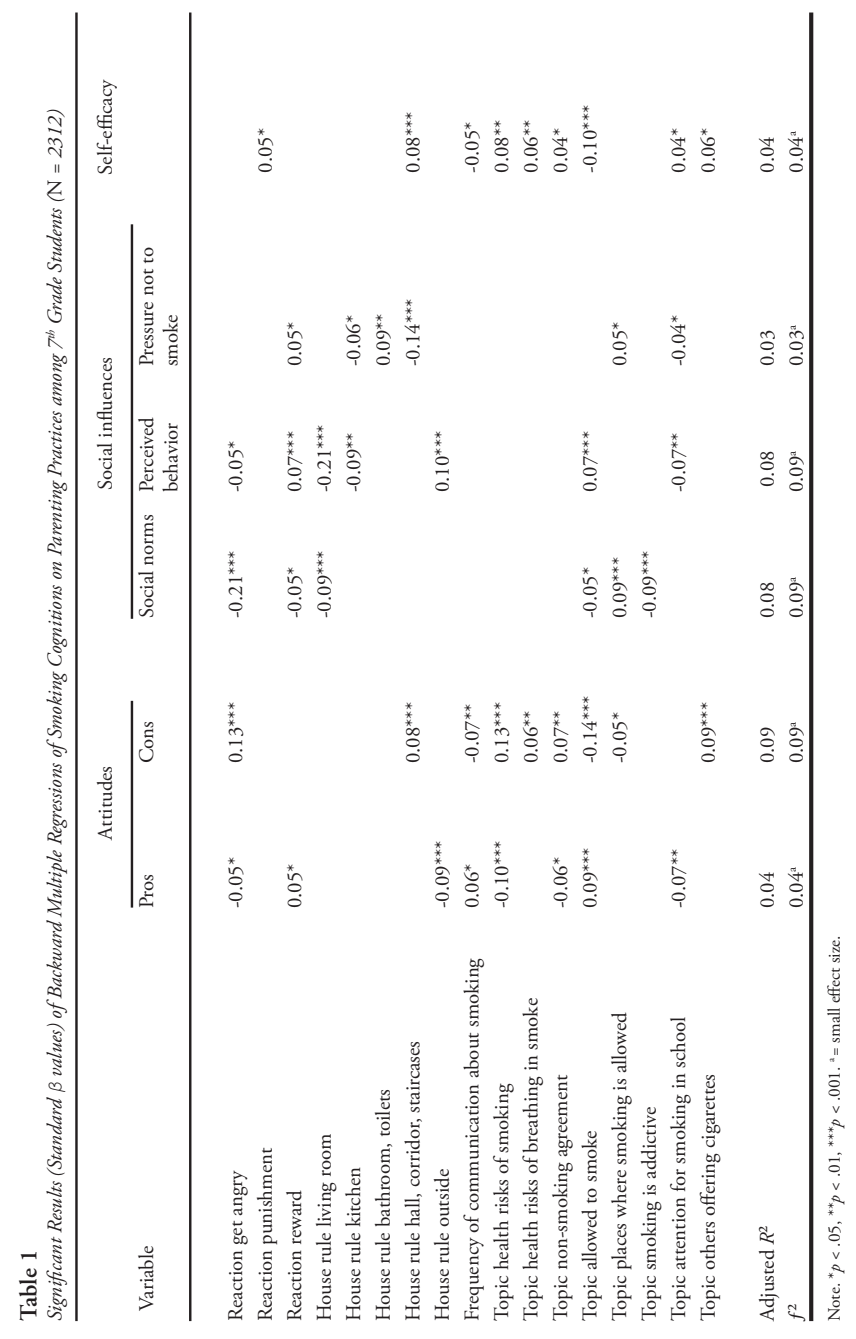




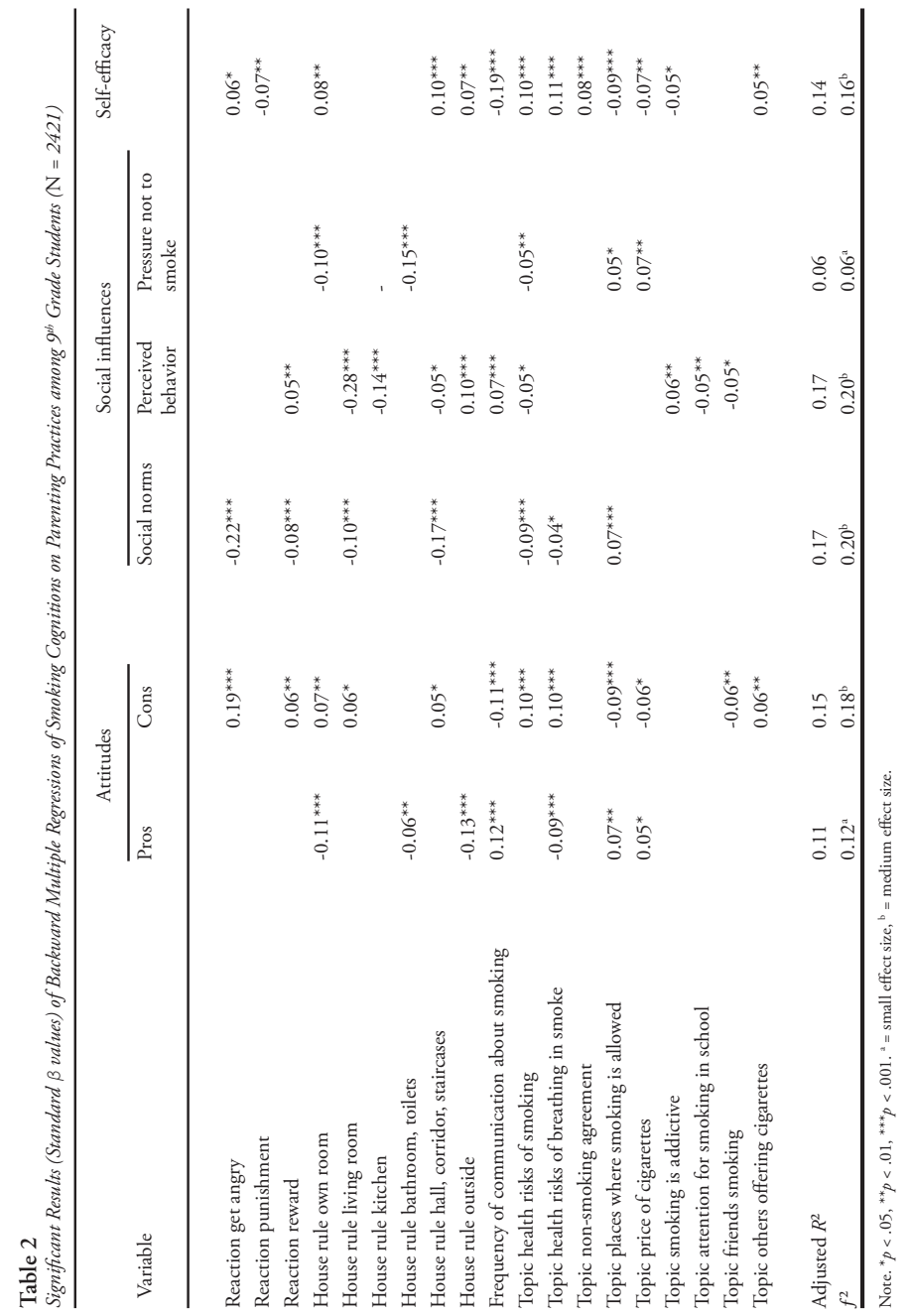




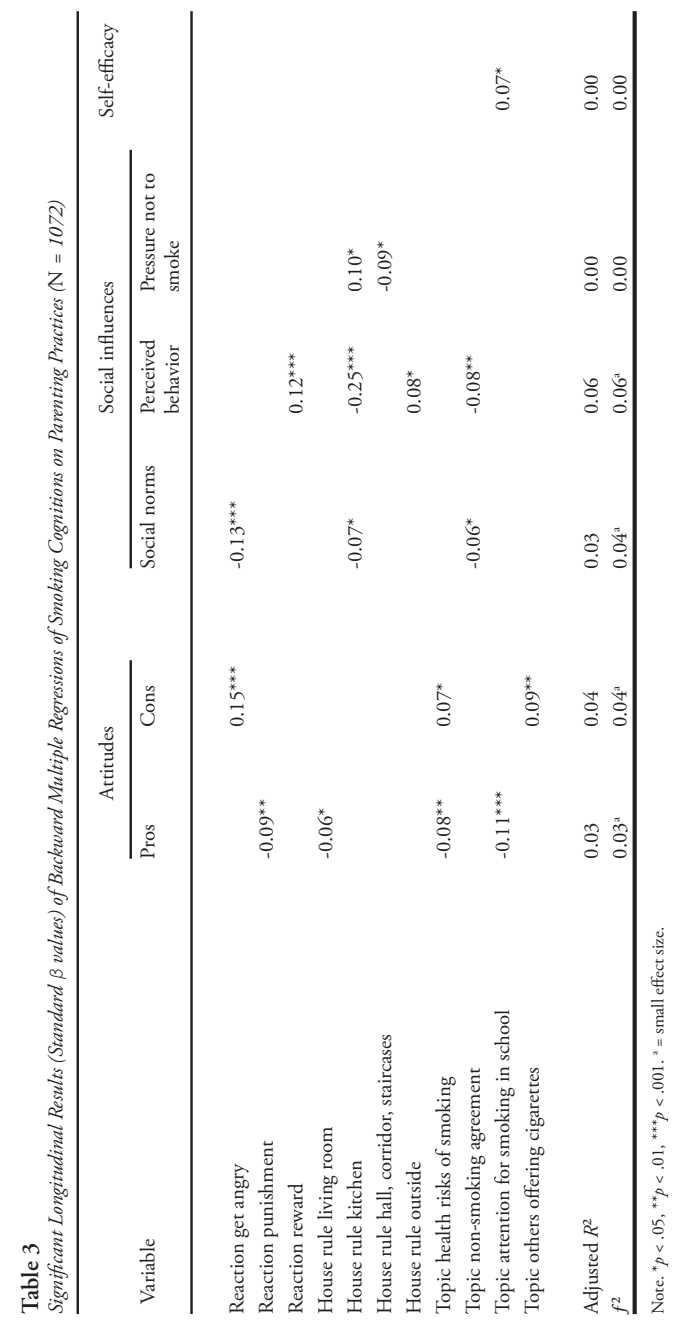


Effects of Anti-Smoking Parenting Practices on Smoking Behavior, and Mediating Effects of Smoking-related Cognitions and Intention

Tables 4, 5, and 6 show the results of the logistic regression analyses at $\mathrm{T} 1, \mathrm{~T} 2$, and longitudinally predicting ever smoking by demographics (step 1), anti-smoking parenting practices (step 2), attitudes, social influences and self-efficacy (ASE)(step 3), and intention (step 4), in order to shed light on the process by which parenting practices operate on smoking behavior and the role of smoking-specific cognitions and intention herein.

\section{Step 1.}

The first columns of Tables 4, 5, and 6 show the results of the regression analyses with age and gender. It is apparent that older adolescent's are more likely to have smoked in at both T1 and T2. At T1, girls were less likely to have smoked than boys.

\section{Step 2.}

As can be seen from the third column of Table 4, at T1, some practices (communication about health risks of breathing in smoke and about addictive qualities of smoking) were inversely related to ever having smoked, whereas others (reward for not smoking; the frequency of communication about smoking; communication about being allowed to smoke and about the price of cigarettes) were significantly associated with higher chances of lifetime smoking. At T2 (Table 5), more parenting practices were related to smoking behavior directly. As at T1, while some practices were associated with less smoking (house rules for smoking in the living room and outside; communication about health risks of smoking, health risks of breathing in smoke, attention paid to smoking in school), others were related to an increase in smoking behavior (frequency of communication about smoking; communication about being allowed to smoke, price of cigarettes, friends smoking). Table 6 shows that, whereas discussing attention paid to smoking in school at T1 led to decreased chances of smoking initiation at T2, the opposite was true for the prospect of a reward for not smoking. Effect sizes were small in all analyses. 
Table 4

Results of Logistic Regression among $7^{\text {th }}$ Grade Students of Ever Smoking on Demographics (Step 1), Parenting Practices (Step 2), Attitude, Social Influence, Self-Efficacy (Step 3), and Intention (Step 4) $(\mathrm{N}=2312$ )

\begin{tabular}{|c|c|c|c|c|c|c|c|c|}
\hline \multirow[b]{2}{*}{ Variable } & \multicolumn{2}{|c|}{ Step 1} & \multicolumn{2}{|c|}{ Step 2} & \multicolumn{2}{|c|}{ Step 3} & \multicolumn{2}{|c|}{ Step 4} \\
\hline & OR & $p$ & OR & $\bar{p}$ & OR & $\bar{p}$ & OR & $p$ \\
\hline Age & 1.48 & $<.001$ & 1.49 & $<.001$ & 1.41 & $<.001$ & 1.35 & $<.001$ \\
\hline Gender & 0.75 & .001 & 0.73 & $<.001$ & 0.71 & $<.001$ & 0.64 & $<.001$ \\
\hline Reaction reward & & & 1.08 & .035 & 1.10 & .009 & 1.12 & .006 \\
\hline Frequency of communication & & & 1.18 & $<.001$ & 1.19 & $<.001$ & 1.20 & $<.001$ \\
\hline Topic health risks breathing in smoke & & & 0.55 & $<.001$ & 0.63 & .001 & 0.64 & .002 \\
\hline Topic allowed to smoke & & & 1.93 & $<.001$ & 1.53 & $<.001$ & 1.39 & .004 \\
\hline Topic price of cigarettes & & & 1.31 & .033 & 1.33 & .035 & 1.33 & .047 \\
\hline Topic smoking is addictive & & & 0.76 & .009 & 0.83 & .092 & 0.88 & .273 \\
\hline Pros of smoking & & & & & 1.05 & $<.001$ & 1.05 & .003 \\
\hline Cons of smoking & & & & & 0.92 & $<.001$ & 0.99 & .562 \\
\hline Perceived social norm parents & & & & & 1.09 & .002 & 1.05 & .119 \\
\hline Perceived behavior parents & & & & & 1.35 & $<.001$ & 1.26 & $<.001$ \\
\hline Perceived pressure not to smoke & & & & & 1.16 & .022 & 1.05 & .519 \\
\hline Perceived behavior parents & & & & & 1.35 & $<.001$ & 1.26 & $<.001$ \\
\hline Perceived pressure not to smoke & & & & & 1.16 & .022 & 1.05 & .519 \\
\hline Self-efficacy & & & & & 0.97 & $<.001$ & 0.98 & .001 \\
\hline Intention to smoke & & & & & & & 1.92 & $<.001$ \\
\hline Nagelkerke's $R^{2}$ & & 0.03 & & 0.09 & & 0.25 & & 0.36 \\
\hline$f^{2}$ & & $0.03^{\mathrm{a}}$ & & $0.10^{\mathrm{a}}$ & & $0.33^{\mathrm{b}}$ & & $0.56^{c}$ \\
\hline
\end{tabular}

Note. ${ }^{2}=$ small effect size, ${ }^{b}=$ medium effect size, ${ }^{c}=$ large effect size.

\section{Step 3.}

Results of the T1 and T2 analyses indicate that relationships between some practices and smoking were mediated by smoking-related cognitions (fifth columns of Tables 4 and 5, respectively). The increased p-levels and consequently fewer significant effects of parenting practices on smoking behavior after including smoking-related cognitions, were most pronounced at T2, where six of the nine effects became insignificant, and were not seen in the longitudinal analysis. Effect sizes were medium at $\mathrm{T} 1$, large at T2, and small in the longitudinal analysis. 
Table 5

Results of Logistic Regression among $9^{\text {th }}$ Grade Students of Ever Smoking on Demographics (Step 1), Parenting Practices (Step 2), Attitude, Social Influence, Self-Efficacy (Step 3), and Intention (Step 4) $(\mathrm{N}=2421$ )

\begin{tabular}{|c|c|c|c|c|c|c|c|c|}
\hline \multirow[b]{2}{*}{ Variable } & \multicolumn{2}{|c|}{ Step 1} & \multicolumn{2}{|c|}{ Step 2} & \multicolumn{2}{|c|}{ Step 3} & \multicolumn{2}{|c|}{ Step 4} \\
\hline & OR & $p$ & OR & $p$ & $\overline{\mathrm{OR}}$ & $p$ & OR & $p$ \\
\hline Age & 1.31 & $<.001$ & 1.28 & $<.001$ & 1.17 & .007 & 1.19 & .003 \\
\hline House rule living room & & & 0.59 & $<.001$ & 0.96 & .812 & 0.88 & .486 \\
\hline House rule outside & & & 0.71 & .005 & 0.89 & .404 & 0.94 & .671 \\
\hline Frequency of communication & & & 1.24 & $<.001$ & 1.11 & .032 & 1.06 & .205 \\
\hline Topic health risks of smoking & & & 0.78 & .015 & 0.97 & .791 & 1.08 & .531 \\
\hline Topic health risks breathing in smoke & & & 0.61 & $<.001$ & 0.82 & .179 & 0.86 & .343 \\
\hline Topic allowed to smoke & & & 1.39 & .001 & 1.28 & .023 & 1.12 & .324 \\
\hline Topic price of cigarettes & & & 1.49 & .001 & 1.23 & .131 & 1.24 & .141 \\
\hline Topic attention for smoking in school & & & 0.68 & .044 & 0.82 & .353 & 0.82 & .366 \\
\hline Topic friends smoking & & & 1.36 & .006 & 1.33 & .017 & 1.31 & .034 \\
\hline Pros of smoking & & & & & 1.13 & $<.001$ & 1.11 & $<.001$ \\
\hline Cons of smoking & & & & & 0.93 & $<.001$ & 0.98 & .242 \\
\hline Perceived social norm parents & & & & & 1.08 & .012 & 1.05 & .089 \\
\hline Perceived behavior parents & & & & & 1.38 & $<.001$ & 1.28 & .001 \\
\hline Perceived pressure not to smoke & & & & & 1.07 & .562 & 1.03 & .776 \\
\hline Self-efficacy & & & & & 0.95 & $<.001$ & 0.98 & $<.001$ \\
\hline Intention to smoke & & & & & & & 2.05 & $<.001$ \\
\hline Nagelkerke's $R^{2}$ & & 0.02 & & 0.12 & & 0.33 & & 0.41 \\
\hline$f^{2}$ & & $0.02^{\mathrm{a}}$ & & $0.14^{\mathrm{a}}$ & & $0.50^{c}$ & & $0.69^{c}$ \\
\hline
\end{tabular}

Note. ${ }^{\mathrm{a}}=$ small effect size, ${ }^{\mathrm{c}}=$ large effect size.

\section{Step 4.}

As predicted by the I-Change Model, $p$-values of attitude, social influence and self-efficacy increased after taking intention into account. This was not the case longitudinally, as self-efficacy continued to make a unique significant contribution. Results at T2 showed that after intention had been included, effects of two of the three remaining parenting practices became insignificant. At T1, 75.2\% of respondents were correctly classified. These percentages were $75.1 \%$ and $64.8 \%$ at T2 and in the longitudinal analyses, respectively. Effect size of the full model was medium at T1, large at T2, and small in the longitudinal analysis. 
Table 6

Results of Logistic Regression of Smoking Initiation on Demographics (Step 1), Parenting Practices (Step 2), Attitude, Social Influence, Self-Efficacy (Step 3), and Intention (Step 4)(N = 1072)

\begin{tabular}{|c|c|c|c|c|c|c|c|c|}
\hline \multirow[b]{2}{*}{ Variable } & \multicolumn{2}{|c|}{ Step 1} & \multicolumn{2}{|c|}{ Step 2} & \multicolumn{2}{|c|}{ Step 3} & \multicolumn{2}{|c|}{ Step 4} \\
\hline & OR & $p$ & OR & $p$ & OR & $p$ & OR & $p$ \\
\hline Reaction reward & & & 1.18 & .001 & 1.20 & $<.001$ & 1.20 & .001 \\
\hline Topic attention for smoking in school & & & 0.59 & .035 & 0.59 & .040 & 0.58 & .037 \\
\hline Pros of smoking & & & & & 0.97 & .202 & 0.97 & .162 \\
\hline Cons of smoking & & & & & 0.97 & .110 & 0.99 & .629 \\
\hline Perceived social norm parents & & & & & 1.05 & .273 & 1.03 & .501 \\
\hline Perceived behavior parents & & & & & 1.17 & .074 & 1.16 & .101 \\
\hline Perceived pressure not to smoke & & & & & 0.88 & .310 & 0.88 & .286 \\
\hline Self-efficacy & & & & & 0.98 & .001 & 0.99 & .025 \\
\hline Intention to smoke & & & & & & & 1.39 & $<.001$ \\
\hline Nagelkerke's $R^{2}$ & & 0.00 & & 0.02 & & 0.05 & & 0.07 \\
\hline$f^{2}$ & & $0.00^{\mathrm{a}}$ & & $0.02^{\mathrm{a}}$ & & $0.05^{a}$ & & $0.08^{\mathrm{a}}$ \\
\hline
\end{tabular}

Note. ${ }^{2}=$ small effect size.

\section{Additional Analyses}

Interaction analyses were carried out to test whether effects of antismoking parenting practices varied by perceived parental smoking behavior or adolescent gender. Due to the polytomous nature of the variable for parental smoking status, dummy variables were used, relating to maternal or paternal smoking behavior. After correcting for gender and age, at T1, the enforcement of house rules about smoking outside by non-smoking mothers was related to increased chances of adolescent smoking $(\mathrm{OR}=0.56,95 \%$ confidence interval $[\mathrm{CI}]=0.36-0.88, p<$ $.05)$. Considering the cross-sectional nature of these findings, a possible explanation holds that smoking adolescents were being banned outside by their non-smoking mothers. Communication about friends offering cigarettes was only associated with less smoking if fathers did not smoke $(\mathrm{OR}=1.77,95 \% \mathrm{CI}=1.12-2.80, p<.05)$. At T2, talking about a nonsmoking agreement was related to decreased chances of smoking for children of smoking mothers $(\mathrm{OR}=0.55,95 \% \mathrm{CI}=0.34-0.90, p<.05)$. If mothers did not smoke, discussing the price of cigarettes was associated 
with increased chances of adolescent smoking $(\mathrm{OR}=0.57,95 \% \mathrm{CI}=$ $0.35-0.95, p<.05)$. Possibly, non-smoking mothers thought this a useful argument to prevent smoking progression, once initiation had occurred. Communication about attention for smoking in school was only related to decreased chances of lifetime smoking for children of non-smoking mothers $(\mathrm{OR}=3.25,95 \% \mathrm{CI}=1.24-8.51, p<.05)$. Furthermore, along the lines of the results of the cross-sectional regression analyses where more frequent communication about smoking was related to higher chances of lifetime smoking, the more frequent non-smoking mothers talked about smoking at T1, the higher the chances of adolescent smoking were at $\mathrm{T} 2(\mathrm{OR}=0.75,95 \% \mathrm{CI}=0.59-0.95, p<.05)$. Similar to the significant interaction effect of communication about a non-smoking agreement with parental smoking status at T2, longitudinally, communication on this topic by smoking fathers predicted reduced chances of smoking uptake $(\mathrm{OR}=0.50,95 \% \mathrm{CI}=0.26-1.00, p<.05)$. We then tested whether effects of parenting practices differed for boys and girls and found no significant interactions at T1 or T2. Longitudinally, frequency of communication about smoking was again positively associated with smoking initiation, but only for girls $(\mathrm{OR}=1.30,95 \% \mathrm{CI}=1.03-1.64$, $p<.05)$. As in both cross-sectional regression analyses of smoking on parenting practices, communication about the health risks of breathing in smoke at T1 was related to lower levels on smoking initiation at T2, but only for girls $(\mathrm{OR}=0.37,95 \% \mathrm{CI}=0.19-0.73, p<.01)$. Given that out of the many possible interactions relatively few proved to be significant, these were not further taken into account. The finding that parental smoking behavior does not interact with anti-smoking practices has also been reported elsewhere (e.g., Jackson \& Henriksen, 1997).

\section{Discussion}

This study investigated effects of anti-smoking parenting practices on adolescent smoking initiation by explaining the role of smoking-specific cognitions in this process. As hypothesized, anti-smoking practices were associated with adolescent cognitions that predict smoking 
behavior, namely attitude, perceived social influences and self-efficacy expectations. Furthermore, effects of practices on lifetime smoking were at least partially mediated by smoking-specific cognitions and intention to smoke. These findings support the idea that anti-smoking parenting practices can be viewed as predisposing processes operating on adolescent smoking behavior through cognitions.

Anti-smoking practices favorably related to adolescent smoking included house rules for smoking in the living room, and outside; communication about the health risks of smoking, the health risks of breathing in smoke, addictive qualities of smoking, and attention for smoking in school. However, increased chances of lifetime smoking were found for rewards for not smoking; frequency of communication about smoking; and communication about being allowed to smoke, price of cigarettes, friends smoking. These reversed odds ratios could not be ascribed to multicollinearity (Tabachnick \& Fidell, 2001). Several interpretations are possible. Anti-smoking practices might lead to increased chances of lifetime smoking, out of adolescent rebelliousness. To examine situations in which these counter productive effects take place, not only the content of practices should be taken into account, but also the way in which they are conveyed (Jaccard \& Dittus, 1993; Olsen Fulero \& Conforti, 1983), which was not possible in our study. Additionally, earlier research suggests that adolescents not only react to parenting practices, but that parents are also influenced by adolescent behavior (Engels et al., 2005; Ennett, Bauman, Foshee et al., 2001; Jaccard \& Dittus, 1993). While in cross-sectional research it appears as though some practices result in smoking initiation, it is plausible that only after teens have started smoking, parents explicitly engage in expressing anti-smoking practices. Similarly, parents might engage in more acts of socialization if they feel their son or daughter is likely to smoke. The increase in smoking behavior associated with rewards, for example, may be explained by the fact that parents promise rewards if they feel their offspring has started or is likely to start smoking. Similar explanations can be given for the effects of the frequency of communication about smoking, communication about being allowed to smoke and about the price of cigarettes. Thus, 
the counter intuitive associations between some practices and smoking, and the few significant effects of anti-smoking practices on smoking uptake in the longitudinal analysis, might be explained by a reciprocal relationship between parents' and offspring's behaviors.

As predicted by the I-Change Model, the effects of anti-smoking parenting practices were partially mediated by attitudes, social influences and selfefficacy. The decrease in significant unique contributions of practices after including smoking-related cognitions in the model was more pronounced at T2 than T1, and was not seen longitudinally. Several explanations are possible. Some practices might serve as predisposing processes, while others influence behavior directly. For instance, the effects of the prospect of a reward for not smoking, the frequency of communication about smoking and communication about being allowed to smoke remained in the model after cognitions and intention had been accounted for. Effects of other practices, such as communication about health risks of breathing in smoke and the price of cigarettes, were direct in $7^{\text {th }}$ grade and mediated by cognitions two years later. It seems that at a young age, practices may lead to behavior change without change in cognitions, indicating barrier effects on smoking without internalization. These acts may lead to cognitive changes in older teenagers. Possibly, smokingrelated cognitions may not have fully developed in early adolescence, causing practices to influence behavior directly (Kremers, Mudde, \& De Vries, 2004). The increased number of significant associations between anti-smoking practices and cognitions, as well as the larger effect size at step 3 in the $9^{\text {th }}$ grade analyses could indicate this.

The current study is subject to limitations. First, effect sizes were small. However, since smoking behavior is determined by multiple factors, a selection of factors will never explain all of the variance. Moreover, a concept can show small levels of explained variance and still have theoretical relevance (Rosenthal, 1990). Second, not all aspects of parenting were taken into account, due to limited response time. Besides parental reactions, house rules and communication about smoking, other anti-smoking parenting practices may be of importance. Examples include parental monitoring of substance use (Beal, Ausiello, 
\& Perrin, 2001; Fearnow et al., 1998; Jackson, 1997; Ma et al., 2003) and availability of tobacco (Engels \& Willemsen, 2004; Engels et al., 2005; Ennett, Bauman, Pemberton et al., 2001; Jackson, 1997; Ma et al., 2003). Moreover, parenting style, defined as a global climate in which a family functions, was not investigated in the present study and can influence the way in which anti-smoking practices affect adolescent behavior (Darling \& Steinberg, 1993). Future research should consider these additional aspects of parenting. Additionally, the notion that parents do not only influence their offspring's smoking behavior, but that this behavior might also affect acts of parenting, as is discussed above, needs to be considered in more detail. More attention should be paid to longitudinal effects of parenting in order to examine the sequence in which parents and adolescents influence each other (Engels et al., 2005; Ennett, Bauman, Foshee et al., 2001; Jaccard \& Dittus, 1993). Finally, it could be argued that parental social influences can be regarded as more distal factors. However, measures were based on adolescent perceptions and reports and that is why in most social cognitive models these perceptions are regarded within the concept of social influences, such as in the Theory of Planned Behavior (Ajzen, 1991) and Social Cognitive Theories (Bandura et al., 1977). Because the model currently used is based on these traditions, we believe that testing the place of these constructs is beyond the scope of this article. The authors intend to test alternative models making use of Structural Equation Modeling techniques in the future.

In conclusion, our study suggests that parents have a role in adolescent smoking behaviors and that adolescent smoking-specific cognitions operate as mediating factors at least to an extent. Practical implications of this research include incorporating the mediating role of smoking-related cognitions in future research and interventions. Additional aspects of parenting and the order in which parents and adolescents influence each other should be subject of additional research. Interventions aimed at prevention of smoking uptake should encourage those anti-smoking parenting practices that influence adolescent smoking-related cognitions in a favorable manner. 



\section{Chapter 4}

\section{Personality and parenting style}

Based on: Huver, R. M. E., Engels, R. C. M. E., \& De Vries, H. (submitted). Personality and parenting style. Journal of Adolescence. 



\begin{abstract}
Since parental personality traits are assumed to play a role in parenting behaviors, the current study examined the relation between parental personality and parenting style among 688 Dutch parents of adolescents in the SMILE study. The study assessed Big Five personality traits and derived parenting styles (authoritative, authoritarian, permissive, and neglectful) from scores on the underlying dimensions of support and strict control. Regression analyses were used to determine which personality traits were associated with parenting dimensions and styles. As regards dimensions, the two aspects of personality reflecting interpersonal interaction (extraversion and agreeableness) were related to supportiveness. Emotional stability was associated with lower strict control. As regards parenting styles, extraverted, agreeable and less emotionally stable individuals were most likely to be authoritative parents. Conscientiousness and openness did not relate to general parenting, but may be associated with more content-specific acts of parenting.
\end{abstract}




\section{Introduction}

Parenting style has been defined as a global climate in which a family functions and in which childrearing takes place (Darling \& Steinberg, 1993). Four distinct parenting styles have been distinguished, namely the authoritative, authoritarian, permissive, and neglectful styles, based on the two underlying dimensions of parental support and strict control (e.g., Baumrind, 1966, 1971; Maccoby \& Martin, 1983). Parental support refers to parental affectionate qualities and is associated with characteristics like warmth, acceptance, and involvement. Strict control reflects parental control over their children's behaviors and as such includes parental knowledge of these activities as well as active monitoring attempts (Stattin \& Kerr, 2000). Authoritative parents offer their children a democratic climate of both high support and strict control. Authoritarian parents provide strict control without being supportive, and are therefore perceived as demanding and power-assertive. Children experiencing support in the absence of strict control are being reared by permissive parents, who are allowing and indulgent. These parents apply few rules to constrain their children. Finally, parents with a neglectful parenting style are neither supportive nor controlling, and are indifferent and uninvolved with respect to their children.

General parenting styles have been found to relate to children's development (Collins et al., 2000), and authoritative parenting in particular has been found to have beneficial effects on adolescent lifestyles. Adolescents being raised in an authoritative parenting climate eat more fruit, smoke less, drink less alcohol, and are less likely to use marihuana (e.g., Jackson et al., 1998; Kremers et al., 2003; Radziszewska et al., 1996). In addition, adolescents with authoritative parents show better psychosocial development, greater academic competence, less delinquent behavior, and fewer somatic symptoms (e.g., Steinberg et al., 1994).

If parenting influences adolescent development, then individual characteristics affecting parenting may be of indirect relevance to issues related to adolescent development (Belsky \& Barends, 2002; Prinzie et 
al., 2004). Determinants of parenting have indeed been studied, focusing upon occupational status, well-being, and to a lesser extent parental personality (e.g., Fox, Platz, \& Bentley, 1995). Of the individual factors shaping parenting, personality aspects are most likely to contribute, as these aspects are also likely to influence other determinants of parenting, such as marital quality, occupational aspects, and social support (Belsky $\&$ Barends, 2002). The present study therefore concentrated on the relation between personality and parenting style.

There is relative consensus on a five-factor structure of personality, based on a bipolar taxonomy of underlying traits (e.g., Costa \& McCrae, 1992; Digman, 1990; Saucier \& Goldberg, 1998), which is supported by factor analyses of extensive lists of trait adjectives (Goldberg, 1990). The five broad personality dimensions are commonly labeled extraversion, conscientiousness, agreeableness, emotional stability, and openness. It should be noted that these dimensions are not types, meaning that personality is made up of scores on the five dimensions. Extraversion reflects the frequency and quality of interpersonal contact, capacity for joy, activity level, and stimulation-seeking behavior. Conscientious persons are best described as dutiful, scrupulous, perseverant, punctual, and organized. Agreeable individuals are compassionate, goodnatured, complying, and trusting. Emotional stability is the opposite of neuroticism. As such, emotionally stable individuals are calm, unemotional, and self-satisfied, whereas neurotic persons are nervous, touchy, anxious, depressed, and insecure. Finally, openness comprises characteristics such as curiousness, versatility, creativity, and originality (Costa \& McCrae, 1992).

Previous research into the relations between parents' personality and their parenting style has revealed certain patterns, and there is empirical evidence for this relation for each of the five dimensions. First, extraversion appears to be associated with positive parenting (Belsky \& Barends, 2002). Although another study among parents of adult twins failed to find such an association (Kendler et al., 1997), a study among parents of children under the age of 8 years reported positive correlations between 
extraversion and positive support (Losoya, Callor, Rowe, \& Goldsmith, 1997). Second, Losoya et al. (1997) found that conscientiousness was related to higher levels of supportive parenting and less negative control. Similarly, conscientious mothers of infants have prospectively been found to be more responsive (Clark, Kochanska, \& Ready, 2000). Third, although agreeableness has less often been subject of study, one would intuitively expect agreeable persons to be more responsive and supportive parents. Previous research tentatively supports this idea. Losoya et al. (1997) found agreeableness to be positively associated with positive support and inversely with negative, controlling parenting. Moreover, disagreeableness interfered with adaptive parenting (Kochanska et al., 1997). By contrast, another study (Prinzie et al., 2004) found higher levels of parental agreeableness to be associated with increased coercion. Fourth, neuroticism, the opposite of emotional stability, has received most attention, possibly because neuroticism is thought to be most predictive (Belsky, Crnic, \& Woodworth, 1995) and neurotic parents are believed to be less competent (Downey \& Coyne, 1990; Kochanska et al., 1997). Kendler et al. (1997) found neuroticism to be related to less parental warmth. According to Prinzie and colleagues (2004), reduced emotional stability is associated with more overreacting. Finally, while rarely studied, openness and parental support have been reported to coincide (Clark et al., 2000; Losoya et al., 1997).

Most studies examining the relationship between personality and parenting have focused on mothers of toddlers and young children. Moreover, most knowledge in this field is based on research into relations between parental psychopathology, such as depression, and parenting (Downey \& Coyne, 1990). The main aim of the present study was therefore to examine the relation between personality and parenting style, for mothers and fathers of adolescents, with the help of widely used and validated instruments to assess personality and parenting style. We hypothesized that for parents of adolescents, extraversion, agreeableness, conscientiousness, emotional stability, and openness would relate to the parenting dimensions accounting for authoritative parenting, namely high levels of support and strict control. Furthermore, these personality 
traits were expected to be associated most strongly with authoritative parenting, as compared to authoritarian, permissive or neglectful parenting.

\section{Methods}

\section{Participants and Procedures}

In the spring of 2003, 688 inhabitants of the Dutch city of Eindhoven participated in the Study of Medical Information and Lifestyles in Eindhoven (SMILE). The SMILE study is a joint project of Maastricht University and 23 family physicians from seven practices located in Eindhoven, a city of approximately 200,000 inhabitants situated in the southern part of the Netherlands. Participants' addresses were obtained through their family physicians. Parents of children in the 12 to 19 year age bracket filled out self-administered 16-page questionnaires. Pilot tests showed that it took 30 to 45 minutes to complete the questionnaire. Telephone help lines were available for questions, as was a website. Anonymity was guaranteed.

\section{Measures}

Demographics included in the present study were age and gender, with answers 0 "male" and 1 "female". In addition, respondents were asked about their marital status (0 "not married", 1 "married"). Another question assessed whether respondents were living together with their partners (1) or not (0) and respondents were asked to report the number of children living with them. Respondents were asked to indicate their educational level by choosing one of eight categories ranging from "elementary school" to "university education". Monthly net income was measured on an 11-point scale, with answers ranging from "less than $€ 750$ " to "€3000 or more". Participants could choose "no answer" as an additional option. Religiousness was coded as 0 "not religious" or 1 "religious". The question "How important is religion in your life?" assessed 
the significance of religion ("not important", 2 "slightly important", 3 "somewhat important", and 4 "very important"). Ethnicity was derived from parental origin (0 "not of Dutch origin", 1 "of Dutch origin").

Personality was assessed by the Quick Big Five (Gerris et al., 1998), a thirty-item Dutch version of the original Big Five questionnaire (Goldberg, 1992). Respondents were asked to rate the extent to which certain qualities such as "nervous" or "artistic" applied to them, to assess extraversion $(\alpha=.86)$, conscientiousness $(\alpha=.87)$, agreeableness $(\alpha=$ $.84)$, emotional stability $(\alpha=.83)$, and openness $(\alpha=.83)$. Answers were rated on 7-point Likert scales.

Parenting styles were assessed using a Dutch instrument (Beyers \& Goossens, 1999) based on work by Steinberg and colleagues, which has shown good external validity, internal consistency, and test-retest reliability (Lamborn, Mounts, Steinberg, \& Dornbusch, 1991). This questionnaire assessed two dimensions of parenting style, namely support $(\alpha=.77)$ and strict control $(\alpha=.74)$. Participants could indicate on 5point Likert scales whether they agreed or disagreed with 15 statements such as "My child can count on me to help him/her out, if he/she has some kind of problem" and "I TRY to keep track of where my child goes at night". Two additional questions were asked about curfews on weekdays (Monday through Thursday) and weekends (Friday and Saturday), with responses on 7-point scales, ranging from "before 9 PM" to "after midnight" for weekdays and from "before 11 PM" to "after 2 AM" for weekends, including the two additional options of "not allowed to go out" and "no curfew". Answers were transformed to z-values, prior to summing scores on the variables in order to form scales. Parents were classified as authoritative, authoritarian, permissive, or neglectful, based on median splits; e.g., participants with scores in the upper half of the support and strict control scales were categorized as authoritative (Steinberg et al., 1992). 


\section{Statistical Analyses}

Contrast analyses were used to compare authoritative, authoritarian, permissive, and neglectful parents in terms of the demographic variables of age, gender, marital status, living together with a partner, number of children, educational level, net income, religiousness, significance of religion, and ethnicity. To identify the demographic differences between parents characterized by the four parenting styles, cross-tabulations were used for nominal variables and ANOVAs were used for continuous variables Post-hoc comparisons were made according to the Tukey HSD method. To see which personality traits were associated with parenting dimensions and styles, regression analyses were performed, controlling for those demographical variables that significantly distinguished between parents of different styles in the contrast analyses. First, to examine the relation between personality and parenting dimensions, two separate multiple regressions were run of the support and strict control dimensions on Big Five personality traits. In regressing the individual dimensions on the personality variables, the other dimension was corrected for. Correlations were calculated between independent variables and the dependent parenting dimension variables. Second, to determine associations between personality and parenting style, a multinomial logistic regression analysis was conducted. This is an extension of binary logistic regression analysis, allowing for simultaneous estimations of the odds of being classified as authoritarian, permissive or neglectful, compared to being classified as authoritative.

Our sample sometimes included both parents of one family. This might theoretically lead to bias, as parents in the same household tend to converge in parenting style (Baumrind, 1991) and partners tend to have similar personality characteristics (Byrne, 1997). To test whether inclusion of mother-father dyads biased the results, we randomly selected either the mother or the father of these families and reran our analyses only with individuals from unique households $(N=495)$. This yielded similar associations between personality and parenting dimensions and styles. 


\section{Results}

\section{Description of the Sample}

Participants were mostly female (63.8\%), with a mean age of 45.98 years $(S D=5.34)$. Of all participants, $82.1 \%$ were married and $87.2 \%$ lived in the same house as their partner, together with an average of 2.2 children $(S D=0.97)$, which is comparable to national statistics (Hartgers, 2001). Participants most often reported that they had a university degree (26.6\%), earned a net income of $€ 3000$ or more (23.8\%), adhered to a religion (67.2\%), valued religion as "slightly important" in their lives $(33.0 \%)$, and were of Dutch origin $(82.6 \%)$.

Table 1a presents results of comparisons between authoritative, authoritarian, permissive, and neglectful parents in terms of dichotomous demographic variables. Results of contrast analyses relating to continuous demographic factors are presented in Table $1 \mathrm{~b}$.

Table 1a

Univariate Associations between Parenting Styles and Gender, Marital Status, Living with one's Partner, Religiousness and Ethnicity

\begin{tabular}{|c|c|c|c|c|c|}
\hline \multirow[b]{2}{*}{ Dichotomous factors } & \multicolumn{4}{|c|}{ Parenting style } & \multirow[b]{2}{*}{$\chi^{2}$} \\
\hline & Authoritative $^{a}$ & Authoritarian $^{\text {b }}$ & Permissive $^{c}$ & Neglectful $^{\mathrm{d}}$ & \\
\hline \multicolumn{6}{|l|}{ Gender (\%) } \\
\hline Male & 19.34 & 19.34 & 15.23 & 46.09 & \multirow[t]{2}{*}{$32.730^{* * *}$} \\
\hline Female & 36.02 & 15.88 & 20.38 & 27.73 & \\
\hline \multicolumn{6}{|l|}{ Marital Status (\%) } \\
\hline Not married & 27.68 & 13.39 & 26.79 & 32.14 & \multirow[t]{2}{*}{6.418} \\
\hline Married & 30.31 & 17.79 & 16.88 & 35.03 & \\
\hline \multicolumn{6}{|l|}{ Living with partner (\%) } \\
\hline No & 29.87 & 12.99 & 23.38 & 33.77 & \multirow[t]{2}{*}{2.068} \\
\hline Yes & 30.05 & 17.79 & 17.79 & 34.37 & \\
\hline \multicolumn{6}{|l|}{ Religious (\%) } \\
\hline No & 30.32 & 14.03 & 22.17 & 33.48 & \multirow[t]{2}{*}{4.812} \\
\hline Yes & 29.93 & 18.82 & 16.33 & 34.92 & \\
\hline \multicolumn{6}{|l|}{ Ethnicity (\%) } \\
\hline Non-native & 27.78 & 25.93 & 14.81 & 31.48 & \multirow[t]{2}{*}{7.017} \\
\hline Native & 29.95 & 15.61 & 19.24 & 35.21 & \\
\hline
\end{tabular}

Note. ${ }^{2} N=199,{ }^{\mathrm{b}} N=114,{ }^{\mathrm{c}} N=123,{ }^{\mathrm{d}} N=229 .{ }^{*} p<.05,{ }^{* *} p<.01,{ }^{* * *} p<.001$. 
Table $1 \mathbf{b}$

Univariate Associations between Parenting Styles and Age, Number of Children, Education, Income, and Significance of Religion

\begin{tabular}{|c|c|c|c|c|c|c|c|c|c|c|}
\hline \multirow[b]{3}{*}{ Continuous factors } & \multicolumn{8}{|c|}{ Parenting style } & \multirow{3}{*}{$F$} & \multirow{3}{*}{$\begin{array}{l}\text { Tukey HSD } \\
\text { Contrasts }\end{array}$} \\
\hline & \multicolumn{2}{|c|}{$\mathrm{At}^{2}$} & \multicolumn{2}{|c|}{$\mathrm{An}^{\mathrm{b}}$} & \multicolumn{2}{|l|}{$\mathrm{P}^{\mathrm{c}}$} & \multicolumn{2}{|c|}{$\mathrm{N}^{\mathrm{d}}$} & & \\
\hline & $M$ & $S D$ & $M$ & $S D$ & $M$ & $S D$ & $M$ & $S D$ & & \\
\hline Age & 45.21 & 4.70 & 44.70 & 5.76 & 46.85 & 5.37 & 47.06 & 5.32 & $8.08^{* * *}$ & $\mathrm{Av}, \mathrm{An}<\mathrm{P}, \mathrm{N}$ \\
\hline Number of children & 2.34 & 0.89 & 2.05 & 0.80 & 2.02 & 0.84 & 2.17 & 1.10 & $3.76^{*}$ & $\mathrm{Av}>\mathrm{An}, \mathrm{P}$ \\
\hline Education & 5.37 & 2.12 & 4.96 & 2.28 & 5.43 & 2.11 & 5.11 & 2.24 & 1.44 & n.s. \\
\hline Income & 8.76 & 3.13 & 8.07 & 3.23 & 9.05 & 2.98 & 8.49 & 3.21 & 2.13 & n.s. \\
\hline Significance religion & 2.38 & 0.95 & 2.30 & 1.04 & 2.57 & 1.00 & 2.39 & 1.00 & 1.68 & n.s. \\
\hline
\end{tabular}

Note. Av $=$ Authoritative, $\mathrm{An}=$ Authoritarian, $\mathrm{P}=$ Permissive, $\mathrm{N}=$ Neglectful. ${ }^{\mathrm{a}} N=199,{ }^{\mathrm{b}} N=114,{ }^{\mathrm{c}} N=123,{ }^{\mathrm{d}} N=229 .{ }^{*} p<.05$, ${ }^{* *} p<.01,{ }^{* * *} p<.001$.

Authoritative, authoritarian, permissive, and neglectful parents differed significantly in terms of gender. While most men were classified as neglectful, most women were authoritative. Significant differences were found for age, with authoritative and authoritarian parents being younger than permissive and neglectful parents. Additionally, authoritative parents had significantly more children living with them than authoritarian and permissive parents. No significant differences between parents of different styles were found as regards marital status, living together with a partner, educational level, income, religiousness, significance attached to religion, or ethnicity. The demographics that were significant in these contrast analyses were included as covariates in the regression analyses.

\section{Personality in Relation to the Parenting Dimensions of Support and Strict Control}

Table 2 presents results of the multiple regression analysis of parental support on the five personality traits, after controlling for the demographical variables of age, gender and number of children, and reported levels of strict control. More extraverted and agreeable parents provided higher levels of support. While the correlational analyses (last 
column in Table 2) found conscientiousness and openness to be positively related to support, these results became non-significant after accounting for the other variables in the regression analysis. No effects were found for emotional stability. The proportion of variance accounted for by the model (Nagelkerke's $R^{2}$ ) was $30 \%$.

Table 2 also shows the results of the multiple regression analysis of parental exertion of strict control on the personality dimensions, accounting for background variables and the parenting dimension of support. The analysis found that more emotionally stable parents exerted lower levels of strict control. While agreeableness correlated positively with strict control, this pattern was not seen in the multivariate regression analysis. Nor were associations found between strict control and extraversion, conscientiousness, or openness. The proportion of explained variance was $26 \%$.

Table 2

Multiple Regressions of the Parenting Dimensions of Support and Strict Control on Big Five Personality Traits, with Pearson Correlations

\begin{tabular}{llllll}
\hline \multirow{2}{*}{ Variable } & \multicolumn{2}{c}{ Support } & & \multicolumn{2}{c}{ Strict control } \\
\cline { 2 - 3 } \cline { 5 - 6 } Age & $\beta$ & $r$ & & \\
Gender & 0.06 & -.07 & & & $r$ \\
Number of children & $0.11^{* *}$ & $.22^{* * *}$ & & $-0.21^{* * *}$ & $-.28^{* * *}$ \\
Other parenting dimension & 0.03 & .04 & 0.02 & $.18^{* * *}$ \\
Extraversion & $0.40^{* * *}$ & $.42^{* * *}$ & & 0.06 & $.13^{* * *}$ \\
Conscientiousness & $0.13^{* * *}$ & $.24^{* * *}$ & & $0.43^{* * *}$ & $.42^{* * *}$ \\
Agreeableness & 0.05 & $.12^{* *}$ & & -0.07 & .03 \\
Emotional stability & $0.22^{* * *}$ & $.37^{* * *}$ & & -0.01 & .04 \\
Openness & 0.00 & .05 & $0.02)$ & $.13^{* *}$ \\
Adjusted $R^{2}$ & 0.07 & $.15^{* * *}$ & $-0.10^{* *}$ & $-.11^{* *}$ \\
\hline
\end{tabular}

Note. ${ }^{*} p<.05,{ }^{* *} p<.01,{ }^{* * *} p<.001$. 


\section{Personality in Relation to Parenting Styles}

Results of the multinomial logistic regression analysis of parenting styles on the five personality factors are presented in Table 3. With the authoritative parenting style as the reference category, and after correcting for the background variables of age, gender, and number of children, personality traits were associated with authoritarian, permissive, and neglectful parenting. The more extraverted parents were, the less likely they were to be classified as authoritarian. More agreeable parents were less likely to be authoritarian and neglectful. Furthermore, more emotionally stable individuals were more likely to be classified as permissive and neglectful parents. Conscientious and openness were not significantly associated with the parenting styles. The model accounted for $22 \%$ of the explained variance (Pseudo Nagelkerke's $R^{2}$ ).

Table 3

Multinomial Logistic Regression of Parenting Style on Big Five Personality Traits

\begin{tabular}{llll}
\hline \multirow{2}{*}{ Variable } & \multicolumn{3}{l}{ Parenting style } \\
\cline { 2 - 4 } & Authoritarian & Permissive & Neglectful \\
\hline Age & $0.5(0.90-1.00)$ & $1.05(1.00-1.10)$ & $1.04(1.00-1.09)$ \\
Gender & $0.49(0.27-0.87)^{*}$ & $0.97(0.56-1.69)$ & $0.48(0.30-0.76)^{* *}$ \\
Number of children & $0.67(0.50-0.88)^{* *}$ & $0.74(0.57-0.97)^{*}$ & $0.80(0.64-1.00)$ \\
Extraversion & $0.94(0.90-0.98)^{* *}$ & $1.00(0.96-1.04)$ & $0.98(0.95-1.02)$ \\
Conscientiousness & $0.99(0.95-1.03)$ & $1.01(0.97-1.05)$ & $0.98(0.95-1.01)$ \\
Agreeableness & $0.87(0.81-0.94)^{* * *}$ & $0.95(0.88-1.04)$ & $0.85(0.79-0.91)^{* * *}$ \\
Emotional stability & $1.04(0.99-1.08)$ & $1.07(1.03-1.12)^{* *}$ & $1.07(1.03-1.10)^{* * *}$ \\
Openness & $0.98(0.94-1.02)$ & $1.03(0.99-1.08)$ & $0.99(0.96-1.03)$ \\
\hline
\end{tabular}

Note. Reference category is the authoritative parenting style. Pseudo Nagelkerke's $R^{2}=0.22$. ${ }^{*} p<.05,{ }^{* *} p<.01,{ }^{* * *} p<.001$.

\section{Discussion}

Since authoritative parenting has shown beneficial effects on adolescent development (e.g., Jackson et al., 1998), it is important to examine factors relating to this parenting style. Our results show that two aspects of parent's personality, namely those reflecting interpersonal interaction (extraversion and agreeableness) were related to levels of supportiveness, 
while emotional stability was associated with the exertion of strict control by parents. Extraverted, agreeable and less emotionally stable individuals were most likely to be authoritative parents.

The findings for extraversion are in line with those of previous research. Extraverted parents were more supportive, and extraverted individuals were less likely to be characterized by an authoritarian than an authoritative parenting style. This is in agreements with the findings of previous research, which suggests that extraverted individuals raise their children in a more positive manner (Belsky \& Barends, 2002). Moreover, our findings show that the association between extraversion and supportive parenting is not exclusively restricted to parents of toddlers (Losoya et al., 1997), but also applies to parents of adolescents. This underlines the robust link between extraversion and parenting. Key to this finding is that this feature of personality is mainly associated with the affective aspect of parenting and not with the control aspect.

With respect to conscientiousness, its previously reported association with supportiveness (Losoya et al., 1997) was confirmed, but this association disappeared after controlling for the other variables. As such, conscientiousness did not relate to parenting dimensions or styles in our sample of parents of adolescents. Further, agreeable parents were more supportive and were consequently less likely to engage in authoritarian or neglectful parenting than in authoritative parenting. This supports the idea of agreeable individuals as more pleasant parents (Kochanska et al., 1997; Losoya et al., 1997). Like extraversion, agreeableness was not associated with the control dimension of parenting.

As regards emotional stability, we hypothesized that emotionally stable individuals would be more competent parents (Downey \& Coyne, 1990) and display more supportiveness and strict control as such. However, parental level of emotional stability was not related to their supportive parenting qualities, contrary to findings by Kendler and colleagues (1997). Moreover, more emotionally stable parents exerted less strict control. Perhaps, since emotionally unstable individuals are more likely to exhibit maladaptive coping responses (Costa \& McCrae, 1992), these 
parents resort more easily to controlling their children. This may explain why emotionally stable parents are more likely to engage in permissive or neglectful parenting, as these styles are characterized by low strict control. Along these lines of reasoning, high emotional instability could result in harsh parenting, as reported previously (e.g., Prinzie et al., 2004). Finally, openness was not related to parenting dimensions or styles accounted for in our study, after correcting for background variables and the other personality traits, in disagreement with previously reported findings (Clark et al., 2000; Losoya et al., 1997).

In short, parental support is associated with the two aspects of personality that reflect the extent of interpersonal interaction, namely extraversion and agreeableness (Pervin \& John, 2001). Since individuals high on these two traits generally socialize more, they may also be more sociable with respect to their children, and more supportive as a result. People with high scores on agreeableness have more explicit content of schemas for handling relationships in general (Baldwin \& Fergusson, 2001), and these people also seem to have parenting schemas, which are generally considered adequate. It should be noted, however, that what is adequate for one child is not necessarily optimal for another. What constitutes adequate parenting is situationally and culturally determined and dependent on the children's needs. Second, more emotionally unstable individuals are known to exhibit maladaptive coping responses (Costa \& McCrae, 1992). Similarly, in our study these parents more readily exerted harsh control over children. Several reasons are conceivable for these maladaptive coping responses and heightened levels of strict control. One possibility has to do with the relation between emotional instability and internal negative affect (Watson \& Clark, 1992). As emotionally unstable individuals are prone to subjective distress and overall dissatisfaction, these parents might vent their negative affect on their children, by means of increased strict control. Another possibility is related to the feelings of inadequacy that emotionally unstable persons experience (Costa \& McCrae, 1992). If emotionally unstable individuals feel inadequate as parents, exerting strict control over their children could be a means of compensating for this. 
This study was subject to certain limitations. First, a third dimension of parenting style has recently been suggested, besides those of support and strict control, namely psychological control, defined as a intrusive form of control parents attempt to hold over their children's psychological world and functioning (Barber, 2002). It is definitely conceivable that personality traits also relate to this additional parenting dimension. As less emotionally stable parents resort more quickly to controlling their children's behaviors, they might also be more easily inclined to control psychological functioning. In contrast to psychological control, autonomy granting has been proposed as a third dimension (e.g., Lamborn et al., 1991), which can be described as the extent to which parents encourage their children to think for themselves. Research suggests that psychological control and autonomy granting are not opposite ends of a continuum, but distinct constructs leading to different behavior in children (Silk et al., 2003). Further work is needed to improve our understanding of these possible additional dimensions of parenting and the parental factors associated with them. Second, our study had a cross-sectional nature, which means we have to be cautious in drawing conclusions on causality. However, it is likely that the personality aspects assessed here precede parenting strategies, in view of the stability of personality (McCrae \& Costa, 1997) and the relative instability of parenting style (e.g., Goossens \& Beyers, 1999; Juang \& Silbereisen, 1999). Moreover, available research findings suggest a biological basis of personality, underlining the stability of personality and thus confirming the idea of personality preceding parenting.

Our study has provided further insight into parental personality characteristics that are related to general parenting dimensions and styles. The main objective was to assess which personality characteristics play a role, in order to add to existing knowledge about parenting. We conclude that extraverted, agreeable, or emotionally unstable parents are most likely to exhibit the favorable, so called authoritative parenting style. Extraversion and agreeableness relate to affective qualities of parenting, while emotional stability is associated with less provision of strict control. The finding that conscientiousness and openness are 
not multivariately related to parenting style or its dimensions does not mean that these personality traits are unrelated to any facets of parenting per se. These traits may well relate to content-specific acts of parenting. Conscientious parents may be more likely to socialize their children with respect to tidiness and meticulousness, while open parents could stimulate creativity and other artistic capacities. 



\section{PART II}

on inconsistent

relations between antismoking socialization and adolescent smoking 



\section{Chapter 5}

\section{Is parenting style a context for anti-smoking socialization?}

Based on: Huver, R. M. E., Engels, R. C. M. E., Vermulst, A. A., \& De Vries, H. (resubmitted-a). Is parenting style a context for antismoking socialization? Drug and Alcohol Dependence. 



\begin{abstract}
This study examined whether global parenting style can be regarded as a context in which anti-smoking socialization is related to adolescent smoking cognitions and behaviors. Data were gathered through selfadministered questionnaires from 482 adolescents aged 12-19 years, who were participating in the Study of Medical Information and Lifestyles in Eindhoven (SMILE). We assessed parenting style dimensions (support, strict control, psychological control), smoking-specific socialization (communication, house rules, availability, non-smoking agreement), smoking-related cognitions according to the I-Change Model (attitude, social norm, self-efficacy, intention), and smoking behavior. Structural equation models were computed and compared for adolescents in different parenting climates. Results showed that communication and availability were related to adolescents' attitude towards smoking. Availability was additionally associated with reduced self-efficacy to refrain from smoking. Attitude and self-efficacy were subsequently related to intention to smoke, which in turn was related to smoking behavior. No direct relations were found between socialization aspects and adolescent smoking behavior. These results were not dependent on the parenting climate. Parenting style thus did not serve as a context for anti-smoking socialization, indicating that these facets of parenting operate independently, and that anti-smoking socialization efforts may be effective regardless of parenting climate.
\end{abstract}




\section{Introduction}

The steady increase in adolescent smoking (STIVORO - rookvrij, 2004b; U.S. Department of Health and Human Services, 1994) underlines the need to examine relevant explanatory factors. The role of parents has been studied for many years and several relevant aspects of parenting behavior have emerged, including the global parenting climate in which a child is reared and parental anti-smoking socialization efforts (e.g., Jackson \& Henriksen, 1997; O’Byrne et al., 2002). According to Darling and Steinberg (1993) "Parenting style alters the parents' capacity to socialize their children by changing the effectiveness of their parenting practices". From this perspective, parenting style can be thought of as a contextual variable that moderates the relationship between anti-smoking socialization and adolescent smoking behavior. The current study tested this idea, while also accounting for smoking-related cognitions in explaining adolescent smoking behavior.

Parental anti-smoking socialization efforts have frequently been reported to have beneficial effects on adolescent smoking behavior. Parentchild communication about smoking, for example, has been favorably associated with a decrease in smoking rates (Chassin, Presson, Todd et al., 1998; Engels \& Willemsen, 2004; Fearnow et al., 1998), although unfavorable effects have also been reported (Ennett, Bauman, Foshee et al., 2001; Harakeh et al., 2005). Furthermore, house rules about smoking in the home have been linked to a reduced risk of adolescent smoking (Andersen et al., 2004; Henriksen \& Jackson, 1998; Jackson $\&$ Henriksen, 1997), but less conclusive evidence has also been found (Den Exter Blokland et al., 2006; Harakeh et al., 2005; Huver et al., 2006). In addition, the availability of cigarettes in the household has been related to increased adolescent smoking, and parental attempts to reduce availability have been shown to be beneficial (Engels \& Willemsen, 2004; Engels et al., 2005; Jackson, 1997; Ma et al., 2003), although a longitudinal study failed to find any effects (Den Exter Blokland et al., 2006). Finally, parents often try to get their children to enter into non-smoking agreements by offering the prospect of rewards 
for non-smoking, but the effectiveness of these strategies is questionable (Harakeh et al., 2005; Huver et al., 2006). Summarizing, it seems that parental socialization efforts may be beneficial in some circumstances, but the contradictory results of previous studies suggest that more insight into these circumstances is needed. Contrary to common belief, although parental modeling of smoking behavior is a major factor in their children's smoking behavior (Andrews, Hops, Ary, Tildesley, \& Harris, 1993; Avenevoli \& Merikangas, 2003), it does not necessarily moderate the effects of socialization efforts (Jackson \& Henriksen, 1997).

According to Darling and Steinberg (1993), the effects of socialization depend on the global parenting climate. Parents can be classified as authoritative, permissive, authoritarian, rejecting, or neglectful, based on scores on the dimensions underlying the parenting style, namely support, strict control (Baumrind, 1966, 1971; Maccoby \& Martin, 1983), and psychological control (Den Exter Blokland et al., 2001; Goossens \& Beyers, 1999; Steinberg et al., 1989). Support refers to the affective component of parenting, whereas strict control comprises parental knowledge of children's whereabouts and active behavioral monitoring efforts undertaken to gain this knowledge (Stattin \& Kerr, 2000). Psychological control refers to the intrusive and manipulative parental control over their children's psychological world, consisting of thoughts and feelings (Barber, 2002; Gray \& Steinberg, 1999). Authoritative parenting and its underlying dimensions (high support, high strict control, low psychological control) have been found to have favorable effects on adolescent smoking (Glendinning et al., 1997; Gray \& Steinberg, 1999; Huver, Engels, Van Breukelen et al., in press; Jackson et al., 1998; O’Byrne et al., 2002; Pierce et al., 2002; Radziszewska et al., 1996; Simons Morton, 2002).

In addition to aspects of parenting considered to explain adolescent smoking, social cognition theories suggest that smoking is the result of social-cognitive factors (e.g., Ajzen, 1991; Conrad et al., 1992). Previous studies suggest that the effects of parenting on adolescent smoking may be moderated by these cognitive factors (Harakeh et al., 2004; Huver 
et al., 2006; Huver et al., in press). According to the I-Change Model (Integrated Model for Change)(De Vries, Mudde et al., 2003), the set of cognitions (attitude, perceived social influences and self-efficacy expectations) influences the intention to smoke, in turn predicting smoking behavior. Attitudes consist of the advantages and disadvantages a person perceives with regard to smoking. Perceived social norm is a form of social influence pertaining to perceptions of what others would expect one to do. Finally, self-efficacy has been described as the estimated ability to engage in a certain behavior (Bandura, 1986a), in this case refraining from smoking. Anti-smoking socialization is assumed to play a distal role in the I-Change Model, operating on adolescent smoking through cognitions. Socialization - assessed by parental reactions to smoking, house rules on smoking, and communication about smoking - is indeed predictive of smoking-related cognitions (Otten, Harakeh, Vermulst, Van den Eijnden, \& Engels, in press). Associations between the frequency and content of parental communication and attitude, social norms regarding smoking, and self-efficacy have also been reported elsewhere (Huver et al., in press). In this prospective study, aspects of parent-child communication on smoking behavior were mediated by cognitions. These findings suggest that effects of smoking-specific parenting operating on adolescent smoking behavior may be mediated by smoking-related cognitions.

We propose a model (Figure 1) to test the idea of parenting style as a context for anti-smoking socialization in its relation to adolescent smoking cognitions and behavior. In this model, socialization is related to adolescent smoking cognitions and behavior. The model was tested for adolescents experiencing either high or low levels of parental support, strict control, or psychological control. We hypothesized that (a) parental anti-smoking socialization would be related to adolescent smoking cognitions and behavior and that (b) these relations would be moderated by the parenting climate they take place in, with antismoking socialization being most beneficial to adolescents experiencing the high support, high strict control and low psychological control that characterize authoritative parenting. 


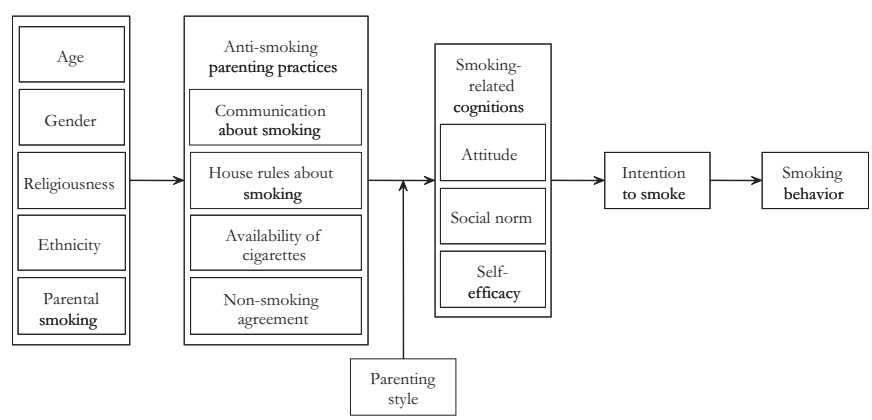

Figure 1

Conceptual model tested in the present study

\section{Methods}

\section{Sample and Procedures}

In May 2003, 482 adolescents aged 12 to 19 years took part in the Study of Medical Information and Lifestyles in Eindhoven (SMILE) by filling out self-administered questionnaires. SMILE is a joint project of Maastricht University and 23 family physicians from seven medical practices located in Eindhoven, a city of approximately 200,000 inhabitants situated in the southern part of the Netherlands. Family physicians provided participant addresses. The 16-page questionnaire took 30 to 45 minutes to complete, and a telephone helpline and website were available for additional information. Anonymity was guaranteed and the adolescents were informed that participation would not be disclosed to family physicians.

\section{Measures}

\section{Background variables.}

Demographic factors included in this study were age, gender (1 "boy", 2 "girl"), religiousness (1 "not religious", 2 "religious"), and ethnicity 
as derived from parental origin (1 "not of Dutch origin", 2 "of Dutch origin"). Parental smoking status was assessed with scores ranging from 0 to 2 , indicating whether none, one or both parents were perceived as smokers.

\section{Anti-smoking socialization.}

Four forms of smoking-specific parental socialization were assessed: communication about smoking, house rules about smoking, availability of cigarettes at home and non-smoking agreements. First, an eight-item instrument based on work by Ennett and colleagues (Ennett, Bauman, Foshee et al., 2001) assessed the content and frequency of parent-child communication about smoking (e.g., "In the past 12 months, how often have your parents encouraged you not to use tobacco?"). Higher scores on this scale indicate more discouragement of tobacco use. Responses ranged from 1 "never" to 5 "very often". Cronbach's $\alpha$ was .86.

Second, five items were used to assess the presence of rules on smoking in and around the house (e.g., "We have clear rules on smoking at home"), with responses on five-point scales ranging from 1 "completely false" to 5 "completely true" (Engels \& Willemsen, 2004). Higher scores on this scale indicated that respondents experienced clear house rules. Cronbach's $\alpha$ was .82.

Third, two questions on the availability of cigarettes were asked - whether tobacco products were present at home and whether several packets were available, with possible responses from 1 "never" to 4 "always" (Engels $\&$ Willemsen, 2004). The correlation between the two items was 0.86 , $p<.001$.

The final questions asked were whether the respondents had an agreement with their parents not to smoke until a certain age and whether their parents had promised a reward for not smoking. Both items could be answered by 1 "no" or 2 "yes".

\section{Parenting style.}

Parenting style was assessed using a Dutch translation (Beyers \& Goossens, 1999) of a widely used instrument by Steinberg et al., with good external 
validity, internal consistency, and test-retest reliability (Steinberg et al., 1989). This measure assessed the three parenting dimensions, with respondents reporting on their mothers' and fathers' parenting. To assess support, respondents were asked to indicate for each parent how much they agreed with eight statements such as "I can count on my mother/ father to help me out, if I have some kind of problem". Cronbach's $\alpha$ was .86. The degree of strict control was assessed using six items for each parent and assessed parental knowledge (e.g., "My mother/father REALLY knows where I go at night") and active monitoring efforts (e.g., "My mother/father TRIES to keep track of where I go at night"). The value of Cronbach's $\alpha$ was .85. Two sets of nine statements such as "My mother/father acts in a cold and unfriendly manner if I do something she/he doesn't like" assessed maternal and paternal psychological control. Cronbach's $\alpha$ was .83. Responses were rated on five-point Likert scales.

\section{Attitude.}

Attitude toward smoking was assessed by four questions asking to what extent the respondents found smoking unhealthy/healthy, bad/good, tasting bad/good, and unpleasant/pleasant ( Huver et al., in press). Responses were rated on seven-point scales with higher scores indicating a more positive attitude toward smoking. Cronbach's $\alpha$ was .85.

\section{Social norm.}

Participants were asked to indicate to what extent they believed their mothers, fathers, brothers, sisters, friends, best friend, and boyfriend/ girlfriend thought they ought to smoke. Response categories on these seven items ranged from 1 "I definitely should not smoke" to 7 "I definitely should smoke” (Kremers et al., 2001b). Cronbach's $\alpha$ was .96.

\section{Self-efficacy.}

Self-efficacy assessed the extent to which respondents thought themselves capable of not smoking in certain situations and was assessed with an instrument based on earlier work by Lawrance (1988). Ten questions such as "When you are upset, are you able not to smoke?" were scored on seven-point scales, with responses ranging from 1 "I am sure I will smoke" to 7 "I am sure I won't smoke" (Kremers et al., 2001b). Higher 
scores indicated a higher self-efficacy to refrain from smoking. The value of Cronbach's $\alpha$ was .97.

\section{Intention.}

Two items assessed the intention to start and quit smoking. Regarding the intention to start smoking, participants were asked to indicate which of eight statements described them best (Kremers, De Vries et al., 2004). Responses were recoded into four choices - "I am sure I will never start smoking", "I think I will start smoking in the future", "I think I will start smoking within the next month" and "I already smoke" - due to the skewness of the distribution of this variable. Respondents could indicate their intention to quit smoking on a four-point scale in the same way.

\section{Adolescent smoking behavior.}

Two questions related to smoking behavior. Participants were classified as never smokers if they indicated never to have smoked ("not even one puff"), as occasional smokers if they smoked monthly or less, and as regular smokers if they smoked weekly or more (Flay, 1993; Kremers et al., 2001a). An additional question asked about the total number of cigarettes smoked during the respondent's lifetime, with possible answers being 0 " 0 ", 1 "between 1 and 4", 2 "between 5 and 99" and 3 "100 or more". The correlation between the two items was $0.91, p<.001$.

\section{Statistical Analyses}

The models were tested using structural equation modeling (SEM) with the help of the MPLUS 3.0 software package (Muthén \& Muthén, 19982004). The exogenous variables were age, gender, religiousness, ethnicity, and parental smoking. The nine endogenous variables were the four aspects of socialization, which can be regarded as the distal factors in the model, while the smoking-related cognitions of attitude, social norm, and self-efficacy can be seen as more proximal factors for the explanation of intention to smoke and smoking behavior. All endogenous variables were latent variables. Four of them - the availability of cigarettes, nonsmoking agreements, intention to smoke and smoking behavior - were 
assessed by two items. The other five latent variables were assessed by scales consisting of item pools. The number of parameters to be estimated would have been too large relative to the sample size if the individual items were used as indicators for each of the five latent variables. This problem was solved by using parcels as indicators for the five latent variables (Bandalos \& Finney, 2001), with the exception of the social norm variable, which was divided into the social norm of family and that of friends. Parcels are combinations of subsets of items underlying a latent variable. The items were divided into two equivalent parts for each of the five latent variables. The eight items relating to communication about smoking were divided into two parcels of four items each. The five items relating to house rules were divided into two parcels of three and two items, the four items relating to attitude into parcels of two items each, and those for self-efficacy into parcels of five items each. Scores on parcels were computed by summing the scores on the items for each part. The measurement part of the model of Figure 2 (the factor model) is given in Appendix A. It shows that the loadings are sufficiently high, with some loadings above 1 . This is allowed because loadings are standardized regression weights and these weights can have values above 1 (Jöreskog, 2005).

Moderation effects of the parenting variables of support, strict control, and psychological control were investigated by forming two groups for each of the parenting variables, using the split half method. One group had scores below the median (the low group), the other group had scores above the median (the high group). See Harakeh et al. (2004) for a description of this procedure. This resulted in six groups: respondents reporting high/low support, high/low strict control, and high/low psychological control. Differences in structural paths between the two groups were tested for each parenting dimension using multigroup analysis (Bollen, 1989). A significant difference in a path (a relation between two variables) between the low group and the high group for a particular parental variable means that this particular variable moderates the relation between these two variables. Before testing moderation effects, the corresponding factor loadings (lambdas) of a low group and a high 
group are constrained to be equal as a default in MPLUS before testing moderation effects. The chi-square value of this lambda-constrained model is computed first. The next step is to constrain all corresponding gamma weights (relations between exogenous and endogenous variables) of the two groups to be equal. If a significant difference exists between the chi-square of the lambda-constrained model and the gamma-constrained model, one or more gamma weights are different between the two groups. The gamma weights responsible for this significant difference are found by repeating the previous step for each of the gamma weights separately. The same procedure was used for the relations between the endogenous variables (beta weights). See Byrne (1998) for more information about this procedure.

All SEM models were tested with help of the Maximum Likelihood estimation method. We used two fit measures recommended by several authors: the Root Mean Square Error of Approximation (RMSEA)(Byrne, 1998), and the Comparative Fit Index (CFI) by Bentler (Marsh, Balla, $\&$ Hau, 1996). RMSEA is used to assess approximate fit, preferably with values less than or equal to 0.05 , but values between 0.05 and 0.08 are indicative of a fair fit (Kaplan, 2000). CFI is a comparative fit index, and values above 0.95 are preferred (Kaplan, 2000) but they should not be lower than 0.90 (Kline, 1998).

To prevent the description and graphical representation of the results from becoming too complex, the measurement part of the model is reported in Appendix A. The correlations between independent variables and between the disturbance terms of the latent variables are reported in Appendix B.

\section{Results}

\section{Descriptives}

The adolescents taking part in the SMILE study had a mean age of 15.35 years $(S D=2.02)$, and slightly more girls than boys $(55.6 \%)$ took part 
in the study. Participants were mostly of Dutch origin (90.5\%), and most of them indicated that they had some kind of religious background (54.4\%). Never smokers made up $60.2 \%$ of the sample, $31.6 \%$ were occasional smokers and $8.2 \%$ were regular smokers. Whereas $60.2 \%$ of the respondents indicated not to have smoked any cigarettes in their lifetime, $20.2 \%$ had smoked between 1 and 4 cigarettes, $9.8 \%$ between 5 and 99 , and another $9.8 \%$ had smoked 100 cigarettes or more. With respect to parental smoking, $58.3 \%$ of the respondents indicated that neither parent smoked, $29.0 \%$ that one parent smoked, and $12.6 \%$ that both parents smoked.

\section{Anti-smoking Socialization, Adolescent Smoking Cognitions and Behavior}

The model depicted in Figure 1 was tested for all respondents and for respondents with parents with high/low scores on the support, strict control and psychological control dimensions. The fit indices for the seven models are listed in Table 1 . The unstandardized beta weights for the models are given in Table 2 .

Figure 2 shows the standardized results of the model for the total sample. Only significant paths are shown, even though non-significant paths remained in the model, and the fit was satisfactory (RMSEA $=0.047$, CFI $=0.969)$. Several background variables were significantly associated with perceived socialization. Older respondents reported that they communicated less about smoking with their parents and had easier access to cigarettes. Cigarettes were more easily available for girls than for boys, and religious respondents communicated more about smoking with their parents than non-religious respondents. Compared to respondents of non-Dutch origin, Dutch respondents reported less communication, fewer house rules and easier access to cigarettes. As could be expected, parental smoking was related to fewer house rules about smoking and 
Table 1

Fit Measures For Each of the seven Models

\begin{tabular}{|c|c|c|c|c|c|c|c|}
\hline & \multirow[t]{2}{*}{ Total } & \multicolumn{2}{|c|}{ Support } & \multicolumn{2}{|c|}{ Strict control } & \multicolumn{2}{|c|}{ Psychological control } \\
\hline & & Low & High & $\overline{\text { Low }}$ & High & Low & High \\
\hline$N$ & 482 & 218 & 219 & 217 & 219 & 216 & 217 \\
\hline Df & 179 & 179 & 179 & 179 & 179 & 179 & 179 \\
\hline$\chi^{2}$ & 373.4 & 235.3 & 307.5 & 307.8 & 259.2 & 259.8 & 259.8 \\
\hline RMSEA & .047 & .043 & .057 & .058 & .051 & .050 & .046 \\
\hline CFI & .969 & .974 & .957 & .956 & .966 & .963 & .973 \\
\hline
\end{tabular}

Table 2

Structural Parameter Estimates of the seven Models (Unstandardized Weights)

\begin{tabular}{|c|c|c|c|c|c|c|c|c|}
\hline & & \multirow[t]{2}{*}{ Total } & \multicolumn{2}{|c|}{ Support } & \multicolumn{2}{|c|}{ Strict control } & \multicolumn{2}{|c|}{$\begin{array}{l}\text { Psychological } \\
\text { control }\end{array}$} \\
\hline & & & Low & High & Low & High & Low & High \\
\hline From & To (gammas) & & & & & & & \\
\hline Age & Communication & -.09 & $\underline{. .05}$ & -.12 & -.06 & -.10 & -.10 & -.09 \\
\hline Age & House rules about smoking & $\underline{-.03}$ & .00 & -.04 & .03 & -.06 & .00 & $\underline{-.02}$ \\
\hline Age & Availability of cigarettes & .04 & .04 & .03 & .03 & .05 & .03 & .06 \\
\hline Age & Non-smoking agreement & .01 & $\underline{-.00}$ & .01 & .00 & .01 & .00 & .01 \\
\hline Age & Smoking behavior & .08 & .10 & .06 & .09 & .06 & .07 & .09 \\
\hline Gender & Communication & $\underline{-.03}$ & $\underline{-.01}$ & $\underline{-.05}$ & .07 & $\underline{-.07}$ & .06 & $\underline{-.10}$ \\
\hline Gender & House rules about smoking & $\underline{-.07}$ & -.08 & -.04 & .02 & $\underline{-.09}$ & .13 & -.26 \\
\hline Gender & Availability of cigarettes & .22 & .17 & .25 & .16 & .23 & .23 & .17 \\
\hline Gender & Non-smoking agreement & .05 & .06 & .06 & .08 & .02 & .08 & .03 \\
\hline Religiousness & Communication & .13 & .08 & .20 & .03 & .22 & .12 & .09 \\
\hline Religiousness & House rules about smoking & $\underline{-.01}$ & .09 & -.12 & -.08 & .02 & $\underline{-.01}$ & $\underline{-.07}$ \\
\hline Religiousness & Availability of cigarettes & .02 & -.09 & .20 & -.05 & .16 & .14 & -.07 \\
\hline Religiousness & Non-smoking agreement & .03 & .02 & .06 & -.02 & .08 & .03 & $\underline{-.02}$ \\
\hline Ethnicity & communication & -.35 & -.20 & -.42 & $\underline{-.06}$ & -.54 & $\underline{-.00}$ & -.48 \\
\hline Ethnicity & House rules about smoking & -.36 & -.14 & -.50 & -.17 & -.49 &. .19 & -.48 \\
\hline Ethnicity & Availability of cigarettes & .18 & .22 & .10 & .20 & .11 & .20 & .08 \\
\hline Ethnicity & Non-smoking agreement & $\underline{-.01}$ & .08 & $\underline{-.11}$ & .05 & $\underline{-.07}$ & .13 & $\underline{-.06}$ \\
\hline Parental smoking & Communication & .01 & .06 & .00 & .01 & .07 & .05 & .00 \\
\hline Parental smoking & House rules about smoking & -.71 & -.60 & -.78 & -.71 & -.71 & -.72 & -.72 \\
\hline Parental smoking & Availability of cigarettes & 1.23 & 1.30 & 1.23 & 1.29 & 1.22 & 1.35 & 1.15 \\
\hline Parental smoking & Non-smoking agreement & $\underline{-.01}$ & $\underline{. .03}$ & .04 & .01 & $\underline{-.01}$ & $\underline{. .02}$ & .01 \\
\hline
\end{tabular}


Table 2 (continued)

\begin{tabular}{|c|c|c|c|c|c|c|c|c|}
\hline & & \multirow[t]{2}{*}{ Total } & \multicolumn{2}{|c|}{ Support } & \multicolumn{2}{|c|}{ Strict control } & \multicolumn{2}{|c|}{$\begin{array}{l}\text { Psychological } \\
\text { control }\end{array}$} \\
\hline & & & Low & High & Low & High & Low & High \\
\hline From & To (betas) & & & & & & & \\
\hline Communication & Attitude & -.18 & -.12 &. .18 & -.17 & -.12 & -.05 & -.38 \\
\hline Communication & Social norm & -.02 & .06 & .03 & -.21 & .14 & -.02 & $\underline{-.01}$ \\
\hline Communication & Self-efficacy &. .01 & -.13 & -.00 & .03 & -.14 & -.08 & .06 \\
\hline $\begin{array}{l}\text { House rules about } \\
\text { smoking }\end{array}$ & Attitude & $\underline{-.06}$ & $\underline{-.07}$ &. .04 & -.01 & -.08 & $\underline{-.02}$ & -.05 \\
\hline $\begin{array}{l}\text { House rules about } \\
\text { smoking }\end{array}$ & Social norm & $\underline{-.09}$ & -.18 &. .10 & -.07 & -.13 & -.10 & -.11 \\
\hline $\begin{array}{l}\text { House rules about } \\
\text { smoking }\end{array}$ & Self-efficacy & $\underline{-.03}$ & $\underline{-.01}$ &. .04 & $\underline{-.03}$ & -.01 & $\underline{-.00}$ & -.05 \\
\hline $\begin{array}{l}\text { Availability of } \\
\text { cigarettes }\end{array}$ & Attitude & .20 & .21 & .15 & .23 & .16 & .15 & .26 \\
\hline $\begin{array}{l}\text { Availability of } \\
\text { cigarettes }\end{array}$ & Social norm & .07 & .02 & .03 & .02 & .07 & $\underline{-.08}$ & .20 \\
\hline $\begin{array}{l}\text { Availability of } \\
\text { cigarettes }\end{array}$ & Self-efficacy & -.23 & -.18 & -.18 & -.22 & -.14 & -.14 & -.25 \\
\hline $\begin{array}{l}\text { Non-smoking } \\
\text { agreement }\end{array}$ & Attitude & .22 & .09 & .15 & .30 & .14 & .15 & .30 \\
\hline $\begin{array}{l}\text { Non-smoking } \\
\text { agreement }\end{array}$ & Social norm & .01 & -.10 & .10 & -.08 & .08 & $\underline{-.06}$ & -.07 \\
\hline $\begin{array}{l}\text { Non-smoking } \\
\text { agreement }\end{array}$ & Self-efficacy & -.20 & -.18 & -.13 & -.35 & -.12 & $\underline{-.03}$ & -.47 \\
\hline Attitude & Intention to smoke & .27 & .24 & .32 & $.19^{\mathrm{a}}$ & $.33^{\mathrm{a}}$ & $.18^{\mathrm{b}}$ & $.32^{\mathrm{b}}$ \\
\hline Social norm & Intention to smoke &. .02 & $\underline{-.11}$ & .07 & -.15 & .10 & -.08 & .07 \\
\hline Self-efficacy & Intention to smoke & -.41 & -.48 & -.32 & $-.56^{c}$ & $-.24^{c}$ & $-.51^{\mathrm{d}}$ & $-.34^{\mathrm{d}}$ \\
\hline Intention to smoke & Smoking behavior & .60 & .59 & .58 & .58 & .57 & $.69^{\mathrm{c}}$ & $.52^{\mathrm{c}}$ \\
\hline
\end{tabular}

Note: The underlined estimates are not significant $(p>.05){ }^{2, \mathrm{~b}, c, \mathrm{~d}, \mathrm{e}}=$ different at $p<.05$.

greater availability of cigarettes. The modification indices suggested an additional relation that was not specified by the model, viz. that the age of the respondents had a positive relation with smoking behavior. Associations were found between perceived socialization and respondents' 
cognitions about smoking. Children of parents who communicated about smoking had a less positive attitude toward smoking. Availability of cigarettes was related to a more positive attitude and a lower selfefficacy to refrain from smoking. Neither the presence of house rules about smoking, nor having a non-smoking agreement was significantly related to smoking cognitions. No associations were found between smoking-related socialization and the social norms that the respondents perceived with respect to smoking. In line with the assumptions of the I-Change Model, respondents with a pro-smoking attitude and reduced self-efficacy had a greater intention to smoke. Social norm was not related to the intention to smoke. Intention was positively associated with smoking behavior. No indications of direct associations between socialization and smoking intention or behavior were found.

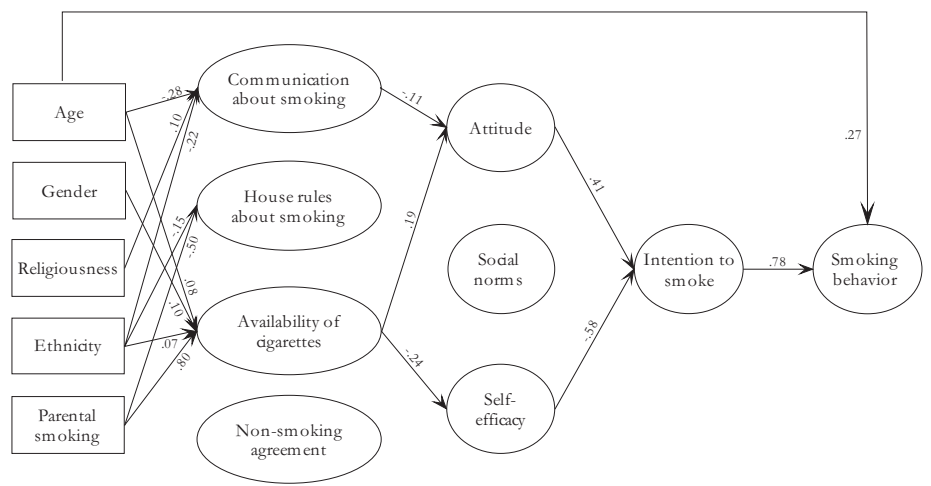

Figure 2

Structural equation model of associations between smoking-specific socialization and adolescent smoking cognitions and behavior $\mathrm{N}=482$ (all adolescents), $\mathrm{X}^{2}(179)=373.45, \mathrm{p}<.001, R M S E A=0.047, C F I=0.969$, and TLI $=0.958$. Only significant paths are presented 


\section{Support as a Context}

The models for adolescents perceiving either high or low levels of parental support were compared to test whether parental support moderated the associations in the model. Table 2 shows the unstandardized gamma and beta weights for both groups. No significant differences were found, indicating that the model was equal for all respondents, regardless of parental support $\left(\Delta \chi^{2}(16)=13.99\right.$, n.s. $)$.

\section{Strict Control as a Context}

The unstandardized parameter estimates of the models for respondents perceiving high and low levels of parental strict control are given in Table 2 . The models differed significantly $\left(\Delta \chi^{2}(16)=41.41, p<.001\right)$. The two groups of respondents differed in the relations between cognitions and the intention to smoke. Attitude toward smoking was more strongly associated with the intention to smoke for respondents indicating that they experienced high levels of strict control $\left(\Delta \chi^{2}(1)=5.07, p<\right.$ $.05)$. Furthermore, while self-efficacy was inversely associated with the intention to smoke, this relation was weaker under high strict control $\left(\Delta \chi^{2}(1)=21.26, p<.001\right)$. No significant differences in gamma weights were found.

\section{Psychological Control as a Context}

Unstandardized parameter estimates of the model under high and low psychological control can be seen in the last two columns of Table 2 . Some relations between constructs in the model were moderated by psychological control $\left(\Delta \chi^{2}(16)=39.92, p<.001\right)$. Attitude toward smoking was more strongly associated with the intention to smoke for respondents experiencing high levels of psychological control $\left(\Delta \chi^{2}(1)=\right.$ $4.73, p<.05)$ and relations of self-efficacy with intention were weaker $\left(\Delta \chi^{2}(1)=4.35, p<.05\right)$. The intention-behavior link was also weaker in a high psychological control climate $\left(\Delta \chi^{2}(1)=6.72, p<.001\right)$. No 
significant differences in gamma weights were found between the two groups of respondents.

\section{Discussion}

The main goal of this study was to assess whether general parenting, as assessed by support, strict control, and psychological control, could be considered a context for smoking-specific socialization (communication about smoking, house rules, availability of tobacco products, nonsmoking agreements). A model of smoking-specific socialization and adolescent smoking cognitions and behavior was proposed, which was then compared for respondents experiencing high or low support, strict control, or psychological control. Aspects of anti-smoking socialization were associated with smoking-related cognitions and related to smoking behavior. Parenting style did not serve as a context for these results.

Our first hypothesis was that anti-smoking socialization would be associated with adolescent smoking cognitions and behavior. The data suggested that parental communication about smoking may indeed be effective in lowering adolescent pro-smoking attitudes. This has also been reported elsewhere (Huver et al., 2006; Otten et al., in press). Additionally, reduced availability could also reduce positive attitudes and improve self-efficacy to refrain from smoking. It should be pointed out here that parental smoking status, well-established as a predictor of adolescent smoking (Avenevoli \& Merikangas, 2003), was strongly associated with the availability of cigarettes at home. However, parents can be smokers without granting their children access to cigarettes, a seemingly effective strategy. No associations with smoking-related cognitions were found for either house rules about smoking or having a non-smoking agreement, not even if parents did not smoke themselves. This is remarkable, as setting house rules is generally considered an effective anti-smoking socialization strategy (Clark et al., 1999). Nonsmoking agreements are common in the Netherlands and other European countries, but in the light of the current and previous findings, their 
effectiveness may not be as robust as has been assumed. Interestingly, the data did not suggest direct relations between aspects of socialization and smoking behavior. This could be taken to mean that effective socialization operates on smoking behavior only through smoking-related cognitions. Continuing this line of reasoning, effects of socialization may need to be internalized by adolescents to lead to a change in smoking behavior (Kelman, 1958).

The second hypothesis was that general parenting would serve as a context for anti-smoking socialization, as has been suggested by Darling and Steinberg (1993), with anti-smoking socialization being most beneficial in households where adolescents perceive high support, high strict control, and low psychological control. However, this was not supported by the data, as socialization functioned equally for all adolescents, regardless of the perceived parenting climate. While the idea of global parenting style as a context for anti-smoking socialization is convincing, it has rarely been studied. Chassin et al. (2005) also failed to find moderating effects of parenting style in the relationship between socialization and adolescent smoking. While additional research is needed to replicate findings, at this stage it seems that socialization may be effective in deterring adolescent smoking regardless of the parenting climate in which these behaviors are expressed. Apparently, parenting style does not serve as a context in which anti-smoking socialization operates on adolescent smoking cognitions and behavior.

With respect to smoking-related cognitions in their relation to adolescent smoking, as predicted by the I-Change Model, a higher pro-smoking attitude was associated with a greater intention to smoke, as was a reduced self-efficacy to refrain from smoking. Intention to smoke was in turn positively associated with an increase in smoking. Socio-cultural factors, such as parenting practices, appear to influence the development of smoking-related cognitions in agreement with the hypothesis of the I-Change Model. The position of social norms might need to be reconsidered. If the more distal position of parenting is established and is interpreted as a form of social influence, then social norms may need 
to be regarded as more distal influences than attitudes and self-efficacy in the process of smoking, unlike what has been assumed previously (Huver et al., 2006). The fact that we did not find associations between social norm and either parenting factors of intention to smoke underlines the significance of this. Attitude was a stronger predictor of intention for respondents under higher levels of either strict or psychological control, while self-efficacy was less protective against a greater intention to smoke. The intention-behavior link was strongest for respondents under low psychological control.

Although parental support is not as strong a predictor of adolescent problem behaviors as strict control (Gray \& Steinberg, 1999), support has frequently been directly associated with adolescent smoking (Chassin et al., 2005). However, in Dutch samples, researchers have failed to find similar results. The current findings suggest that parental support may not be an issue in Dutch adolescent populations as regards smoking behavior.

Certain aspects of the moderation processes should be emphasized when discussing strict and psychological control moderating the relations between adolescent smoking-related cognitions and behavior. First, it appears that cognition-intention and intention-behavior links are more closely dependent on the parenting climate, making smoking behavior the result of more "reasoned action". An example of this is the stronger relation between attitude and intention for respondents reporting high strict control. Second, while greater self-efficacy is assumed to protect against smoking, this is less true under some circumstances than others, such as high psychological control. It seems plausible that if adolescents are being limited in their psychological functioning by manipulative parental efforts, confidence in their own skills is less strongly linked to behavior. This underlines the undermining effects of psychological control and the resulting need for parents to grant autonomy. Selfefficacy is not only less of a protective factor against smoking under high psychological control, it has also been shown that children experiencing high levels of psychological control have a reduced self-efficacy to refrain 
from smoking (Huver et al., in press). Finally, processes of adolescent reaction should be considered (Brehm, 1966). Adolescents with a more positive attitude towards smoking are more likely to start smoking, especially under high psychological control. Adolescents already having a positive attitude to smoke may be even more likely to smoke under high psychological control, out of recalcitrance and rebelliousness in reaction to this unpleasant form of control.

The present study has several strengths and limitations. We have proposed an integrative theoretical model of adolescent smoking in which associations between parental smoking-specific socialization and adolescent smoking are explained by the mediating role of smokingrelated cognitions. Additionally, these socialization processes were tested to see whether they were moderated by the global parenting climate in which they were expressed. This was all rigidly tested, making use of advanced structural equation modeling techniques. On the other hand, the study was subject to certain limitations. Assessments of parenting were limited to reports by the adolescents. However, there are indications that reports on parenting by adolescents may be more reliable than reports by the parents themselves (e.g., Engels et al., 2001), as social desirability plays a large role in these assessments (Brown et al., 1993; Van der Vorst et al., 2005). Furthermore, while child and parent ratings might not agree, it is not so much what parents do that influences their children as how the children experience it (Chassin et al., 2005). Another limitation of our study is its cross-sectional design, making it impossible to draw conclusions on causality. Parenting strategies need not be stable over time (Goossens \& Beyers, 1999; Juang \& Silbereisen, 1999) and while it is commonly assumed that parenting influences adolescent behavior, there may be a case for a more reciprocal relation between parenting and adolescent smoking, with adolescent behavior also controlling parental actions. For example, one study (Huver et al., 2006) showed that the prospect of a reward for non-smoking was a strong predictor of smoking uptake two years later. This was explained by increased parental socialization efforts as a result of expected changes in adolescent smoking behavior. In other words, these parents did not offer the prospect of the 
reward until they felt that their children were likely to start smoking, and smoking uptake took place regardless. Likewise, the cognitionbehavior link is not necessarily unidirectional. Internal processes aimed at reducing cognitive dissonance (Festinger, 1957) may result in altered cognitions after a behavior change has taken place. Similarly, intention and behavior may be hard to disentangle in cross-sectional research. It should be noted, though, that previous research has found the supposed prospective effects (Chassin et al., 2005; Harakeh et al., 2004; Kremers, De Vries et al., 2004; Kremers, Mudde, \& De Vries, 2004).

Summarizing, it may be concluded that some aspects of smoking-specific socialization were indeed related to adolescent smoking cognitions and hence to behavior, and that parenting style did not serve as a context for anti-smoking socialization. Interventions aimed at preventing or reducing adolescent smoking are sometimes aimed at changing aspects of socialization (e.g., Bauman, Foshee, Ennett, Hicks, \& Pemberton, 2001; De Vries, Mudde et al., 2003). This study suggests that these interventions need not be tailored to the global parenting climate, as effectiveness of socialization seems to be independent of this. However, at this point we are unable to make definite recommendations for the content of these interventions. Inconsistencies in findings thus far, the lack of findings showing effects of house rules and availability, and previously reported counterproductive effects of socialization practices suggest that caution is required in encouraging these practices and that there is a need for a better understanding of the circumstances in which socialization efforts are beneficial. 
Appendix A

Factor Loadings (Lambdas) for the seven Models Tested

\begin{tabular}{|c|c|c|c|c|c|c|c|}
\hline \multirow[b]{2}{*}{ Indicators for latent variables } & \multirow[t]{2}{*}{ Total } & \multicolumn{2}{|c|}{ Support } & \multicolumn{2}{|c|}{ Strict Control } & \multicolumn{2}{|c|}{$\begin{array}{l}\text { Psychological } \\
\text { Control } \\
\end{array}$} \\
\hline & & Low & High & Low & High & Low & High \\
\hline Communication about smoking 1 & .91 & .83 & .91 & .83 & .91 & .76 & .97 \\
\hline Communication about smoking 2 & .85 & .79 & .88 & .85 & .86 & .98 & .79 \\
\hline House rules about smoking 1 & .91 & .90 & .96 & .88 & .99 & .98 & .90 \\
\hline House rules about smoking 2 & .86 & .87 & .83 & .89 & .81 & .79 & .88 \\
\hline Availability of cigarettes 1 & .95 & .96 & .95 & .96 & .92 & .94 & .95 \\
\hline Availability of cigarettes 2 & .91 & .93 & .92 & .94 & .92 & .92 & .94 \\
\hline Non-smoking agreement 1 & 1.01 & 1.08 & .94 & .84 & .87 & .88 & .79 \\
\hline Non-smoking agreement 2 & .62 & .58 & .70 & .71 & .74 & .78 & .70 \\
\hline Attitude 1 & .94 & .98 & .90 & .93 & .95 & .93 & .95 \\
\hline Attitude 2 & .93 & .89 & .95 & .93 & .91 & .91 & .93 \\
\hline Social norm 1 & .75 & .90 & .71 & .87 & .63 & .77 & .80 \\
\hline Social norm 2 & .87 & .70 & .91 & .73 & 1.06 & .92 & .76 \\
\hline Self-efficacy 1 & .89 & .80 & .89 & .84 & 1.00 & .84 & .89 \\
\hline Self-efficacy 2 & .94 & .95 & .96 & .93 & .92 & .89 & .97 \\
\hline Intention to smoke 1 & .86 & .83 & .84 & .86 & .84 & .77 & .88 \\
\hline Intention to smoke 2 & .80 & .77 & .81 & .79 & .79 & .62 & .84 \\
\hline Smoking behavior 1 & .93 & .93 & .92 & .92 & .91 & .89 & .93 \\
\hline Smoking behavior 2 & .97 & .96 & .99 & .96 & 1.00 & .99 & .97 \\
\hline
\end{tabular}




\section{Appendix B}

Correlations between Independent Variables and between Disturbance Terms of Latent Variables for each of the seven Models

\begin{tabular}{|c|c|c|c|c|c|}
\hline \multirow[t]{2}{*}{ Total } & Support & \multicolumn{2}{|c|}{$\begin{array}{l}\text { Strict } \\
\text { Control } \\
\end{array}$} & \multicolumn{2}{|c|}{$\begin{array}{l}\text { Psychological } \\
\text { Control }\end{array}$} \\
\hline & High & Low & High & Low & High \\
\hline
\end{tabular}

Correlations between independent variables

\begin{tabular}{|c|c|c|c|c|c|c|c|c|}
\hline Age & Gender & .07 & .07 & .11 & .01 & .12 & .08 & .07 \\
\hline Age & Religiousness & $\underline{-.06}$ & -.12 & -.01 & $\underline{-.03}$ & -.11 & -.00 & -.15 \\
\hline Age & Ethnicity & .06 & .10 & .06 & .05 & .10 & .12 & .04 \\
\hline Age & Parental smoking & .03 & .11 & -.06 & .14 & $\underline{-.09}$ & .05 & .03 \\
\hline Gender & Religiousness & .02 & .07 & .00 & .02 & .08 & .01 & .09 \\
\hline Gender & Ethnicity & -.04 & -.04 & -.08 & -.11 & -.02 & .04 & -.17 \\
\hline Gender & Parental smoking & -.01 & .03 & -.04 & .05 & $\underline{-.08}$ & -.04 & .00 \\
\hline Religiousness & Ethnicity & -.26 & -.26 & -.19 & -.21 & .24 & -.06 & -.33 \\
\hline Religiousness & Parental smoking & -.08 & .05 & -.18 &. .04 & $\underline{-.09}$ & -.07 & -.06 \\
\hline Ethnicity & Parental smoking & -.09 & -.25 & .03 & -.22 & -.01 & -.07 & -.15 \\
\hline
\end{tabular}

Correlations between disturbance terms of latent variables

Communication

$\begin{array}{llllllll}\text { House rules about smoking } & .23 & .24 & .20 & .36 & \underline{.10} & .28 & .18\end{array}$

Communication

$\begin{array}{llllllll}\text { Availability of cigarettes } & \underline{-.01} & \underline{-.09} & \underline{.06} & \underline{. .09} & \underline{.06} & \underline{-.02} & \underline{.00}\end{array}$

Communication

$\begin{array}{llllllll}\text { Non-smoking agreement } & .17 & .20 & .13 & .20 & .15 & .04 & .29\end{array}$

House rules about smoking Availability of cigarettes $\begin{array}{llllllll}-.15 & -.24 & -.08 & -.18 & -.13 & -.12 & -.19\end{array}$

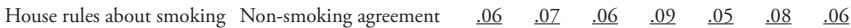

$\begin{array}{lllllllll}\text { Availability of cigarettes } \quad \text { Non-smoking agreement } & \underline{.02} & \underline{-.02} & \underline{.05} & \underline{-.02} & \underline{.06} & \underline{-.05} & .12\end{array}$

Attitude

$\begin{array}{llllllll}\text { Social norm } & .37 & .30 & .37 & .40 & .32 & .46 & .22\end{array}$

Attitude

Self-efficacy

$\begin{array}{lllllll}-.62 & -.64 & -.58 & -.67 & -.54 & -.73 & -.52\end{array}$

Social norm

Self-efficacy

$\begin{array}{lllllll}-.37 & -.31 & -.34 & -.38 & -.30 & -.40 & -.27\end{array}$

Note: The underlined estimates are not significant $(p>.05)$. 




\section{Chapter 6}

\section{Bi-directional relations between anti- smoking parenting practices and adolescent smoking}

Based on: Huver, R. M. E., Engels, R. C. M. E., Vermulst, A. A., \& De Vries, H. (resubmitted-b). Bi-directional relations between anti-smoking parenting practices and adolescent smoking. Health Psychology. 



\begin{abstract}
Parenting is generally regarded a determinant of adolescent behavior, whereas the reverse is seldom considered. Previously reported findings on effects of anti-smoking parenting practices on adolescent smoking have been inconsistent. Cross-sectional relations have been found, but these have not been confirmed in longitudinal analyses, suggesting that cross-sectional results may have been misinterpreted and child effects have been overlooked. Bi-directional relations between anti-smoking socialization and adolescent smoking were studied using a cross-lagged model where anti-smoking house rules, communication about smoking, and adolescent smoking were assessed at three subsequent years. The most prominent finding was that adolescent smoking was a stronger predictor of parenting than vice versa. Additionally, anti-smoking house rules decreased as a result of adolescent smoking, while communication increased. The reduction in house rules was more pronounced if parents smoked, while the increase in communication was greater for nonsmoking parents. Results were independent of adolescent sex. Further research is needed to establish which aspects of parenting can be effective in deterring adolescent smoking. This study emphasizes the need for caution in interpreting cross-sectional research findings relating parenting to adolescent smoking.
\end{abstract}




\section{Introduction}

As adolescents continue to take up smoking (STIVORO - rookvrij, 2004b; U.S. Department of Health and Human Services, 1994), research into determinants of adolescent smoking accumulates. In this context, anti-smoking parenting practices have received considerable attention. Two of the most widely acknowledged forms of anti-smoking socialization are anti-smoking rules in the house set by the parents and parent-child communication about smoking (Harakeh et al., 2005).

Intuitively, enforcing anti-smoking house rules and frequent smokingrelated communication between parents and children are assumed to have preventive effects on adolescent smoking. Adolescents who are not allowed to smoke at home are expected to smoke less than peers growing up in a more tolerant home environment. Similarly, it is thought that the more frequently parents discuss negative aspects of smoking, the less likely the adolescents will start and continue smoking. Indeed, several cross-sectional studies have supported these assumptions (Andersen et al., 2004; Chassin, Presson, Todd et al., 1998; Henriksen \& Jackson, 1998; Jackson \& Henriksen, 1997). However, other cross-sectional studies have reported contrasting results, finding that the presence of anti-smoking house rules and more frequent discussion about smokingrelated topics were actually associated with increased rates of adolescent smoking (Engels \& Willemsen, 2004; Harakeh et al., 2005; Huver et al., 2006; Huver et al., resubmitted-a). In addition, results from longitudinal research have failed showing protective effects of house rules or communication on adolescent smoking (Den Exter Blokland et al., 2006; Engels et al., 2005; Ennett, Bauman, Foshee et al., 2001; Huver et al., 2006). Thus, research findings relating these anti-smoking parenting practices to adolescent smoking have been inconsistent.

From scholars in the area of developmental psychology we know that the relationship between parents and offspring is of bi-directional nature, implying that parents influence their children, and children influence their parents (for a review see Bell, 1968; Lytton, 1990). Nevertheless, bi-directional relations are often overlooked in studies on the associations 
between parenting and adolescent problem behavior, as parenting is typically regarded as a determinant of adolescent behavior. The few studies that have accounted for child effects do indeed support the idea that parents react to adolescent problem behavior. For example, Kerr and Stattin (2003) showed that parenting does not predict over-time changes in adolescent delinquency, but that adolescent delinquency causes a change in parenting behavior, manifesting itself in reduced monitoring efforts as a result of parental adaptation. Stice and Barerra (2005) examined bi-directional links between parental support and strict control on the one hand and adolescent drug use, alcohol use and externalizing problems on the other, and found the relationship to be fully bi-directional for adolescent substance use. By contrast, parenting did not predict externalizing symptoms but parents reacted to adolescents' externalizing problems by withdrawing support and control. Similarly, research in a Dutch population found reciprocity between adolescent drinking and parental strict control, in which monitoring prevented alcohol use and alcohol use evoked reduced levels of strict control (Van der Vorst et al., in press).

In brief, the evidence for bi-directional associations is gradually growing in the field of adolescent problem behavior. However, bi-directional relations between anti-smoking parenting practices and adolescent smoking have not yet been studied. In view of the inconsistent findings of research relating the two, the causality that has been inferred from studies employing cross-sectional designs may be erroneous and some longitudinal designs may have been inadequate to thoroughly study the origins of the relations (Kazantzis, Ronan, \& Deane, 2001). For instance, a positive cross-sectional association between house rules and reduced adolescent smoking can be interpreted in two ways. It is possible that, for instance, the presence of anti-smoking house rules causes a reduction in adolescent smoking, but it is even likely that adolescents' smoking leads to a decline in anti-smoking house rules as a result of parental adaptation to the adolescents' behavior. Likewise, the association between communication and adolescent smoking does not necessarily have to be unidirectional, as has been traditionally assumed and tested (see Ennett, 
Bauman, Foshee et al., 2001). It is intuitively appealing to think that parents communicate more with their children as the children progress through the smoking stages.

To study bi-directional relations between anti-smoking parenting practices and adolescent smoking, we used the cross-lagged model depicted in Figure 1, in which anti-smoking house rules, communication about smoking, and adolescent smoking were assessed at three points in time, with one-year intervals. Cross-sectional relations were examined at the three waves. Furthermore, presumed parental influences on adolescent smoking were tested (reflected by paths 1,2,3, and 4), as were adolescent influences on parenting practices (paths 5, 6, 7, and 8), to explain the direction of the cross-sectional results. We additionally tested whether patterns differed with the respondents' sex and parental smoking status. We tested whether associations between parenting and adolescent smoking would differ for boys and girls. Moreover, in general, smoking parents feel less capable of socializing their children with respect to smoking and are less often engaged in anti-smoking socialization (Clark et al., 1999; Harakeh et al., 2005; Jackson \& Henriksen, 1997). It was expected that parents who smoked would be less effective in preventing their offspring from smoking and that they would give in to adolescent smoking more easily as compared to non-smoking parents.

\section{Methods}

Data were gathered between 1998 and 2000 among 2410 high school students, as part of the European Smoking prevention Framework Approach (ESFA)(De Vries, Mudde et al., 2003). All Dutch $7^{\text {th }}$ graders (i.e., students in their first year of high school) in the control condition of ESFA were asked to fill in self-administered questionnaires in class at the beginning of the school year (T1). This cohort was asked to participate again one and two years later (T2 and T3, respectively). The questionnaires had been qualitatively pre-tested (Vroom, 1994) in a representative sample of youngsters. Completed questionnaires were 


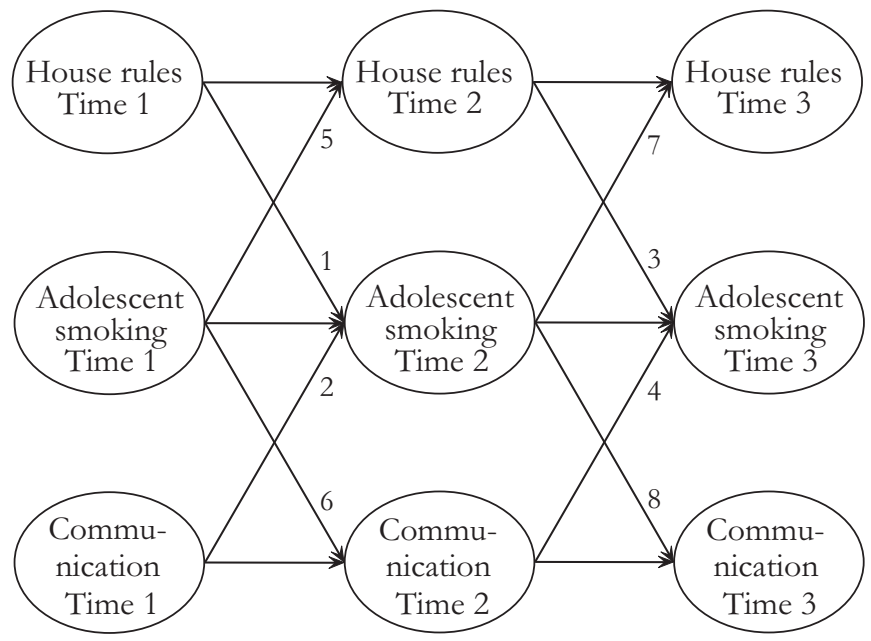

Figure 1

Conceptual model tested in the present study

put in envelopes and individually sealed, after which the teacher put all the envelopes in a larger one that was sealed in front of the class. Only students who participated in all three waves were included $(N=1721$, $71.4 \%$ ) and were compared with dropouts (viz., those not participating in all three waves) in a logistic regression analysis. Dropouts were older $(\mathrm{OR}=1.32,95 \% \mathrm{CI}=1.11-1.56)$, less likely to be religious $(\mathrm{OR}=$ $0.83,95 \% \mathrm{CI}=0.69-0.99)$, less likely to be of Dutch origin $(\mathrm{OR}=$ $0.64,95 \% \mathrm{CI}=0.52-0.79)$, and were in more advanced stages of the smoking adoption $(\mathrm{OR}=1.31,95 \% \mathrm{CI}=1.19-1.45)$, and had smoked more cigarettes during their lifetime $(\mathrm{OR}=1.80,95 \% \mathrm{CI}=1.08-3.00)$ than participants (these measures are explained in more detail in the Measures section). No sex differences were found. 


\section{Measures}

\section{Background variables.}

Age, sex (1 "male", 2 "female"), religiousness (1 "not religious", 2 "religious") and ethnicity (1 "not of Dutch origin", 2 "of Dutch origin") of the respondents were assessed. In addition, parental smoking status was assessed (0 "neither parent smokes", 1 "one parent smokes", 2 "both parents smoke"). It has been found that adolescents are capable of accurately indicating the smoking status of their parents (Vink, Willemsen, \& Boomsma, 2003).

\section{Adolescent smoking behavior.}

As previous research had established the high validity and reliability of self-report measures to assess adolescent smoking (e.g., Kentala, Utriainen, Pahkala, \& Mattila, 2004), we used two questionnaire items to assess adolescent smoking behavior. The first question pertained to current smoking status. The respondents were asked to indicate which of nine statements best described them, ranging from "I have never smoked a cigarette, not even one puff" to "I smoke at least once a day". Respondents were classified as never smokers (0) if they indicated never to have smoked ("not even one puff"), as non-smokers (1) if they had smoked less than four cigarettes or had quit, as triers (2) if they smoked less than once a month, as experimenters (3) if they smoked more than once a month but less than weekly, and as regular smokers (4) if they smoked at least once a week (Flay, 1993; Kremers et al., 2001a). Second, the respondents were asked to indicate the number of cigarettes they had smoked during their lifetime $(0=$ "0", $1=$ " $1-4 ", 2=$ = $5-99 ", 3$ = "100 or more")(Kremers et al., 2001a; WHO, 1988). Answers were cross-validated using a four-item algorithm assessing current and lifetime smoking status (De Vries, Mudde et al., 2003). Cronbach's $\alpha$ was .87 at $\mathrm{T} 1, .91$ at $\mathrm{T} 2$, and .92 at $\mathrm{T} 3$.

\section{House rules.}

Respondents could indicate whether they perceived they were allowed to smoke in their own room; the living room; the kitchen; bathrooms and toilets; the hall, corridors and staircases; and outside, specifically in 
the garden, yard, garage, or shed (Huver et al., 2006). A score of 1 was assigned if they were allowed to smoke and a score of 2 if they were not. Principal axis factor analysis with oblimin rotation consistently revealed two factors in the data of all three waves. The first factor included house rules about smoking in the living room, the kitchen, and outside $(\alpha=.82$ $\mathrm{T} 1 ; .82 \mathrm{~T} 2 ; .84 \mathrm{~T} 3$ ). The second factor included smoking in their own room, the bathrooms and toilets, and the hall, corridors and staircases ( $\alpha=.78 \mathrm{~T} 1 ; .82 \mathrm{~T} 2 ; .83 \mathrm{~T} 3)$. The items were summed to compute two indicators of the number of house rules, with scores of both indicators ranging from 1 to 6 .

\section{Communication about smoking.}

To assess parent-child communication about smoking, respondents were asked to indicate the perceived frequency with which their parents talked to them about smoking (Huver et al., 2006)(1 = "never", 2 = "talked about it, but not in the last year", 3 = "once", 4 = "now and then", $5=$ "quite often", 6 = "often"). In addition, respondents could tick ten topics they perceived to have been discussed at home, namely health risks of smoking, health risks of breathing in smoke, non-smoking agreements, being allowed to smoke, places where the adolescent could or could not smoke, prices of cigarettes, addiction, attention paid to smoking in school, friends who smoke, and others offering cigarettes. If respondents did not tick a particular topic, this item was scored as 1 . If they indicated to have talked about it, it was scored as 2 . These were summed to obtain an indicator of the number of topics discussed, ranging between 1 and $20(\alpha=.70 \mathrm{~T} 1 ; .68 \mathrm{~T} 2 ; .72 \mathrm{~T} 3)$.

\section{Statistical Analyses}

First, means and standard deviations of the variables pertaining to antismoking parenting practices were calculated and paired t-tests were carried out to compare mean scores of each variable at the three waves. In addition, correlations between model variables were calculated.

Next, the model proposed in Figure 1 was tested by means of structural 
equation modeling (SEM) with Mplus 3.11 (Muthén \& Muthén, 19982004). The background variables (age, sex, religiousness, ethnicity, and parental smoking status) were included as exogenous variables, while the anti-smoking parenting practices and adolescent smoking were endogenous latent variables at all three waves. The respondents' smoking behavior was assessed by the two items assessing current smoking stage and lifetime number of cigarettes smoked. House rules were measured by the two above-mentioned summed indicators of the number of places in the house where non-smoking rules applied. Communication about smoking was assessed by the frequency of communication about smoking and the number of topics talked about at home. The Maximum Likelihood estimation method was used. The two fit measures taken into account were the Root Mean Square Error of Approximation (RMSEA)(Byrne, 1998) and the Comparative Fit Index (CFI) by Bentler (Marsh et al., 1996). RMSEA is used to assess approximate fit, with values preferably smaller than or equal to 0.05 , and values between 0.05 and 0.08 indicating a fair fit (Kaplan, 2000). CFI is a comparative fit index, with preferred values above 0.95 (Kaplan, 2000) and values above 0.90 considered acceptable (Kline, 1998).

Multigroup analyses were used to test whether results were moderated by the respondents' sex or parental smoking status (Bollen, 1989). The model was tested for boys and girls separately. Moderation by parental smoking status was assessed by testing separate models for respondents with nonsmoking parents and those with at least one parent who smoked. Paths were then compared between the groups. Before testing moderation effects, a lambda-constrained model was computed, in which the corresponding factor loadings (lambdas) of two groups were constrained to be equal. The chi-square value of this lambda-constrained model was computed first. Next, beta weights (relations between endogenous variables) were additionally constrained to be equal. If the value of the chi-square of this beta-constrained model was significantly different from the lambda-constrained model, the beta weights were tested one by one to detect which beta weights were significantly different. This procedure is explained in more detail in Byrne (1998) and an example can be found in Huver et al. (resubmitted-a). 


\section{Results}

\section{Participants}

The respondents had a mean age of 12.83 years $(S D=0.52)$ at $\mathrm{T} 1$. The sample consisted of slightly more boys $(50.7 \%)$ than girls. Most respondents were not religious $(51.9 \%)$ and were of Dutch origin (78.0\%). Half of the respondents (50.0\%) indicated that neither of their parents smoked, whereas $31.7 \%$ indicated to have one smoking parent and $18.3 \%$ indicated that both parents smoked. At T1, 63.4\% of the adolescents were classified as never smokers, $26.2 \%$ as non-smokers, $5.8 \%$ as triers, $1.5 \%$ as experimenters and $3.1 \%$ as regular smokers. At T2, $54.3 \%$ were never smokers, $29.4 \%$ non-smokers, $5.0 \%$ triers, $3.0 \%$ experimenters, and $8.4 \%$ regular smokers. At T3, $44.2 \%$ were never smokers, $30.3 \%$ non-smokers, $2.0 \%$ triers, $6.5 \%$ experimenters, and $17.0 \%$ regular smokers

\section{Descriptive Statistics}

The mean levels of perceived anti-smoking parenting practices at the three waves are presented in Table 1. Respondents perceived significantly fewer anti-smoking house rules as they got older. There was no change over time in the frequency of smoking-related communication. The mean number of topics discussed, however, was larger at T2 and T3 than at T1.

Table 1

Mean Scores (SDs) on Indicators of Anti-Smoking Parenting Practices at three Waves in the Model

\begin{tabular}{llll}
\hline Variable & \multicolumn{1}{c}{ T1 } & \multicolumn{1}{c}{ T2 } & \multicolumn{1}{c}{ T3 } \\
\hline House rules 1 & & & \\
House rules 2 & $5.64(0.83)_{a}$ & $5.48(0.96)_{\mathrm{b}}$ & $5.35(1.06)_{\mathrm{c}}$ \\
Communication frequency & $3.04(1.45)_{\mathrm{a}}$ & $5.77(0.68)_{\mathrm{b}}$ & $5.69(0.78)_{\mathrm{c}}$ \\
Communication topics & $12.16(1.97)_{\mathrm{a}}$ & $12.28(2.03)_{\mathrm{b}}$ & $3.05(1.43)_{\mathrm{a}}$ \\
\hline
\end{tabular}

Note. Means in the same row that do not share subscripts differ at $p<.05$ in paired $t$-tests. 
Cross-Sectional Correlations between Anti-Smoking Parenting Practices and Adolescent Smoking

Table 2 shows the correlations between the indicators of parenting practices and adolescent smoking at the three waves. It can be seen from the results printed in italics that cross-sectional associations between anti-smoking parenting practices and adolescent smoking became stronger as time passed. Additional analyses were carried out in Mplus to examine whether changes in cross-sectional correlations over time were significant. Results indicated that the negative relations between house rules and adolescent smoking became significantly stronger over time. The cross-sectional negative correlations between communication and adolescent smoking remained the same at Times 1 and 2, but became significantly stronger at Time 3 .

\section{Effects of Anti-Smoking Parenting Practices on Adolescent Smoking}

We tested the model of anti-smoking parenting practices and adolescent smoking depicted in Figure 1. Standardized results of the model are presented in Figure 2. Only significant paths are shown, even though non-significant paths remained included in the model. The fit was good $\left(\chi^{2}(169)=432.82, p<.001 ; \mathrm{RMSEA}=0.030 ; \mathrm{CFI}=0.985\right)$. To prevent the description and graphical representation of the results from becoming too complex, the measurement part of the model is not represented.

We found no effects of parenting at T1 on adolescent smoking one year later (paths 1 and 2). At T2, a larger number of house rules was associated with reduced adolescent smoking at T3 (path 3), whereas communication at T2 was not predictive of adolescent smoking at T3 (path 4). The great stability of the paths indicates that all factors were predictive of the same factor measured a year later. The factor reflecting parent-child communication about smoking was relatively more stable than the factor reflecting house rules. 


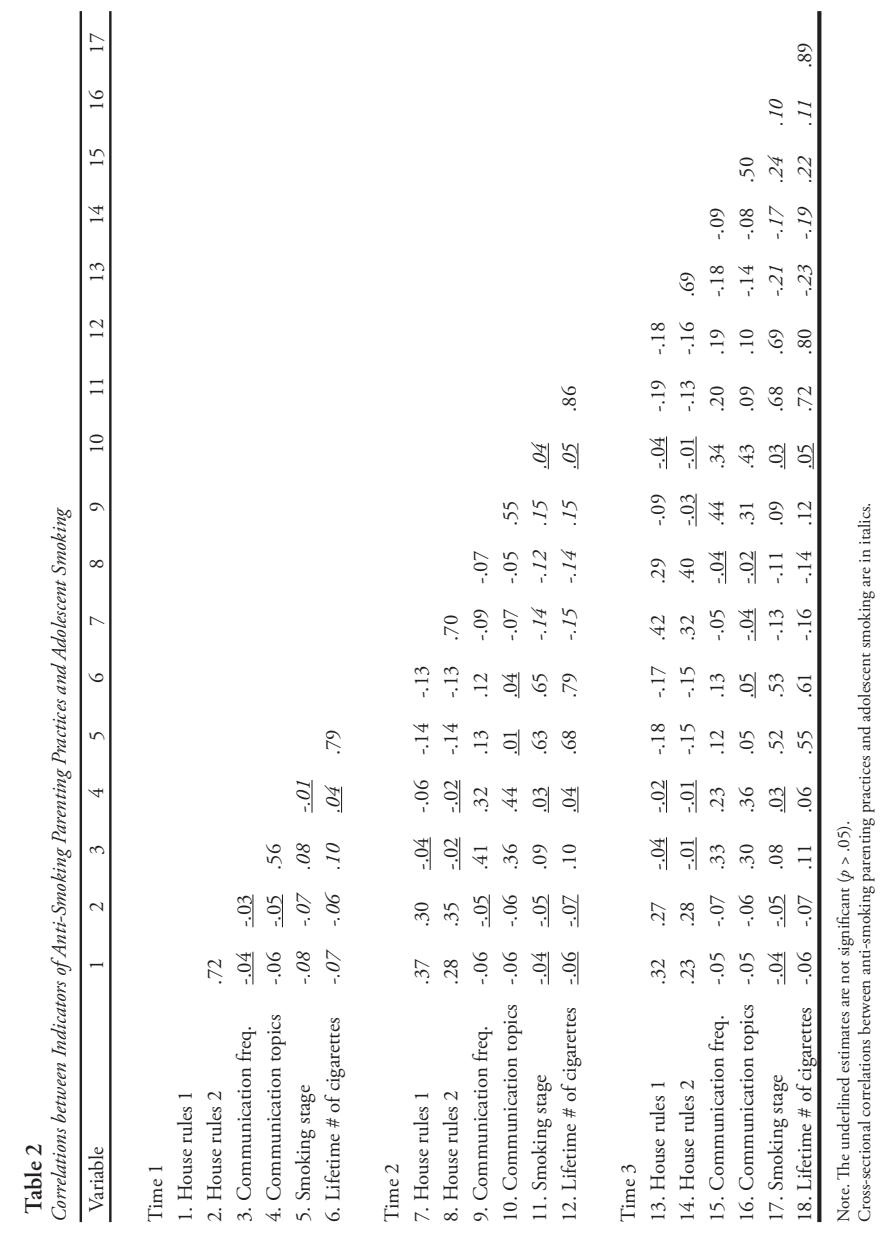




\section{Effects of Adolescent Smoking on Anti-Smoking Parenting Practices}

Regarding the presumed effects of adolescent smoking on parental antismoking practices, we found several significant cross-lagged paths. The more respondents smoked at T1, the fewer house rules they experienced (path 5) and the more their parents would communicate with them about smoking a year later (path 6). Equally, the more respondents smoked at T2, the fewer house rules and the more communication they reported at T3 (paths 7 and 8, respectively). These findings suggest that parents adapted to an increase in their children's smoking behavior by reducing the number of anti-smoking rules in the house and by increased communication with their child.

\section{Background Variables}

Regarding the exogenous background variables in Figure 2, older respondents smoked more, while girls where less likely to smoke and communicated more with their parents about smoking than boys. Religious adolescents perceived more anti-smoking house rules and were less likely to smoke than non-religious adolescents. Dutch responders reported fewer anti-smoking rules at home than non-native responders and reported more smoking-related communication with their parents. Perceived parental smoking was associated with a smaller number of anti-smoking house rules and an increase in adolescent smoking.

\section{Moderation by the Adolescents' Sex}

The model was then compared for boys and girls, to see if the adolescents' sex influenced the reported findings (viz., paths 1 to 8 ). Although significant differences in were found $\left(\Delta \chi^{2}(14)=27.80, p<.05\right)$, these differences reflected only differences in stability paths and not in crosslagged paths. Since the latter were the focus of this study, we will not describe these differences in further detail, as they do not suggest different patterns in bi-directional relations between parental behaviors and adolescent smoking for male and female adolescents. 


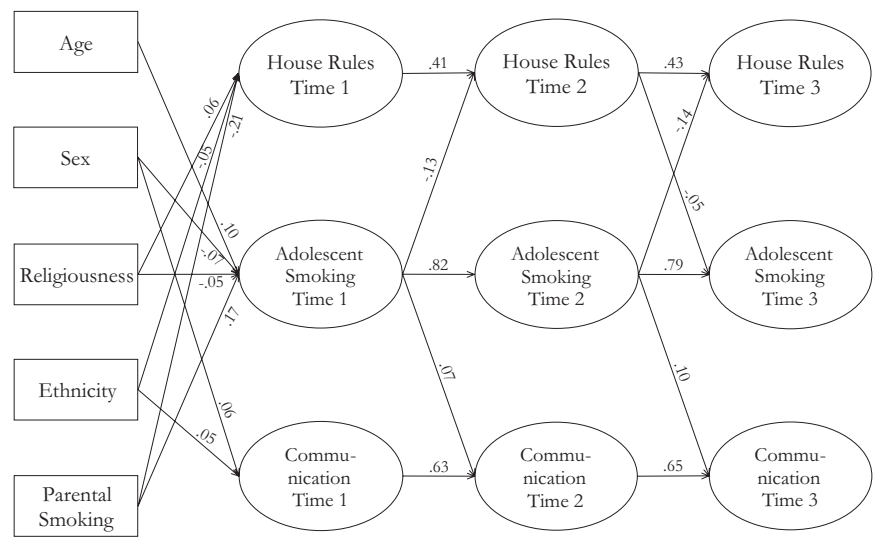

Figure 2

Structural equation model of associations between smoking-specific socialization and adolescent smoking behavior. $\mathrm{N}=1721, \mathrm{X}^{2}(169)=432.82, \mathrm{p}<.001 ; R M S E A=0.030 ; C F I=0.985$. Only significant paths are presented

\section{Moderation by Parental Smoking Status}

To test whether the reported findings were moderated by parental smoking status, the model was compared for smoking and non-smoking parents. Significant differences in beta weights were found between adolescents of smoking and non-smoking parents $\left(\Delta \chi^{2}(14)=41.96, p\right.$ $<.001)$. While associations between parenting and adolescent smoking were independent of parental smoking status, the associations between adolescent smoking and parenting practices were moderated by parental smoking status. Interestingly, the path from adolescent smoking at T2 to house rules at T3 (path 7) was stronger if parents smoked (unstandardized $\mathrm{B}_{\text {non-smoking parents }}=-.06, \mathrm{~B}_{\text {smoking parents }}=-.16 ; \Delta \chi^{2}(1)=5.09$, $p<.05)$ indicating that if parents smoked, adolescent smoking increase predicted a more pronounced decrease in the number of house rules. In addition, adolescent smoking at T2 was only predictive of an increase in 
communication about smoking at T3 (path 8) for adolescents of nonsmoking parents (unstandardized $\mathrm{B}_{\text {non-smoking parents }}=.22, \mathrm{~B}_{\text {smoking parents }}=.06$; $\left.\Delta \chi^{2}(1)=4.1, p<.05\right)$.

\section{Discussion}

Studies relating parenting to adolescent problem behavior typically consider parenting as a determinant of adolescent behavior, whereas the reverse is seldom considered. Nevertheless, the notion of reciprocal relations between parents and children is commonly accepted in developmental psychology and has been confirmed by the few studies that accounted for child effects (e.g., Kerr \& Stattin, 2003; Stice \& Barrera, 1995; Van der Vorst et al., in press). As far as we are aware, this aspect has not yet been studied with respect to adolescent smoking. Previous research findings relating anti-smoking parenting practices to adolescent smoking have been inconsistent. While cross-sectional relations have been found, these were not seen in longitudinal analyses (Den Exter Blokland et al., 2006; Engels et al., 2005; Ennett, Bauman, Foshee et al., 2001). In an attempt to explain these inconsistencies by suggesting that child effects have been overlooked, this study examined bi-directional relations between anti-smoking parenting practices and adolescent smoking. A longitudinal cross-lagged model was tested, in which anti-smoking house rules, communication about smoking, and adolescent smoking were assessed at three points in time, with one-year intervals. We found not only that adolescent smoking affected parental responses more strongly than the other way around, but also that parents reacted to adolescent smoking increase by weakening anti-smoking rules at home and discussing more smoking-related topics.

The most striking finding was that adolescent smoking was a stronger predictor of anti-smoking parenting practices over time than vice versa. Over the three waves, an increase in adolescent smoking was consistently followed by fewer anti-smoking rules at home and more communication about smoking one year later. This is in line with the small body of 
previously published literature on reciprocity between parenting and adolescent problem behavior, such as delinquency, alcohol and drug use, and externalizing behaviors (e.g., Stice \& Barrera, 1995; Van der Vorst et al., in press), which now seems to hold for the topic of adolescent smoking as well. With respect to effects of parenting on adolescent smoking, we found a protective effect of anti-smoking house rules on adolescent smoking. However, this effect was small and was not seen in all analyses, in line with previously reported longitudinal findings (Den Exter Blokland et al., 2006; Engels et al., 2005; Huver et al., 2006). Communication did not predict changes in adolescent smoking, as has been reported previously (Den Exter Blokland et al., 2006; Engels et al., 2005; Ennett, Bauman, Foshee et al., 2001). These patterns were similar for boys and girls.

It seems remarkable that as adolescents smoked more, parents seemed to be more willing to allow their children to smoke in the house, particularly if they smoked themselves. Put differently, as their children's smoking behavior increased, parents responded by relaxing their rules instead of tightening them. We thus found evidence not only for reverse causality, as Kerr and Stattin (2003) elegantly labeled it, but also that parental reactions consisted of yielding to adolescent smoking by weakening the enforcement of anti-smoking house rules, contrary to intuitive expectations. Several explanations can be suggested for this pattern of parental withdrawal. First, parents may feel insecure or inadequate about keeping their children from smoking and give up their efforts to do so when the child starts smoking. Previous research has indicated that smoking parents feel less adequate when engaging in anti-smoking practices than non-smoking parents (Clark et al., 1999). This could explain why these parents more easily relax their anti-smoking policy and do not attempt to communicate more, which is regrettable, as smoking parents have proven to be equally effective in anti-smoking parenting strategies as non-smoking parents (Huver et al., 2006; Jackson \& Henriksen, 1997). In more negative terms, smoking parents may be more willing to give up anti-smoking house rules out of idleness. Their children's smoking could in fact be an excuse for them to smoke in the 
house. A second possible explanation is that parents' relaxing of house rules is not necessarily a response to adolescent smoking, but could be the result of the adolescents getting older and being granted more autonomy, regardless of their smoking behavior (Steinberg, 1990). Thirdly, parents may in fact think of indulgence as a way to control their children's smoking behavior. Parents may feel that if their children smoke anyway, they might as well do it under their roof, instead of unsupervised.

Despite these patterns, parents did not simply give in to adolescent smoking. Compared to changes in house rules, communication was more stable over time and less influenced by adolescent smoking. Nevertheless, increased adolescent smoking was followed by more parent-child communication about smoking, especially if parents did not smoke themselves. Perhaps non-smoking parents were more set upon deterring adolescent smoking (Clark et al., 1999). As the frequency of communication was quite stable over time, while the number of smoking-related topics discussed grew, parental reactions consisted of the latter. Apparently, parents did not talk to their children more often but discussed more topics.

Although boys were more likely to smoke than girls, bi-directional relations between parenting and adolescent smoking did not depend on adolescent sex. Although rarely subject to study, there is some preliminary work supporting our findings. In a previous study, communication about smoking was related to increased smoking two years later, but only for girls (Huver et al., 2006). However, this finding was dismissed as effects of many other facets of anti-smoking socialization including parental reactions to adolescent smoking, house rules and additional aspects of communication were not dependent on adolescent gender. Similar findings have been reported by Harakeh et al. (2005) who found effects of non-smoking agreements, house rules, availability of cigarettes, and communication about smoking to be equal for boys and girls. Likewise, effects of parental expectations of amongst others smoking have been found to be independent of the gender of the adolescent (Simons Morton et al., 1999). Apparently, the way in which parents influence 
their children's smoking by anti-smoking socialization efforts and the way in which children's smoking affects parenting is the same for boys and girls.

This study had its strengths and limitations. It was innovative in considering bi-directional relations between anti-smoking parenting practices and adolescent smoking. This was studied using a large sample of adolescents, an age group where transitions in smoking behavior take place rapidly (STIVORO - rookvrij, 2004b; U.S. Department of Health and Human Services, 1994), and used structural equation modeling techniques. However, the design of this study did not allow us to collect multi-informant data, and as such we were limited to adolescent reports on parenting behaviors. There are indications, though, that adolescent reports on these behaviors may actually be more reliable than parents' own reports (e.g., Engels et al., 2001) as social desirability strongly affects parental responses to questions on child rearing (Brown et al., 1993). Moreover, adolescents are not necessarily influenced by what their parents do, but by how they perceive their parents' actions (Chassin et al., 2005).

Our findings showed that adolescent behavior was more predictive of parental behavior than vice versa. While in response to adolescent smoking increase, parents dropped a number of anti-smoking house rules, they also intensified smoking-related communication. These acts of parenting did not influence adolescent smoking in turn, or did so only marginally. While it may seem that parents have little control over their children's smoking, this is not necessarily so. First, we studied only two forms of smoking-specific parenting, and other anti-smoking socialization strategies, such as reducing the availability of cigarettes and parental monitoring of substance use, may well matter too (Huver et al., resubmitted-a; Jackson \& Henriksen, 1997; Ma et al., 2003). Second, our findings could have been influenced by cultural and age factors. The fact that house rules and communication hardly seemed to influence adolescent smoking in these Dutch adolescents does not imply that these strategies will not be effective in other populations. Finally, although 
anti-smoking parenting practices may be effective regardless of parental smoking status, as has been shown by this study and others (Huver et al., 2006; Jackson \& Henriksen, 1997), one particularly effective strategy parents can adopt to prevent adolescent smoking is not to smoke themselves (Chassin, Presson, Todd et al., 1998; Den Exter Blokland et al., 2004). Interventions targeting parents to reduce adolescent smoking should involve multiple anti-smoking parenting practices for specific populations, and parents should be motivated not to smoke.

Our findings underline the need for caution in interpreting crosssectional findings. While a cross-sectional interpretation of our data would appear to indicate that anti-smoking house rules are effective in deterring adolescent smoking, parents in fact adapted to adolescent smoking by reducing the number of anti-smoking rules in the house. Similarly, cross-sectional interpretation might suggest that parental communication about smoking actually leads to increased adolescent smoking. Our prospective results, however, paint a different picture, in which parents react to adolescent smoking by increased communication about smoking. Future research relating parenting to adolescent smoking should account for bi-directional effects. 



\section{Chapter 7}

General discussion 

Although the hazardous health consequences of smoking are wellknown, adolescents continue to take up smoking, which underlines the need for insight into its explanatory factors (STIVORO - rookvrij, 2004b; U.S. Department of Health and Human Services, 1994). Social cognition researchers have explained adolescent smoking from internal cognitive factors, arguing that adolescents are most likely to smoke if they have a positive attitude toward smoking, perceive pro-smoking social influences, and have low self-efficacy expectations to refrain from smoking (Ajzen, 1991; Conrad et al., 1992; De Vries et al., 1995; Holm, Kremers, \& De Vries, 2003). Researchers from other disciplines have examined the impact of social influences on adolescent smoking, such as those of parents and peers, stating for instance that modeling behavior of significant others is a strong predictor of adolescent smoking. Although most of these studies have focused on the influence of friends, parental influences may be of at least as much importance in this sense (De Vries et al., 2006; Kandel, 1996). While the relevance of both cognitive factors and social influences has been acknowledged, these two approaches have rarely been integrated and it is unclear how smoking-related cognitions are formed (Petraitis et al., 1995). The research reported on in this thesis builds on these two previous approaches by examining whether cognitive and social approaches to adolescent smoking can be integrated by analyzing the impact of parental influences on the development of adolescent smoking cognitions and behaviors. Thus, we studied whether aspects of parenting could be integrated in a social cognitive model, namely the I-Change Model (De Vries, Mudde et al., 2003), and whether parental personality precedes parenting style. In addition, we addressed inconsistencies in previously reported effects of anti-smoking socialization on adolescent smoking. This concluding chapter summarizes the most prominent findings of these studies and presents them in Table 1. It also discusses limitations and recommendations for future research and draws some conclusions. 


\section{Summary of the Main Findings}

\section{Part I: Integrating Parenting in the I-Change Model}

Part I of this thesis aims at integrating two previously unrelated research lines by considering aspects of parenting as distal social factors in the I-Change Model. According to this model, adolescent smoking-related cognitions predict smoking behavior (De Vries, Mudde et al., 2003). In order to study the development of these cognitions and the way in which parenting influences adolescent smoking, we examined whether effects of parenting on adolescent smoking behavior were mediated by smokingrelated cognitions, namely attitude toward smoking, perceived social influences, and self-efficacy expectations. This is examined in Chapters 2 and 3 for global parenting style and smoking-specific parenting practices, respectively. Whereas parenting style is considered to represent a global emotional climate in which a family functions, parents can also socialize their children in a more subject-specific manner, for example with respect to smoking, whereby anti-smoking parenting practices encompass those aspects of socialization aimed at discouraging smoking (Darling \& Steinberg, 1993).

Chapter 2 describes a cross-sectional study under 482 adolescents aged 12-19 years, examining the associations between perceived parenting styles (authoritative, permissive, authoritarian, rejecting, and neglectful, measured by combinations of the underlying support, strict control, and psychological control dimensions) and adolescent smoking cognitions and behavior. The main findings showed that no matter how supportive parents were, this did not affect adolescent smoking. Second, parental strict control (i.e., parental monitoring of child behavior) was associated with reduced lifetime smoking by adolescents and these effects were partly mediated by attitude toward smoking and the intention to smoke. For example, if parents provided higher levels of strict control, adolescents had a less positive attitude toward smoking and were less likely to ever have smoked. Third, parental psychological control (i.e., parental attempts to control their offspring's psychological world) was directly associated with adolescent smoking, in the sense that if parents 
were highly psychologically controlling, adolescents were more likely to have smoked. However, psychological control did not affect the smoking cognitions and its effects were thus not internalized by the cognitions. Combinations of dimensions creating the specific styles were not associated with cognitions or behavior. Parenting by mothers and fathers had the same effects and the effects of parenting were equal for boys and girls. In addition, findings were independent of parental smoking status, meaning that effects of parenting were equal for smoking and non-smoking parents. We concluded that the I-Change Model could be extended with aspects of strict control.

Chapter 3 reports on a study in which anti-smoking practices (parental reactions to smoking, house rules, and frequency and content of communication about smoking) were regarded as distal social factors in the I-Change Model. For a large sample of adolescents, aged 13 at the initial assessment and 15 at the second assessment, we measured whether anti-smoking parenting practices operated on adolescent smoking through cognitions. At age 13, relations between several aspects of parenting practices and adolescent smoking were mediated by cognitions, and these effects were more pronounced when the adolescents were two years older. The prospective relations between parenting practices and smoking-related cognitions and smoking behavior were also examined. Adolescents who at age 13 had been promised a reward for not smoking were more likely to have started smoking two years later. By contrast, adolescents were less likely to have taken up smoking if parents had talked to them about the attention that was being given to smoking in school. These parenting practices directly influenced behavior, without operating on the smoking-related cognitions measured in this study. Effects of anti-smoking socialization were the same for boys and girls, and the parents' smoking behavior did not influence the effectiveness of anti-smoking socialization. We concluded that anti-smoking parenting practices could have beneficial effects on adolescent smoking cognitions and behavior, but that more insight was needed into the circumstances under which anti-smoking socialization efforts could be successful. 
The study reported on in Chapter 4 relates parental personality to parenting style. Most research into determinants of parenting has been limited to determinants of maladaptive parenting, has focused on parenting skills in at-risk samples, or was restricted to parents of toddlers (e.g., Downey \& Coyne, 1990; Simons et al., 1993). Hence, since parental characteristics can be of indirect relevance to child development, there was a need to examine determinants of parenting for typical parents of adolescents. Parental personality is thought to influence other possible determinants of parenting style and is thus a major parental characteristic which could be of indirect relevance to adolescent health behaviors such as smoking (Belsky \& Barends, 2002; Prinzie et al., 2004). In a cross-sectional study among 688 parents of adolescents, we therefore tested whether the Big Five personality traits of extraversion, conscientiousness, agreeableness, emotional stability, and openness were associated with the authoritative, authoritarian, permissive, and neglectful parenting styles, which were created from combinations of scores on the underlying dimensions of support and strict control. The main findings included that extraverted, agreeable, and less emotionally stable individuals were most likely to be characterized by the authoritative parenting style, which has been favorably associated with adolescent health outcomes. Specifically, parents with high scores on interpersonal interaction (those who were extraverted and agreeable) were more supportive, and emotionally stable parents exerted less strict control. We argue that parents with high scores on interpersonal interaction were also more pleasant parents to adolescents, and that affective features of personality were also mainly associated with the affective aspect of parenting. That emotionally stable parents proved less controlling was unexpected, but it was suggested that as emotionally unstable individuals are known to exhibit maladaptive coping responses, they may resort more easily to controlling their children (Costa \& McCrae, 1992). Extreme emotional instability could subsequently result in harsh parenting (Prinzie et al., 2004). Conscientiousness and openness did not relate to general parenting as operationalized in this study, but may be associated with content-specific acts of parenting. If the global parenting climate is considered a distal social factor in the 
I-Change Model, affecting adolescent smoking-related cognitions and behavior, then parental personality could be regarded as an even more distal factor.

Part II: On Inconsistent Relations between Anti-Smoking Socialization and Adolescent Smoking

Part II of this thesis addresses the inconsistent relations between antismoking parenting practices and adolescent smoking that have been reported in previousstudies. Intuitively, parentalanti-smokingsocialization efforts might be thought to have protective effects against adolescent smoking. For example, adolescents who are not allowed to smoke at home are expected to smoke less than those in a more tolerant home environment. While some studies have confirmed the beneficial effects of anti-smoking socialization (Andersen et al., 2004; Chassin, Presson, Todd et al., 1998; Henriksen \& Jackson, 1998; Jackson \& Henriksen, 1997), these effects have not always been replicated. Sometimes no effects of anti-smoking practices on adolescent smoking were found, or such practices were even found to be counter-productive (e.g., Den Exter Blokland et al., 2006; Engels et al., 2005; Ennett, Bauman, Foshee et al., 2001). There are several explanations for these inconsistencies, reflecting characteristics of the parents. First, anti-smoking socialization might only be beneficial to adolescents of non-smoking parents. Adolescents may not appreciate the anti-socialization efforts of their smoking parents, thinking that parents should practice what they preach. Alternatively, parents who smoke themselves could feel that efforts to deter their child from smoking would not be credible or they may simply be less keen on deterring adolescent smoking and thus refrain from attempting to do so (Clark et al., 1999). Thus, overlooking parental smoking status may obscure the effects of anti-smoking socialization. Second, parenting style has been hypothesized to function as a context in which anti-smoking socialization occurs and may need to be accounted for (Darling \& Steinberg, 1993). As such, the effectiveness of anti-smoking socialization could depend on the parenting climate in which these practices are 
expressed. For instance, anti-smoking socialization may only be effective for adolescents experiencing their parents as authoritative. Third, the majority of research relating these practices to adolescent smoking has been based on cross-sectional findings, making it hard to draw inferences on causality. Reported cross-sectional relations between anti-smoking parenting practices and adolescent smoking have not been confirmed in longitudinal analyses, suggesting that cross-sectional results may have been misinterpreted and child effects may have been overlooked. According to this third explanation, seemingly beneficial cross-sectional effects of, for example, anti-smoking house rules on adolescent smoking would not be confirmed in longitudinal studies if it was not the number of house rules that predicts adolescent smoking, but actually adolescent smoking that predicts the presence of anti-smoking house rules.

With respect to the first explanation of previously reported inconsistencies, the findings reported in Chapter 3 and those of other studies indicate that effects of anti-smoking parenting practices are independent of parental smoking status, ruling out parental smoking status as a possible moderator of the effects of anti-smoking socialization on adolescent smoking (Bricker, Leroux et al., 2005; Jackson \& Henriksen, 1997). The other two explanations are addressed in Chapters 5 and 6, respectively.

As regards the second explanation, Darling and Steinberg (1993, p. 493) stated that "Parenting style alters the parents' capacity to socialize their children by changing the effectiveness of their parenting practices", and in Chapter 5 parenting style is considered a contextual variable, moderating the relationship between anti-smoking socialization and adolescent smoking. In the sample of adolescents aged 12-19 years, a model was tested in which anti-smoking practices (communication about smoking, anti-smoking house rules, availability of tobacco products, non-smoking agreements) were cross-sectionally related to adolescent smoking cognitions and behavior. Parent-child communication about smoking was associated with reduced smoking rates and operated through attitude about smoking and the intention to smoke. Increased availability of cigarettes was related to a greater pro-smoking attitude and a reduced 
self-efficacy to refrain from smoking, affecting the intention to smoke and smoking behavior. This model was then compared for adolescents growing up in various parenting climates, namely under high or low levels of support, strict control, and psychological control. While antismoking practices were expected to be most effective under authoritative parenting (high support, high strict control, and low psychological control), results indicated that the effectiveness of parental anti-smoking socialization efforts was independent of parenting climate. Parenting style did thus not serve as a context for anti-smoking socialization, as had been hypothesized by Darling and Steinberg (1993), suggesting that parenting styles and practices may operate independently. The inconsistencies in the findings of previous work linking anti-smoking parenting practices to adolescent smoking could not be ascribed to the parenting climate in which these behaviors were expressed.

The study reported on in Chapter 6 addresses the third explanation for these inconsistencies, and proposed a longitudinal cross-lagged model which was tested by measuring anti-smoking parenting practices (anti-smoking house rules and communication about smoking) and adolescent smoking at three successive points in time, to examine the way in which parents and adolescents influence each other over time. The results indicated that adolescent smoking behavior was a stronger predictor of parenting than vice versa. While the anti-smoking parenting practices hardly affected adolescent smoking, parents reacted to adolescent smoking by reducing the number of anti-smoking rules in the house and by more often talking to their children about smoking. The slackening of house rules was more pronounced if parents smoked, and communication increased more for non-smoking parents than for parents who smoked themselves. The findings were similar for boys and girls. Consequently, the results suggest that parenting should not just be regarded as a determinant of adolescent smoking, but also as a consequence. The previously reported inconsistent effects of anti-smoking parenting practices on adolescent smoking could indeed have been due to a failure to account for child effects. Not including these latter effects makes cross-sectional findings relating parenting practices to adolescent smoking difficult to interpret, 
as it remains unclear who influences whom. The current results indicate that future research studying the effectiveness of parenting should also account for child effects.

Table 1

Summary of the Main Findings Reported in this Thesis

\begin{tabular}{lc}
\hline & Chapter \\
\hline - The I-Change Model can be extended with strict parental control as a distal social & 2 \\
factor, and psychological control operates directly on adolescent smoking, without its \\
effects being internalized by adolescents.
\end{tabular}

\section{Parenting and adolescent smoking cognitions and behavior}

The findings of the studies discussed in this thesis indicate that the IChange Model could be extended with parental strict control as a distal social factor in explaining adolescent smoking. Psychological control was found to relate to adolescent smoking directly, without being mediated by adolescent's pro-smoking attitude, perceived social norm, or selfefficacy expectations, and no associations were found between levels of parental supportiveness and adolescent smoking behavior. Aspects of anti- 
smoking socialization could also be regarded as distal social factors in the I-Change Model, particularly for older adolescents. Parental personality could be considered an even more distal factor, although associations between personality and smoking-specific parenting practices remain to be studied.

It should be noted, however, that in other Dutch samples, no effects of strict control have been found, and supportiveness has proven beneficial (e.g., Engels et al., 2005; Harakeh et al., 2004). In addition, effects of many other smoking-specific parenting practices, such as parental monitoring of adolescent smoking, remain to be studied, as do effects of parenting on progression through smoking stages and smoking cessation. Furthermore, while the present research concentrated on mediating effects of cognitions, effects of parenting may also be moderated by cognitions. For example, parent-child communication about smoking may only have beneficial effects on smoking for adolescents who have a high-self efficacy to refrain from smoking. In addition, it is likely that a complex set of factors, such as child personality or governmental policy actions, help determine how vulnerable an adolescent is to smoking initiation, and these additional explanatory factors should be looked into. As such, the relation between parenting and adolescent smoking-related cognitions and behavior has not yet been conclusively established.

Inconsistencies in previously reported research findings linking antismoking socialization to adolescent smoking could not be explained by accounting for parental smoking status, as the effects of anti-smoking socialization appear to be the same for smoking and non-smoking parents. Nor does the global parenting climate in which these socialization efforts are expressed moderate the effects of these practices, indicating that parenting style and anti-smoking parenting practices operate rather independently in affecting adolescent smoking. However, the fact that most studies have only examined effects of parents on children but not the reverse may have caused some contradictions in previous findings. For instance, cross-sectional inverse relations between the number of anti-smoking house rules and adolescent smoking are commonly 
interpreted as beneficial effects of parenting, whereby more house rules would lead to less adolescent smoking. Chapter 6, however, offers an alternative explanation of this inverse relationship by demonstrating that as adolescents smoked more, the number of house rules in fact decreased. This stresses the importance of accounting for reciprocal relations when associating anti-smoking socialization with adolescent smoking and conducting longitudinal research.

Interventions aimed at reducing adolescent smoking can target parents in several aspects of their functioning. First, these interventions could be designed to improve the general home climate. Parents should be stimulated to exert sufficient strict control over their children and to minimize the use of psychological control. These interventions could be tailored to parental personality by prioritizing high-risk groups, such as parents with low extraversion or agreeableness scores. Second, although there is a wide variety of parenting practices besides those we studied, and studies were not completely comparable due to differences in the operationalization of measures of anti-smoking socialization, there is some indication of what parents should not do with respect to smoking-specific parenting. While Dutch parents often offer their children the prospect of a reward for non-smoking, the effectiveness of this strategy is doubtful. In addition, house rules about smoking do not seem to prevent adolescent smoking. Perhaps, house rules are not discussed until the adolescent has already taken up smoking, instead of being established preventatively. On the other hand, parent-child communication may be effective for smoking and non-smoking parents alike, although further research is needed into the content and quality of effective communication, given our finding that communication about smoking adapts to adolescent smoking behavior. Finally, parents who smoke have to be discouraged from doing so and should at least prevent exposing their children to second-hand smoke. They should also reduce the availability of cigarettes in the home. 


\section{Methodological Issues}

The results and conclusions of the studies discussed in this thesis are innovative and have certain methodological strengths, but are not without shortcomings. These issues are discussed below, starting with a common pitfall of cross-sectional research, namely that of inferences of directionality.

\section{Pitfalls of Cross-Sectional Research}

It has been pointed out that the causality that is sometimes inferred from studies employing cross-sectional designs can be misleading (Kazantzis et al., 2001). From Chapters 3 and 6 it appears that cross-sectional findings in which anti-smoking parenting practices seem to result in smoking initiation could alternatively be explained as more explicit parental efforts to deter adolescent smoking after the teen has started smoking. Extreme caution is not only warranted for the interpretation of effects of parenting: smoking-related cognitions are commonly seen as predictors of smoking behavior, but smoking behavior may also cause changes in cognitions (Kremers, Mudde, De Vries et al., 2004; Stacy et al., 1994). This might for example happen through processes of dissonance reduction (Festinger, 1957). One of the first studies on cognitive dissonance was based on an observation of cult members who believed the Apocalypse to be near. When the Apocalypse failed to occur, it was especially the strong believers, who had quit their jobs and sold their houses, who did not believe they had been mistaken, but attributed the fact that the earth still rotated to their strong faith. The discrepancy between initial cognitions ("the world will come to an end") and the facts (the Apocalypse is yet to come) was reduced by re-interpretation, which is a form of dissonance reduction. Similarly, smoking adolescents convinced of the cons of smoking may reduce the dissonance between what they do and what they think by either quitting smoking or adjusting the way they feel about smoking and perceiving more pros, such as tension relief. In the latter case, behavior has caused a change in cognitions. Taking this 
one step further, adolescent smoking may cause a change in parenting, through a change in adolescent smoking-related cognitions.

However, this does not mean that the cross-sectional findings we have described are invalid, but merely that they should not be unquestioningly accepted. Cross-sectional findings can be as valuable as longitudinal ones if the predictor is constant. For instance, Chapter 4 examined the relation between the personality of parents and their parenting style. In view of the genetic basis and stability of personality (McCrae \& Costa, 1997 ) it is safe to conclude that the formation of personality precedes the development of parenting skills and is thus a predictor of parenting styles. In addition, the presumed prospective effects of parenting and cognitions on behavior have also been found in previous studies (Chassin et al., 2005; Harakeh et al., 2004; Kremers, De Vries et al., 2004; Kremers, Mudde, \& De Vries, 2004).

\section{Effect Sizes and Multiple Testing}

Significant findings should be cautiously interpreted when multiple statistical tests are carried out and when data are gathered in large samples. An artifact of employing a .05 significance level is that one out of every twenty tests will yield false-positive results, also known as Type I errors. To overcome this, a more stringent significance level of .001 was employed when many variables were included in the analyses, such as when we tested for interactions between parenting dimensions in Chapters 2 and 4. Careful interpretation of findings is also warranted when data are gathered in large samples, since null-hypothesis significance tests, such as those performed in the studies in this thesis, are highly dependent on sample size. A large sample size will produce significance even if the effect or correlation tested is very small. Cohen $(1988,1992)$ has argued that significance tests should not be overinterpreted and that information on effect sizes can be additionally informative, as is demonstrated in Chapter 3. It should be noted, however, that a concept can show low levels of explained variance and still have theoretical relevance. Rosenthal 
(1990) described an experiment on the effects of aspirin on heart attacks, which was terminated because effects turned out to be so advantageous in the experimental condition that it would be unethical to carry on without having the control condition benefit from the same treatment. Nevertheless, the proportion of explained variance in relating effects of aspirin to heart attacks was less than $1 \%$. Although the concepts showing low levels of explained variance in our present work might not have as dramatic an impact as those in the aspirin study, this example demonstrates how factors may not contribute much statistically but still have relevance. And since adolescent smoking behavior is determined by multiple causes, and acts of parenting may thus not fully explain all the variance in adolescent smoking-related cognitions and behavior, it is nevertheless important to unravel all facets of parenting associated with adolescent smoking, for the purpose of theory development and as a basis for interventions. For instance, we found that parent-child communication about smoking activities in school may have protective effects against adolescent smoking. Although the effect may be small, it is a potentially beneficial aspect of parent-child communication to some adolescents, and could be easily embedded as a strategy in interventions aimed at preventing adolescent smoking onset or progression.

\section{Data Collection}

The fact that our data were obtained through self-administered questionnaires raises several possible problems, which should be attended to in future research. The first is that the adolescents reported on their own smoking behavior. However, the data were checked for inconsistent and improbable answering patterns, and longitudinally validated where possible. In addition, previous research comparing answers on self-reports with biochemical indices of smoking behavior has confirmed the validity and reliability of self-report measures (Dolcini, Adler, \& Ginsberg, 1996; Kentala et al., 2004). Still, a bogus pipeline procedure could have been used, whereby subjects are led to believe that physiological measurements will assess their true smoking behavior, to improve the 
truthfulness of their self-reports (Aguinis, Pierce, \& Quigley, 1993). Second, several studies required adolescents to report on their parents' smoking behavior. Although adolescents have proven to be capable of accurately indicating the smoking status of their parents, it would have been more elegant to have parent data available (Harakeh, Engels, De Vries, \& Scholte, in press). Third, adolescents were asked to report on the child-rearing behaviors of their parents, as our designs did not allow us to collect multi-informant data. We feel, however, that while child and parent ratings might not always correspond, it is not so much what parents do that influences their children as how the children perceive it (Chassin et al., 2005). In addition, there are indications that adolescent reports on these behaviors may be more reliable than parental reports (e.g., Engels et al., 2001) as data collected amongst parents might be equally biased and social desirability strongly affects parental responses to questions on child rearing (Brown et al., 1993; Van der Vorst et al., 2005). Nevertheless, collecting data among multiple agents, such as adolescents, their parents, and possibly independent observers, would be informative.

\section{Alternative Distinctions in Adolescent Smoking}

In our assessment of adolescent smoking behavior, two studies examined smoking initiation (Chapters 2 and 3), and the studies based on structural equation modeling used a compiled variable (Chapters 5 and 6). In the assessments of smoking initiation, adolescents who had never smoked ("not even one puff") were distinguished from those who had. While this is a tenable conservative distinction and studying the early phases of smoking development is appropriate for the age group of the adolescents we studied, it would also have been informative to study parental influences on adolescent smoking cognitions and behavior as the youngsters progress through more advanced smoking stages, or even try to quit smoking. Indeed, parental influences do not seem to be limited to the initial phases of adolescent cigarette smoking but extend over the whole process of establishing smoking (Otten, Engels, 
Van de Ven, Van den Eijnden, \& Bricker, submitted), and there are some indications that anti-smoking socialization is even associated with adolescent smoking cessation (Van Zundert, Van de Ven, Engels, Otten, \& Van den Eijnden, submitted). In addition, the way in which parental smoking affects adolescent smoking may vary with the adolescents' smoking stage (Bauman, Carver, \& Gleiter, 2001). For example, while some parental anti-smoking strategies may be effective for regularly smoking adolescents, engaging in these acts of socialization may be like preaching to the choir for adolescents who have never smoked or who have quit smoking. Additional research is thus needed to examine the most effective parenting strategies for adolescents in various smoking stages.

\section{What Next?}

\section{Adolescent Personality}

Although they were beyond the scope of this thesis, child characteristics, such as personality traits, have been identified as directly affecting smoking behavior or as possible mediators of parental influences (Burt, Dinh, Peterson, \& Sarason, 2000). Although available reports on this topic are limited, two studies employing a five factor approach to personality reported that adolescents were most likely to have smoked if they had high scores on extraversion, and low scores on conscientiousness, agreeableness, and emotional stability (Harakeh, Scholte, De Vries, \& Engels, 2006; Otten, Engels, \& Van den Eijnden, in press-b). Similar reports have been published on the relations between extraversion and emotional stability on the one hand and adolescent smoking on the other (Byrne, Byrne, \& Reinhart, 1995; Wijatkowski, Forgays, Wrzesniewski, \& Gorski, 1990). It is possible that adolescents with a certain personality disposition are more vulnerable to smoking initiation. For example, neurotic individuals may smoke as a way to reduce stress (Eysenck, Grossarth Maticek, \& Everitt, 1991).

In addition to these direct relations, adolescent personality may 
moderate parental influences, as children with different personalities may react differently to parenting (O’Connor \& Dvorak, 2001). In one study, under-controlling adolescents (characterized by low scores on conscientiousness, moderately low scores on agreeableness, openness, and emotional stability, and average scores on extraversion) from highly restrictive families were especially prone to depressive affect, moodiness, and internalizing problems (Dubas, Gerris, Janssens, \& Vermulst, 2002). Another study reported that over-reactive parental discipline evoked more externalized problem behavior in benevolent children (benevolence being similar to agreeableness) and that coercive parenting was associated with higher levels of externalizing behavior in children with low scores on conscientiousness (Prinzie et al., 2003).

In their 1993 article, Darling and Steinberg proposed a specific facet of a child's personality which may moderate the outcomes of parenting. According to these authors, effects of parenting styles and behavior-specific parenting practices depend on a child's openness to parental influence. As such, children who are willing to be socialized would more readily accept parental smoking prevention strategies. In addition, the effect of parenting style may be moderated by the willingness to be socialized. As an example, an authoritative parenting climate could enhance the effectiveness of anti-smoking socialization through increased adolescent openness to be socialized. Although highly plausible, these ideas have not been extended to the field of adolescent smoking and would be an interesting topic for future study. Models of parenting and adolescent smoking cognitions and behavior could thus be compared or corrected for aspects of the adolescents' personalities.

\section{On a Different Level}

While we have studied distal and proximal influences on adolescent smoking by examining effects of smoking-related cognitions and parenting, respectively, influences on a more ultimate level can be distinguished as well. These influences are beyond the control of the 
adolescent, but can have long-lasting and high impact effects (Flay \& Petraitis, 1994; Flay, 1999). At a macro level, several governmental policy actions may discourage adolescent smoking (Turner, Mermelstein, $\&$ Flay, 2004). One effective policy at the macro level could comprise more stringent enforcement of tobacco control policies. The sales ban to minors could be observed more strictly and places where adolescents obtain tobacco could be targeted to restrict the availability of tobacco products for youngsters (Barovich, Sussman, Dent, Burton, \& Flay, 1991; Lewit, Hyland, Kerrebrock, \& Cummings, 1997). Second, higher cigarette prices lead to reduced smoking, especially among youths who do not smoke on a daily basis (Chaloupka, 2003; Chaloupka, Cummings, Morley, \& Horan, 2002; Harris \& Chan, 1999; Townsend, Roderick, \& Cooper, 1994). This decrease in adolescent smoking may be enhanced by parental reactions to the price inflation (Chaloupka, 2003). Third, just like cigarette advertisements may stimulate smoking among adolescents, anti-smoking messages may reinforce non-smoking. While the amount of money that is being invested in anti-smoking campaigns is only a fraction of the amount the tobacco industry spends on marketing, and US high school students are most likely to smoke Marlboro or Camel cigarettes, which are the most comprehensively advertised brands (Tercyak, Goldman, Smith, \& Audrain, 2002), antismoking advertisements may also be successful (Pierce et al., 2002 for a review). Moreover, not only may effects of pro-smoking advertisements be moderated by parenting (Pierce et al., 2002), but anti-smoking ads can also affect parental anti-smoking norms, in turn influencing adolescent smoking (Wakefield, Flay, Nichter, \& Giovino, 2003). Decisions made at the ultimate level may thus not only impact on adolescent smoking directly, but may also do so through the effects of these policies on parents. Research in a Dutch setting would be valuable to understand the way in which Dutch policy can influence adolescent smoking cognitions and behavior through parents. 


\section{Data Collection in Real Time}

In the studies reported on in this thesis, aspects like parenting style were measured by asking the adolescents to give a global interpretation. It was argued above that adolescents do not always provide accurate and representative answers to self-administered questionnaires and that data could be obtained among multiple observers to reduce bias. A more sophisticated and bias-free way of gathering information on family interactions is to observe families in real time in their natural behavior. Instead of having adolescents and parents fill out questionnaires on the way they interact, these interactions could be monitored in the natural home setting by trained observers or by being videotaped in an unobtrusive manner (Dishion \& Granic, 2004). These techniques have been applied to observe restricted family behaviors such as problem-solving skills (Granic, Hollenstein, Dishion, \& Patterson, 2003), but anti-smoking socialization could similarly be observed by presenting parents and their children with a case on adolescent smoking to discuss. Building on this, more personally relevant data could be obtained in a less limited manner by observing families over a longer period of time with respect to actual smoking-related socialization. In addition to observing content-specific interactions, the global family climate would be a suitable observation topic. Questionnaires on parenting styles in contemporary research often include items on helping with homework and curfews, which are easily monitored. In this manner, valuable information can be obtained on the way in which parents and children interact, beyond simply studying how parental actions and child behaviors correlate.

It was argued above that self-administered questionnaires may not be fully appropriate for measuring adolescent smoking. Although adolescent smoking may be hard to observe in family settings, it is possible to accurately gather relevant data in real time (Walls \& Schafer, 2006). One study has shown that information on smoking relapse was more accurately obtained from information entered in real time on hand-held computers than through recollection (Shiffman, Paty, Gnys, Kassel, \& Hickcox, 1996). And it is not only information on smoking 
behavior that can be entered on these hand-held instruments, but also information on smoking-related cognitions. For instance, real-time data on positive smoking outcomes and abstinence self-efficacy have successfully predicted smoking relapse (Gwaltney, Shiffman, Balabanis, \& Paty, 2005).

In studying relations between parenting and adolescent smoking cognitions and behavior, it is impossible to study actual cognitions and behaviors, but approximations should be as close as possible to allow accurate inferences. Therefore, information on parent-child interactions, as well as smoking-specific cognitions and behavior, should ideally be gathered in real time to make data as accurate as possible and to gain more complete insight into the mechanisms underlying adolescent smoking.

\section{To Conclude}

In the research reported on in this thesis, the development of adolescent smoking cognitions and behavior was studied by examining the impact of parental influences, namely global parenting skills, smoking-specific parenting practices and parents' own smoking behavior. These studies indicate that some aspects of parenting are indeed associated with adolescent smoking behavior through the smoking-related cognitions held by adolescents. The I-Change Model can thus be extended with parental strict control and aspects of smoking-related socialization, especially for older adolescents. In contrast, effects of other aspects of parenting on adolescent smoking, such as parental exertion of psychological control, are not internalized through adolescents' attitude toward smoking, perceived social influences, or self-efficacy expectations. In addition, effects of mothers' and fathers' parenting are equal and similarly affect boys and girls. The effectiveness of smoking-specific socialization does not depend on the parenting climate in which these behaviors are expressed. As such, the extent to which parents are supportive, exert strict control or are psychologically controlling does not affect the way 
in which anti-smoking parenting practices relate to adolescent smoking cognitions and behavior. Similarly, the way parenting affects adolescent smoking cognitions and behavior is identical for smoking and nonsmoking parents. Future research relating these practices to adolescent smoking should account for reciprocity between parenting and adolescent smoking behavior, as our studies indicated adolescent smoking to be a stronger predictor of parenting than vice versa. However, as parental smoking behavior is a predictor of adolescent smoking, smoking parents should practice what they preach by not smoking themselves, as merely preaching is insufficient. 



\section{Notes}

The plural "we" is used throughout this dissertation in acknowledgement of the fact that the research on which it is based was a collaborative endeavor. 



\section{References}

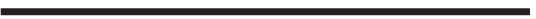



Aguinis, H., Pierce, C. A., \& Quigley, B. M. (1993). Conditions under which a bogus pipeline procedure enhances the validity of self-reported cigarette smoking: A meta-analytic review. Journal of Applied Social Psychology, 23, 352-373.

Aiken, L. S., \& West, S. G. (1991). Multiple regression: Testing and interpreting interactions. Newbury Park, CA: Sage Publications.

Ajzen, I. (1991). The theory of planned behavior. Organizational Behavior and Human Decision Processes, 50, 179-211.

Andersen, M. R., Leroux, B. G., Bricker, J. B., Rajan, K. B., \& Peterson, A. V., Jr. (2004). Antismoking parenting practices are associated with reduced rates of adolescent smoking. Archives of Pediatrics and Adolescent Medicine, 158, 348-352.

Andrews, J. A., Hops, H., Ary, D. V., Tildesley, E., \& Harris, J. (1993). Parental influence on early adolescent substance use: Specific and nonspecific effects. Journal of Early Adolescence, 13, 285-310.

Ausems, M. (2003). Smoking prevention: Comparing in-school, tailored out-of school, and booster interventions. Maastricht, the Netherlands: Maastricht University.

Avenevoli, S., \& Merikangas, K. R. (2003). Familial influences on adolescent smoking. Addiction, 1, 1-20.

Baldwin, M. W., \& Fergusson, P. (2001). Relational schemas: The activation of interpersonal knowledge structures in social anxiety, International handbook of social anxiety: Concepts, research and interventions relating to the self and shyness (pp. 235-257). New York: Wiley.

Bandalos, D. L., \& Finney, S. J. (2001). Item parceling issues in structural equation modeling. In G. A. Marcoulides \& R. E. Schumacker (Eds.), New Developments and Techniques in Structural Equation Modeling (pp. 269-296). Mahwah, NJ: Lawrence Erlbaum Associates.

Bandura, A. (1977). Social Learning Theory. Oxford, England: Prentice-Hall.

Bandura, A. (1986a). The explanatory and predictive scope of self-efficacy theory. Journal of Social and Clinical Psychology, 4, 359-373.

Bandura, A. (1986b). Social foundations of thought and action: A social cognitive theory. Englewood Cliffs, NJ: Prentice-Hall.

Bandura, A., Adams, N. E., \& Beyer, J. (1977). Cognitive processes mediating behavioral change. Journal of Personality and Social Psychology, 35, 125-139.

Barber, B. K. (Ed.). (2002). Intrusive parenting: How psychological control affects children and adolescents. Washington, DC: American Psychological Association.

Barber, B. K., \& Harmon, E. L. (2002). Violating the self: Parental psychological control of children and adolescents. In B. K. Barber (Ed.), Intrusive parenting: How psychological control affects children and adolescents. (pp. 15-52). Washington, DC: American Psychological Association.

Barber, B. K., Olsen, J. E., \& Shagle, S. C. (1994). Associations between parental psychological and behavioral control and youth internalized and externalized behaviors. Child Development, 65, 1120-1136.

Barovich, M., Sussman, S., Dent, C. W., Burton, D., \& Flay, B. R. (1991). Availability of tobacco products at stores located near public schools. International Journal of the Addictions, 26, $837-850$. 
Bauman, K. E., Carver, K., \& Gleiter, K. (2001). Trends in parent and friend influence during adolescence: The case of adolescent cigarette smoking. Addictive Behaviors, 26, 349-361.

Bauman, K. E., Foshee, V. A., Ennett, S. T., Hicks, K. A., \& Pemberton, M. (2001). Family matters: A family-directed program designed to prevent adolescent tobacco and alcohol use. Health Promotion Practice, 2, 81-96.

Baumrind, D. (1966). Effects of authoritative parental control on child behavior. Child Development, 37, 887-907.

Baumrind, D. (1967). Child care practices anteceding three patterns of preschool behavior. Genetic Psychology Monographs, 75, 43-88.

Baumrind, D. (1971). Current patterns of parental authority. Developmental Psychology, 4, $1-103$.

Baumrind, D. (1991). The influence of parenting style on adolescent competence and substance use. Journal of Early Adolescence, 11, 56-95.

Beal, A. C., Ausiello, J., \& Perrin, J. M. (2001). Social influences on health-risk behaviors among minority middle school students. Journal of Adolescent Health, 28, 474-480.

Beck, K. H., Shattuck, T., Haynie, D., Crump, A. D., \& Simons Morton, B. (1999). Associations between parent awareness, monitoring, enforcement and adolescent involvement with alcohol. Health Education Research, 14, 765-775.

Bell, R. Q. (1968). A Reinterpretation of the Direction of Effects in Studies of Socialization. Psychological Review, 75, 81-95.

Belsky, J., \& Barends, N. (2002). Personality and parenting. In M. H. Bornstein (Ed.), Handbook of parenting (2nd ed., Vol. 3: Being and becoming a parent, pp. 415-438). Mahwah, NJ: Lawrence Erlbaum Associates.

Belsky, J., Crnic, K., \& Woodworth, S. (1995). Personality and parenting: Exploring the mediating role of transient mood and daily hassles. Journal of Personality, 63, 905-929.

Beyers, W., \& Goossens, L. (1999). Emotional autonomy, psychosocial adjustment and parenting: Interactions, moderating and mediating effects. Journal of Adolescence, 22, 753769.

Bollen, K. A. (1989). Structural equations with latent variables. New York: Wiley.

Bonneux, L. G., Looman, C. W., \& Coebergh, J. W. (2003). Sterfte door roken in Nederland: 1,2 miljoen tabaksdoden tussen 1950 en 2015 [Mortality due to smoking in the Netherlands: 1.2 million tobacco-related deaths between 1950 and 2015]. Nederlands Tijdschrift voor Geneeskunde, 147, 917-921.

Brehm, J. (1966). A Theory of Psychological Reactance. New York: Academic Press.

Bricker, J. B., Leroux, B. G., Andersen, M. R., Rajan, K. B., \& Peterson, A. V., Jr. (2005). Parental smoking cessation and children's smoking: Mediation by antismoking actions. Nicotine and Tobacco Research, 7, 501-509.

Bricker, J. B., Leroux, B. G., Peterson, A. V., Kealey, K. A., Sarason, I. G., Andersen, M. R., \& Marek, P. M. (2003). Nine-year prospective relationship between parental smoking cessation and children's daily smoking. Addiction, 98, 585-593.

Bricker, J. B., Peterson, A. V., Jr., Leroux, B. G., Andersen, M. R., Rajan, K. B., \& Sarason, I. 
G. (2006). Prospective prediction of children's smoking transitions: Role of parents' and older siblings' smoking. Addiction, 101, 128-136.

Bricker, J. B., Rajan, K. B., Andersen, M. R., \& Peterson, A. V., Jr. (2005). Does parental smoking cessation encourage their young adult children to quit smoking? A prospective study. Addiction, 100, 379-386.

Brown, B. B. (1990). Peer groups and peer cultures. In S. S. Feldman \& G. R. Elliott (Eds.), At the threshold: The developing adolescent. (pp. 171-196). Cambridge, MA: Harvard University Press.

Brown, B. B., Mounts, N., Lamborn, S. D., \& Steinberg, L. (1993). Parenting practices and peer group affiliation in adolescence. Child Development, 64, 467-482.

Brug, J., Lechner, L., \& De Vries, H. (1995). Psychosocial determinants of fruit and vegetable consumption. Appetite, 25, 285-296.

Burt, R. D., Dinh, K. T., Peterson, A. V., Jr., \& Sarason, I. G. (2000). Predicting adolescent smoking: A prospective study of personality variables. Preventive Medicine, 30, 115-125.

Bush, P. J., \& Iannotti, R. J. (1993). Alcohol, cigarette, and marijuana use among fourthgrade urban schoolchildren in 1988/89 and 1990/91. American Journal of Public Health, 83, 111-114.

Bush, T., Curry, S. J., Hollis, J., Grothaus, L., Ludman, E., McAfee, T., Polen, M., \& Oliver, M. (2005). Preteen attitudes about smoking and parental factors associated with favorable attitudes. American Journal of Health Promotion, 19, 410-417.

Byrne, B. M. (1998). Structural equation modeling with LISREL, PRELIS, and SIMPLIS: Basic concepts, applications, and programming. Mahwah, NJ: Lawrence Erlbaum Associates.

Byrne, D. (1997). An overview (and underview) of research and theory within the attraction paradigm. Journal of Social and Personal Relationships, 14, 417-431.

Byrne, D. G., Byrne, A. E., \& Reinhart, M. I. (1995). Personality, stress and the decision to commence cigarette smoking in adolescence. Journal of Psychosomatic Research, 39, 53-62.

Chaloupka, F. J. (2003). Contextual factors and youth tobacco use: Policy linkages. Addiction, 98 Suppl 1, 147-149.

Chaloupka, F. J., Cummings, K. M., Morley, C. P., \& Horan, J. K. (2002). Tax, price and cigarette smoking: Evidence from the tobacco documents and implications for tobacco company marketing strategies. Tobacco Control, 11 Suppl 1, I62-72.

Chassin, L., Presson, C. C., Rose, J., Sherman, S. J., Davis, M. J., \& Gonzalez, J. L. (2005). Parenting style and smoking-specific parenting practices as predictors of adolescent smoking onset. Journal of Pediatric Psychology, 30, 333-344.

Chassin, L., Presson, C. C., Rose, J. S., \& Sherman, S. J. (1996). The natural history of cigarette smoking from adolescence to adulthood: Demographic predictors of continuity and change. Health Psychology, 15, 478-484.

Chassin, L., Presson, C. C., Rose, J. S., \& Sherman, S. J. (1998). Maternal socialization of adolescent smoking: Intergenerational transmission of smoking-related beliefs. Psychology of Addictive Behaviors, 12, 206-216.

Chassin, L., Presson, C. C., Todd, M., Rose, J. S., \& Sherman, S. J. (1998). Maternal 
socialization of adolescent smoking: The intergenerational transmission of parenting and smoking. Developmental Psychology, 34, 1189-1201.

Chassin, L. A., \& et al. (1986). Changes in peer and parent influence during adolescence: Longitudinal versus cross-sectional perspectives on smoking initiation. Developmental Psychology, 22, 327-334.

Clark, L. A., Kochanska, G., \& Ready, R. (2000). Mothers' personality and its interaction with child temperament as predictors of parenting behavior. Journal of Personality and Social Psychology, 79, 274-285.

Clark, P. I., Scarisbrick Hauser, A., Gautam, S. P., \& Wirk, S. J. (1999). Anti-tobacco socialization in homes of African-American and white parents, and smoking and nonsmoking parents. Journal of Adolescent Health, 24, 329-339.

Cohen, J. (1988). Statistical power analysis for the behavioral sciences (2nd ed.). Hillsdale, NJ: Lawrence Erlbaum Associates.

Cohen, J. (1992). A power primer. Psychological Bulletin, 112, 155-159.

Collins, W. A., Maccoby, E. E., Steinberg, L., Hetherington, E. M., \& Bornstein, M. H. (2000). Contemporary research on parenting. The case for nature and nurture. American Psychologist, 55, 218-232.

Conrad, K. M., Flay, B. R., \& Hill, D. (1992). Why children start smoking cigarettes: Predictors of onset. British Journal of Addiction, 87, 1711-1724.

Costa, P. T., \& McCrae, R. R. (1992). Revised NEO Personality Inventory (NEO PI-R) and NEO Five-Factor Inventory (NEO-FFI) Professional Manual. Odessa, FL: Psychological Assessment Resources.

Darling, N., \& Steinberg, L. (1993). Parenting style as context: An integrative model. Psychological Bulletin, 113, 487-496.

De Vries, H., Backbier, E., Dijkstra, M., Van Breukelen, G., Parcel, G., \& Kok, G. (1994). A Dutch social influence smoking prevention approach for vocational school students. Health Education Research, 9, 365-374.

De Vries, H., Backbier, E., Kok, G., \& Dijkstra, M. (1995). The impact of social influences in the context of attitude, self-efficacy, intention, and previous behavior as predictors of smoking onset. Journal of Applied Social Psychology, 25, 237-257.

De Vries, H., Candel, M., Engels, R., \& Mercken, L. (2006). Challenges to the peer influence paradigm: Results for 12-13 year olds from six European countries from the European Smoking Prevention Framework Approach study. Tobacco Control, 15, 83-89.

De Vries, H., Dijkstra, M., \& Kuhlman, P. (1988). Self-efficacy: The third factor besides attitude and subjective norm as a predictor of behavioural intentions. Health Education Research, 3, 273-282.

De Vries, H., Engels, R., Kremers, S., Wetzels, J., \& Mudde, A. (2003). Parents' and friends' smoking status as predictors of smoking onset: Findings from six European countries. Health Education Research, 18, 627-636.

De Vries, H., Mudde, A., Leijs, I., Charlton, A., Vartiainen, E., Buijs, G., Clemente, M. P., Storm, H., Gonzalez Navarro, A., Nebot, M., Prins, T., \& Kremers, S. (2003). The European Smoking Prevention Framework Approach (EFSA): An example of integral prevention. 
Health Education Research, 18, 611-626.

De Vries, H., \& Mudde, A. N. (1998). Predicting stage transitions for smoking cessation applying the Attitude-Social influence-Efficacy Model. Psychology and Health, 13, 369-385.

DEFACTO-rookvrij (2001). Roken, de harde feiten: Jeugd 2000 [Smoking, the harsh facts: Youth 2000]. The Hague, the Netherlands: DEFACTO-rookvrij.

Den Exter Blokland, E., Hale, W. W., Meeus, W., \& Engels, R. C. M. E. (submitted). Parental support and control and early adolescent smoking: A longitudinal study. Substance Use and Misuse.

Den Exter Blokland, E. A., Engels, R. C., Hale, W. W., 3rd, Meeus, W., \& Willemsen, M. C. (2004). Lifetime parental smoking history and cessation and early adolescent smoking behavior. Preventive Medicine, 38, 359-368.

Den Exter Blokland, E. A., Hale, W. W., 3rd, Meeus, W., \& Engels, R. C. (2006). Parental anti-smoking socialization: Associations between parental anti-smoking socialization practices and early adolescent smoking initiation. European Addiction Research, 12, 25-32.

Den Exter Blokland, E. A. W., Engels, R. C. M. E., \& Finkenauer, C. (2001). Parenting styles, self-control and male juvenile delinquency: The mediating role of self-control. In M. Martinez (Ed.), Prevention and Control of Aggression and the Impacts on its Victims (pp. 201207). New York: Kluwer Academic/Plenum Publishers.

Digman, J. M. (1990). Personality structure: Emergence of the five-factor model. Annual Review of Psychology, 41, 417-440.

Dishion, T. J., \& Granic, I. (2004). Naturalistic observation of relationship processes. In S. N. Haynes \& E. M. Heiby (Eds.), Comprehensive handbook of psychological assessment, Vol. 3: Behavioral assessment. (pp. 143-161). Hoboken, NJ: Wiley.

Dolcini, M. M., Adler, N. E., \& Ginsberg, D. (1996). Factors influencing agreement between self-reports and biological measures of smoking among adolescents. Journal of Research on Adolescence, 6, 515-542.

Doll, R., \& Hill, A. B. (1954). The mortality of doctors in relation to their smoking habits: A preliminary report. British Medical Journal, 228, 1451-1455.

Doll, S. R. (2000). Smoking and lung cancer. American journal of respiratory and critical care medicine, 162, 4-6.

Dornbusch, S. M., Ritter, P. L., Leiderman, P. H., Roberts, D. F., \& Fraleigh, M. J. (1987). The relation of parenting style to adolescent school performance. Child Development, 58, 1244-1257.

Downey, G., \& Coyne, J. C. (1990). Children of depressed parents: An integrative review. Psychological Bulletin, 108, 50-76.

Dubas, J. S., Gerris, J. R. M., Janssens, J. M. A. M., \& Vermulst, A. A. (2002). Personality types of adolescents: Concurrent correlates, antecedents and type $\mathrm{X}$ parenting interactions. Journal of Adolescence, 25, 79-92.

Eade, P. (1857). The great tobacco question: Is smoking injurious to health? Effects of smoking on longevity. The Lancet, 69, 301-302.

Engels, R. C., \& Willemsen, M. (2004). Communication about smoking in Dutch families: 
Associations between anti-smoking socialization and adolescent smoking-related cognitions. Health Education Research, 19, 227-238.

Engels, R. C. M. E. (2000). Zoals de ouders zingen, piepen de jongen. Een studie naar de invloed van ouders op rookgedrag van adolescenten. The Hague, the Netherlands: STIVORO.

Engels, R. C. M. E., Finkenauer, C., Kerr, M., \& Stattin, H. (2005). Illusions of Parental Control: Parenting and Smoking Onset in Dutch and Swedish Adolescents. Journal of Applied Social Psychology, 35, 1912-1935.

Engels, R. C. M. E., Finkenauer, C., Meeus, W., \& Dekovic, M. (2001). Parental attachment and adolescents' emotional adjustment: The associations with social skills and relational competence. Journal of Counseling Psychology, 48, 428-439.

Engels, R. C. M. E., Harakeh, Z., \& Scholte, R. H. (2004-2005). Ouders en rookgedrag van adolescenten: Van wie hebben ze het toch? [Parents and adolescent smoking: Where do they get it from?]. In A. Vyt \& M. A. G. Van Aken \& J. D. Bosch \& R. J. Van der Graag \& A. J. J. M. Ruijssenaars (Eds.), Jaarboek ontwikkelingspsychologie, orthopedagogiek en kinderpsychiatrie 6. Houten, the Netherlands: Bohn Stafleu Van Loghum.

Engels, R. C. M. E., Knibbe, R. A., \& Drop, M. J. (1999). Predictability of smoking in adolescence: Between optimism and pessimism. Addiction, 94, 115-124.

Ennett, S. T., Bauman, K. E., Foshee, V. A., Pemberton, M., \& Hicks, K. A. (2001). Parentchild communication about adolescent tobacco and alcohol use: What do parents say and does it affect youth behavior? Journal of Marriage and the Family, 63, 48-62.

Ennett, S. T., Bauman, K. E., Pemberton, M., Foshee, V. A., Chuang, Y. C., King, T. S., \& Koch, G. G. (2001). Mediation in a family-directed program for prevention of adolescent tobacco and alcohol use. Preventive Medicine, 33, 333-346.

Eysenck, H. J., Grossarth Maticek, R., \& Everitt, B. (1991). Personality, stress, smoking, and genetic predisposition as synergistic risk factors for cancer and coronary heart disease. Integrative Physiological and Behavioral Science, 26, 309-322.

Fearnow, M., Chassin, L., Presson, C. C., \& Sherman, S. J. (1998). Determinants of parental attempts to deter their children's cigarette smoking. Journal of Applied Developmental Psychology, 19, 453-468.

Fergusson, D. M., \& Horwood, L. J. (1995). Transitions to cigarette smoking during adolescence. Addictive Behaviors, 20, 627-642.

Festinger, L. (1957). A Theory of Cognitive Dissonance. Oxford, England: Row, Peterson.

Fishbein, M., \& Ajzen, I. (1975). Belief, Attitude, Intention and Behavior: An Introduction to Theory and Research. Reading, MA: Addison-Wesley.

Flay, B., \& Petraitis, J. (1994). The Theory of Triadic Influence: A new theory of health behavior with implications for preventive interventions. Advances in Medical Sociology, 4, 1944.

Flay, B. R. (1993). Youth tobacco use: Risks, patterns, and control. In J. D. Slade \& C. T. Orleans (Eds.), Nicotine addiction: Principles and management (pp. 365-384). London: Oxford University Press.

Flay, B. R. (1999). Understanding environmental, situational and intrapersonal risk and protective factors for youth tobacco use: the Theory of Triadic Influence. Nicotine and tobacco 
research official journal of the Society for Research on Nicotine and Tobacco, 1 Suppl 2, S111-114; discussion 569-170.

Flay, B. R., d'Avernas, J. R., Best, J. A., Kersell, M. W., \& Ryan, K. B. (1983). Cigarette smoking: Why young people do it and ways of preventing it. In P. McGrath \& F. P. (Eds.), Pediatric and Adolescent Behavioral Medicine (pp. 97-127). New York: Springer-Verlag.

Fox, R. A., Platz, D. L., \& Bentley, K. S. (1995). Maternal factors related to parenting practices, developmental expectations, and perceptions of child behavior problems. Journal of Genetic Psychology, 156, 431-441.

Freud, S. (1933). New introductory lectures on psycho-analysis. New York: Norton.

Galambos, N. L., Barker, E. T., \& Almeida, D. M. (2003). Parents do matter: Trajectories of change in externalizing and internalizing problems in early adolescence. Child Development, 74, 578-594.

Gerris, J. R. M., Houtmans, M. J. M., Kwaaitaal-Roosen, E. M. G., De Schipper, J. C., Vermulst, A. A., \& Janssens, J. M. A. M. (1998). Parents, adolescents and young adults in Dutch families: A longitudinal study. Nijmegen: Institute of Family Studies.

Gibbons, F. X., Gerrard, M., \& Lane, D. J. (2003). A social reaction model of adolescent health risk. In J. Suls \& K. A. Wallston (Eds.), Social psychological foundations of health and illness. (pp. 107-136). Malden, MA: Blackwell Publishing.

Glendinning, A., Shucksmith, J., \& Hendry, L. (1997). Family life and smoking in adolescence. Social Science and Medicine, 44, 93-101.

Glynn, T. J. (1993). Improving the health of U.S. children: the need for early interventions in tobacco use. Preventive Medicine, 22, 513-519.

Goddard, E. (1992). Why children start smoking. British Journal of Addiction, 87, 17-18.

Goldberg, L. R. (1990). An alternative „description of personality“: The Big-Five factor structure. Journal of Personality and Social Psychology, 59, 1216-1229.

Goldberg, L. R. (1992). The development of markers for the Big-Five factor structure. Psychological Assessment, 4, 26-42.

Gollwitzer, P. M. (1999). Implementation intentions: Strong effects of simple plans. American Psychologist, 54, 493-503.

Goossens, L., \& Beyers, W. (1999). Parenting style and adolescent adjustment: A two-year longitudinal study. Paper presented at the $9^{\text {th }}$ European Conference on Developmental Psychology, Island of Spetses, Greece.

Goossens, L., \& Beyers, W. (2000). Parenting style and adaptation to college environment: A two-year longitudinal study. Paper presented at the $7^{\text {th }}$ Biennial Conference of the European Association for Research on Adolescence (EARA), Jena, Germany.

Granic, I., Hollenstein, T., Dishion, T. J., \& Patterson, G. R. (2003). Longitudinal analysis of flexibility and reorganization in early adolescence: A dynamic systems study of family interactions. Developmental Psychology, 39, 606-617.

Gray, M. R., \& Steinberg, L. (1999). Unpacking authoritative parenting: Reassessing a multidimensional construct. Journal of Marriage and the Family, 61, 574-587.

Gwaltney, C. J., Shiffman, S., Balabanis, M. H., \& Paty, J. A. (2005). Dynamic self-efficacy 
and outcome expectancies: Prediction of smoking lapse and relapse. Journal of Abnormal Psychology, 114, 661-675.

Harakeh, Z., Engels, R. C., De Vries, H., \& Scholte, R. H. (in press). Correspondence between proxy and self-repots on smoking in a full family study. Drug and Alcohol Dependence.

Harakeh, Z., Scholte, R. H., De Vries, H., \& Engels, R. C. (2005). Parental rules and communication: Their association with adolescent smoking. Addiction, 100, 862-870.

Harakeh, Z., Scholte, R. H., De Vries, H., \& Engels, R. C. (2006). Association between personality and adolescent smoking. Addictive Behaviors, 31, 232-245.

Harakeh, Z., Scholte, R. H., Vermulst, A. A., De Vries, H., \& Engels, R. C. (2004). Parental factors and adolescents' smoking behavior: An extension of the Theory of Planned Behavior. Preventive Medicine, 39, 951-961.

Hardy, J. B., Astone, N. M., Brooks Gunn, J., Shapiro, S., \& Miller, T. L. (1998). Like mother, like child: Intergenerational patterns of age at first birth and associations with childhood and adolescent characteristics and adult outcomes in the second generation. Developmental Psychology, 34, 1220-1232.

Harris, J. E., \& Chan, S. W. (1999). The continuum-of-addiction: Cigarette smoking in relation to price among Americans aged 15-29. Health Economics, 8, 81-86.

Hartgers, M. (2001). Families at work. In E. Schulte Nordholt \& M. Hartgers \& R. Gircour (Eds.), The Dutch Virtual Census of 2001 (pp. 119-142). Voorburg/Heerlen, the Netherlands: Statistics Netherlands.

Henriksen, L., \& Jackson, C. (1998). Anti-smoking socialization: Relationship to parent and child smoking status. Health Communication, 10, 87-101.

Herdman, R., Hewitt, M., \& Laschober, M. (1993). Smoking-related deaths and financial costs: Office of Technology Assessment estimates for 1990. Washington, DC: Office of Technology Assessment, Congress of the United States.

Holm, K., Kremers, S. P., \& De Vries, H. (2003). Why do Danish adolescents take up smoking? European Journal of Public Health, 13, 67-74.

Huver, R. M. E., Engels, R. C. M. E., \& De Vries, H. (2006). Are anti-smoking parenting practices related to adolescent smoking cognitions and behavior? Health Education Research, 21, 66-77.

Huver, R. M. E., Engels, R. C. M. E., \& De Vries, H. (submitted). Personality and parenting style. Journal of Adolescence.

Huver, R. M. E., Engels, R. C. M. E., Van Breukelen, G., \& De Vries, H. (in press). Parenting style and adolescent smoking cognitions and behavior. Psychology and Health.

Huver, R. M. E., Engels, R. C. M. E., Vermulst, A. A., \& De Vries, H. (resubmitted-a). Is parenting style a context for antismoking socialization? Drug and Alcohol Dependence.

Huver, R. M. E., Engels, R. C. M. E., Vermulst, A. A., \& De Vries, H. (resubmitted-b). $\mathrm{Bi}$-directional relations between anti-smoking parenting practices and adolescent smoking. Health Psychology.

Jaccard, J., \& Dittus, P. (1993). Parent-adolescent communication about premarital pregnancy. Families in Society, 74, 329-343. 
Jackson, C. (1997). Initial and experimental stages of tobacco and alcohol use during late childhood: Relation to peer, parent, and personal risk factors. Addictive Behaviors, 22, 685698.

Jackson, C., Bee Gates, D. J., \& Henriksen, L. (1994). Authoritative parenting, child competencies, and initiation of cigarette smoking. Health Education Quarterly, 21, 103-116.

Jackson, C., \& Henriksen, L. (1997). Do as I say: Parent smoking, antismoking socialization, and smoking onset among children. Addictive Behaviors, 22, 107-114.

Jackson, C., Henriksen, L., \& Foshee, V. A. (1998). The Authoritative Parenting Index: Predicting health risk behaviors among children and adolescents. Health Education and Behavior, 25, 319-337.

Janz, N. K., \& Becker, M. H. (1984). The Health Belief Model: A decade later. Health Education Quarterly, 11, 1-47.

Jöreskog, K. G. (2005). How large can a standard coefficient be? Retrieved December 12, 2005 , from http://www.ssicentral.com/lisrel/advancedtopics.html.

Juang, L. P., \& Silbereisen, R. K. (1999). Supportive parenting and adolescent adjustment across time in former East and West Germany. Journal of Adolescence, 22, 719-736.

Kandel, D. B. (1996). The parental and peer contexts of adolescent deviance: An algebra of interpersonal influences. Journal of Drug Issues, 26, 289-315.

Kaplan, D. (2000). Structural Equation Modeling: Foundations and Extensions. Thousand Oaks, CA: Sage Publications.

Kazantzis, N., Ronan, K. R., \& Deane, F. P. (2001). Concluding causation from correlation: Comment on Burns and Spangler (2000). Journal of Consulting and Clinical Psychology, 69, 1079-1083.

Kelder, S. H., Perry, C. L., Klepp, K. I., \& Lytle, L. L. (1994). Longitudinal tracking of adolescent smoking, physical activity, and food choice behaviors. American Journal of Public Health, 84, 1121-1126.

Kelman, H. C. (1958). Compliance, identification, and internalization. Journal of Conflict Resolution, 2, 51-60.

Kendler, K. S., Sham, P. C., \& MacLean, C. J. (1997). The determinants of parenting: An epidemiological, multi-informant, retrospective study. Psychological Medicine, 27, 549-563.

Kentala, J., Utriainen, P., Pahkala, K., \& Mattila, K. (2004). Verification of adolescent selfreported smoking. Addictive Behaviors, 29, 405-411.

Kerr, M., \& Stattin, H. (2000). What parents know, how they know it, and several forms of adolescent adjustment: Further support for a reinterpretation of monitoring. Developmental Psychology, 36, 366-380.

Kerr, M., \& Stattin, H. (2003). Parenting of adolescents: Action or reaction? In A. C. Crouter \& A. Booth (Eds.), Children's influence on family dynamics: The neglected side of family relationships. (pp. 121-151). Mahwah, NJ: Lawrence Erlbaum Associates.

Kessler, R. C., Berglund, P. A., Foster, C. L., Saunders, W. B., Stang, P. E., \& Walters, E. E. (1997). Social consequences of psychiatric disorders, II: Teenage parenthood. American Journal of Psychiatry, 154, 1405-1411. 
Kline, R. B. (1998). Principles and practice of structural equation modeling. New York: The Guilford Press.

Kochanska, G., Clark, L. A., \& Goldman, M. S. (1997). Implications of mothers' personality for their parenting and their young children's development outcomes. Journal of Personality, 65, 387-420.

Kremers, S. P., Brug, J., De Vries, H., \& Engels, R. C. (2003). Parenting style and adolescent fruit consumption. Appetite, 41, 43-50.

Kremers, S. P., De Vries, H., Mudde, A. N., \& Candel, M. (2004). Motivational stages of adolescent smoking initiation: Predictive validity and predictors of transitions. Addictive Behaviors, 29, 781-789.

Kremers, S. P., Mudde, A. N., \& De Vries, H. (2001a). „Kicking the initiation“: Do adolescent ex-smokers differ from other groups within the initiation continuum? Preventive Medicine, 33, 392-401.

Kremers, S. P., Mudde, A. N., \& De Vries, H. (2001b). Subtypes within the precontemplation stage of adolescent smoking acquisition. Addictive Behaviors, 26, 237-251.

Kremers, S. P., Mudde, A. N., \& De Vries, H. (2004). Model of unplanned smoking initiation of children and adolescents: An integrated stage model of smoking behavior. Preventive Medicine, 38, 642-650.

Kremers, S. P., Mudde, A. N., De Vries, N. K., Brug, J., \& De Vries, H. (2004). Unplanned smoking initiation: New insights and implications for interventions. Patient Education and Counseling, 55, 345-352.

Kremers, S. P. J., De Vries, H., \& Mudde, A. N. (2000). Measuring the effectiveness of ESFA: Towards best practices in smoking prevention research. In L. Norheim \& M. Waller (Eds.), Best Practices: A Selection of papers on Quality and Effectiveness in Health Promotion (pp. 236245). Helsinki, Finland: Finnish Centre for Health Promotion.

Lacqueur, T. W. (1995). Smoking and nothingness. New Republic, Sept, 17-24.

Lamborn, S. D., Mounts, N. S., Steinberg, L., \& Dornbusch, S. M. (1991). Patterns of competence and adjustment among adolescents from authoritative, authoritarian, indulgent, and neglectful families. Child Development, 62, 1049-1065.

Larson, P. S., Haag, H. B., \& Silvette, H. (1961). Tobacco experimental and clinical Studies: A comprehensive account of the world literature. Baltimore: Williams and Wilkins.

Lawrance, L. (1988). Validation of a self-efficacy scale to predict adolescent smoking. Health Education Research, 4, 351-360.

Lechner, L., \& De Vries, H. (1995). Starting participation in an employee fitness program: Attitudes, social influence, and self-efficacy. Preventive Medicine, 24, 627-633.

Lechner, L., \& De Vries, H. (2002). Sunbed use at home: Risk behaviour and psychosocial determinants. European Journal of Cancer Prevention, 11, 333-341.

Lechner, L., De Vries, H., \& Offermans, N. (1997). Participation in a breast cancer screening program: Influence of past behavior and determinants on future screening participation. Preventive Medicine, 26, 473-482.

Lewis, C. C. (1981). The effects of parental firm control: A reinterpretation of findings. 
Psychological Bulletin, 90, 547-563.

Lewit, E. M., Hyland, A., Kerrebrock, N., \& Cummings, K. M. (1997). Price, public policy, and smoking in young people. Tobacco Control, 6 Suppl 2, S17-24.

Losoya, S. H., Callor, S., Rowe, D. C., \& Goldsmith, H. H. (1997). Origins of familial similarity in parenting: A study of twins and adoptive siblings. Developmental Psychology, 33, 1012-1023.

Lynch, B. S., \& Bonnie, R. J. (1998). Growing up tobacco free: Preventing nicotine addiction in children and youths ( $4^{\text {th }}$ ed.). Washington, DC: National Academy Press.

Lytton, H. (1990). Child and parent effects in boys' conduct disorder: A reinterpretation. Developmental Psychology, 26, 683-697.

Ma, G. X., Shive, S., Legos, P., \& Tan, Y. (2003). Ethnic differences in adolescent smoking behaviors, sources of tobacco, knowledge and attitudes toward restriction policies. Addictive Behaviors, 28, 249-268.

Maccoby, E. E., \& Martin, J. A. (1983). Socialization in the context of the family: Parentchild interaction. In E. M. Hetherington (Ed.), Handbook of Child Psychology (Vol. 4, pp. 1-101). New York: Wiley.

Marsh, H. W., Balla, J. R., \& Hau, K. (1996). An evaluation of incremental fit indices: A clarification of mathematical and empirical proportions. In G. A. Marcoulides \& R. E. Schumacker (Eds.), Advanced structural equation modeling. Issues and techniques (pp. 347348). Mahwah, NJ: Lawrence Erlbaum Associates.

Mayhew, K., Flay, B. R., \& Mott, J. A. (2000). Stages in the development of adolescent smoking. Drug and Alcohol Dependence, 59, S61-S81.

McCrae, R. R., \& Costa, P. T., Jr. (1997). Personality trait structure as a human universal. American Psychologist, 52, 509-516.

McGroder, S. M. (2000). Parenting among low-income African American single mothers with preschool-age children: Patterns, predictors, and developmental correlates. Child Development, 71, 752-771.

McGuire, W. J. (1989). Theoretical foundations of campaigns. In E. Rice \& C. K. Atkin (Eds.), Public communication campaigns (2nd ed., pp. 43-65). Newbury Park, CA: Sage Publishers.

McLoyd, V. C., Jayaratne, T. E., Ceballo, R., \& Borquez, J. (1994). Unemployment and work interruption among African American single mothers: Effects on parenting and adolescent socioemotional functioning. Child Development, 65, 562-589.

Meinsma, L. (1969). Roken en risico's [Smoking and risks] (3rd ed.). Lochem, the Netherlands: De Tijdstroom.

Mokdad, A. H., Marks, J. S., Stroup, D. F., \& Gerberding, J. L. (2004). Actual causes of death in the United States, 2000. Journal of the American Medical Association, 291, 1238-1245.

Mott, J. A., Crowe, P. A., Richardson, J., \& Flay, B. (1999). After-school supervision and adolescent cigarette smoking: contributions of the setting and intensity of after-school selfcare. Journal of Behavioral Medicine, 22, 35-58.

Muthén, L. K., \& Muthén, B. O. (1998-2004). Mplus user's guide. Third edition. Los Angeles: 
Muthén \& Muthén.

O’Byrne, K. K., Haddock, C. K., \& Poston, W. S. C. (2002). Parenting style and adolescent smoking. Journal of Adolescent Health, 30, 418-425.

O'Connor, B. P., \& Dvorak, T. (2001). Conditional associations between parental behavior and adolescent problems: A search for personality-environment interactions. Journal of Research in Personality, 35, 1-26.

O'Connor, T. G. (2002). Annotation: The 'effects' of parenting reconsidered: Findings, challenges, and applications. Journal of Child Psychology and Psychiatry, 43, 555-572.

Olsen Fulero, L., \& Conforti, J. (1983). Child responsiveness to mother questions of varying type and presentation. Journal of Child Language, 10, 495-520.

Otten, R., Engels, R. C. M. E., Van de Ven, M. O. M., Van den Eijnden, R. J. J. M., \& Bricker, J. B. (submitted). How parental smoking affects adolescent smoking transitions.

Otten, R., Engels, R. C. M. E., \& Van den Eijnden, R. J. J. M. (in press-a). The relative contribution of parenting practices in smoking behavior of adolescents with and without asthma. Nicotine and Tobacco Research.

Otten, R., Engels, R. C. M. E., \& Van den Eijnden, R. J. J. M. (in press-b). Smoking behavior in asthmatic and non-asthmatic adolescents: The role of smoking models and personality. Substance Use and Misuse.

Otten, R., Harakeh, Z., Vermulst, A. A., Van den Eijnden, R. J. J. M., \& Engels, R. C. M. E. (in press). Frequency and quality of parental communication as antecedents of adolescent smoking cognitions and smoking onset. Psychology of Addictive Behaviors.

Panday, S., Reddy, S. P., Ruiter, R. A., Bergstrom, E., \& De Vries, H. (2005). Determinants of smoking cessation among adolescents in South Africa. Health Education Research, 20, 586599.

Pederson, L. L., Koval, J. J., McGrady, G. A., \& Tyas, S. L. (1998). The degree and type of relationship between psychosocial variables and smoking status for students in grade 8: is there a dose-response relationship? Preventive medicine, 27, 337-347.

Perry, C. L., Kelder, S. H., \& Komro, K. A. (1993). The social world of adolescents: Family, peers, schools, and the community. In S. G. Millstein \& A. C. Petersen \& E. O. Nightingale (Eds.), Promoting the health of adolescents: New directions for the twenty-first century (pp. 7396). New York: Oxford University Press.

Pervin, L. A., \& John, O. P. (2001). Personality: Theory and research ( $8^{\text {th }}$ ed.). New York: Wiley.

Petraitis, J., Flay, B. R., \& Miller, T. Q. (1995). Reviewing theories of adolescent substance use: Organizing pieces in the puzzle. Psychological Bulletin, 117, 67-86.

Pierce, J. P., Distefan, J. M., Jackson, C., White, M. M., \& Gilpin, E. A. (2002). Does tobacco marketing undermine the influence of recommended parenting in discouraging adolescents from smoking? American Journal of Preventive Medicine, 23, 73-81.

Piko, B. (2000). Perceived social support from parents and peers: Which is the stronger predictor of adolescent substance use? Substance Use and Misuse, 35, 617-630.

Prinzie, P., Onghena, P., Hellinckx, W., Grietens, H., Ghesquiere, P., \& Colpin, H. (2003). 
The addictive and interactive effects of parenting and children's personality on externalizing behavior. European Journal of Personality, 17, 95-117.

Prinzie, P., Onghena, P., Hellinckx, W., Grietens, H., Ghesquiere, P., \& Colpin, H. (2004). Parent and child personality characteristics as predictors of negative discipline and externalizing problem behaviour in children. European Journal of Personality, 18, 73-102.

Prochaska, J. O., DiClemente, C. C., \& Norcross, J. C. (1992). In search of how people change. Applications to addictive behaviors. American psychologist, 47, 1102-1114.

Raboteg Saric, Z., Rijavec, M., \& Brajsa Zganec, A. (2001). The relation of parental practices and self-conceptions to young adolescent problem behaviors and substance use. Nordic Journal of Psychiatry, 55, 203-209.

Radziszewska, B., Richardson, J. L., Dent, C. W., \& Flay, B. R. (1996). Parenting style and adolescent depressive symptoms, smoking, and academic achievement: Ethnic, gender, and SES differences. Journal of Behavioral Medicine, 19, 289-305.

Robinson, P. W., \& Green, M., R. (2004). A comparative look at the promises of three influential humanistically oriented parenting systems of Freud, Adler and Rogers versus the American family system. American Association of Behavioral Social Science Online Journal, 7 , 1-14.

Rogers, C. R. (1960). A therapist's view of personal goals (Pendle Hill Pamphlet 108). Oxford, England: Pendle Hill.

Rosenthal, R. (1990). How are we doing in soft psychology? American Psychologist, 45, 775777.

Saucier, G., \& Goldberg, L. R. (1998). What is beyond the Big Five? Journal of Personality, 66, 495-524.

Schaefer, E. S. (1959). A circumplex model for maternal behavior. Journal of Abnormal and Social Psychology, 59, 226-235.

Sears, R. R., Maccoby, E. E., \& Levin, H. (1957). Patterns of child rearing. Oxford, England: Row, Peterson and Co.

Shek, D. T. L. (1998). Adolescents' perceptions of paternal and maternal parenting styles in a Chinese context. Journal of Psychology, 132, 527-537.

Shiffman, S., Paty, J. A., Gnys, M., Kassel, J. A., \& Hickcox, M. (1996). First lapses to smoking: Within-subjects analysis of real-time reports. Journal of Consulting and Clinical Psychology, 64, 366-379.

Silk, J. S., Morris, A. S., Kanaya, T., \& Steinberg, L. (2003). Psychological control and autonomy granting: Opposite ends of a continuum or distinct constructs? Journal of Research on Adolescence, 13, 113-128.

Simons Morton, B., Crump, A. D., Haynie, D. L., Saylor, K. E., Eitel, P., \& Yu, K. (1999). Psychosocial, school, and parent factors associated with recent smoking among earlyadolescent boys and girls. Preventive Medicine, 28, 138-148.

Simons Morton, B., Haynie, D. L., Crump, A. D., Eitel, S. P., \& Saylor, K. E. (2001). Peer and parent influences on smoking and drinking among early adolescents. Health Education and Behavior, 28, 95-107. 
Simons Morton, B. G. (2002). Prospective analysis of peer and parent influences on smoking initiation among early adolescents. Prevention Science, 3, 275-283.

Simons, R. L., Beaman, J., Conger, R. D., \& Chao, W. (1993). Stress, support, and antisocial behavior trait as determinants of emotional well-being and parenting practices among single mothers. Journal of Marriage and the Family, 55, 385-398.

Sins, P. H. M. (2006). Students' reasoning during computer-based scientific modeling: The impact of epistemology, motivation and communication mode. Amsterdam, the Netherlands: University of Amsterdam.

Stacy, A. W., Bentler, P. M., \& Flay, B. R. (1994). Attitudes and health behavior in diverse populations: Drunk driving, alcohol use, binge eating, marijuana use, and cigarette use. Health Psychology, 13, 73-85.

Statistics Netherlands (2006). Regionale Statistieken [Regional Statistics]. Retrieved April 3, 2006, from http://statline.cbs.nl.

Stattin, H., \& Kerr, M. (2000). Parental monitoring: A reinterpretation. Child Development, 71, 1072-1085.

Steinberg, L. (1990). Autonomy, conflict, and harmony in the family relationship. In G. R. Elliot (Ed.), At the threshold: The developing adolescent (pp. 255-276). Cambrigde, MA: Harvard University Press.

Steinberg, L., Elmen, J. D., \& Mounts, N. S. (1989). Authoritative parenting, psychosocial maturity, and academic success among adolescents. Child Development, 60, 1424-1436.

Steinberg, L., Lamborn, S. D., Darling, N., Mounts, N. S., \& Dornbusch, S. M. (1994). Over-time changes in adjustment and competence among adolescents from authoritative, authoritarian, indulgent, and neglectful families. Child Development, 65, 754-770.

Steinberg, L., Lamborn, S. D., Dornbusch, S. M., \& Darling, N. (1992). Impact of parenting practices on adolescent achievement: Authoritative parenting, school involvement, and encouragement to succeed. Child Development, 63, 1266-1281.

Stice, E., \& Barrera, M. (1995). A longitudinal examination of the reciprocal relations between perceived parenting and adolescents' substance use and externalizing behaviors. Developmental Psychology, 31, 322-334.

STIVORO (2003). Jaarverslag 2002 [Annual report 2002]. The Hague, the Netherlands: STIVORO voor een rookvrije toekomst.

STIVORO - rookvrij (2004a). Jaarverslag 2003 [Annual report 2003]. The Hague, the Netherlands: STIVORO - rookvrij.

STIVORO - rookvrij (2004b). Roken, de harde feiten: Jeugd 2003 [Smoking, the harsh facts: Youth 2003]. The Hague, the Netherlands: STIVORO - rookvrij.

STIVORO - rookvrij (2004c). Roken, de harde feiten: Volwassenen 2003 [Smoking, the harsh facts: Adults 2003]. The Hague, the Netherlands: STIVORO - rookvrij.

STIVORO - rookvrij (2005). Roken, de harde feiten: Jeugd 2004 [Smoking, the harsh facts: Youth 2004]. The Hague, the Netherlands: STIVORO - rookvrij.

Stolp, D. (1916). Rookende kinderen: Een waarschuwend woord tot ouders en kindervrienden [Smoking children: A word of warning to parents and friends of children]. Dordrecht, the 
Netherlands: Gemeente Bestuur.

Symonds, P. M. (1937). Some basic concepts in parent-child relationships. American Journal of Psychology, 50, 195-206.

Tabachnick, B. G., \& Fidell, L. S. (2001). Using multivariate statistics (4 ${ }^{\text {th }}$ ed.). Boston: Allyn and Bacon.

Tercyak, K. P., Goldman, P., Smith, A., \& Audrain, J. (2002). Interacting effects of depression and tobacco advertising receptivity on adolescent smoking. Journal of Pediatric Psychology, 27, 145-154.

Torrey, E. F. (1992). Freudian fraud: The malignant effect of Freud's theory on American thought and culture. New York: HarperCollins Publishers.

Townsend, J., Roderick, P., \& Cooper, J. (1994). Cigarette smoking by socioeconomic group, sex, and age: Effects of price, income, and health publicity. British Medical Journal, 309, 923-927.

Turner, L., Mermelstein, R., \& Flay, B. (2004). Individual and contextual influences on adolescent smoking. Annals of the New York Academy of Sciences, 1021, 175-197.

U.S. Department of Health, Education and Welfare (1968). Teenage smoking: National patterns of cigarette smoking, ages 12 through 18, in 1968 and 1970. Rockville, MD: U.S. Department of Health, Education, and Welfare, Public Health Service, Health Services and Mental Health Administration, Regional Medical Programs Services, National Clearinghouse for Smoking and Health.

U.S. Department of Health and Human Services (1994). Preventing Tobacco Use among Young People: A Report of the Surgeon General. Atlanta, GA: U.S. Department of Health and Human Services: Public Health Service, Centers for Disease Control and Prevention, National Center for Chronic Disease Prevention and Health Promotion, Office on Smoking and Health.

Van der Vorst, H., Engels, R. C., Meeus, W., Dekovic, M., \& Van Leeuwe, J. (2005). The role of alcohol-specific socialization in adolescents' drinking behaviour. Addiction, 100, 14641476.

Van der Vorst, H., Engels, R. C. M. E., Meeus, W., Dekovic, M., \& Vermulst, A. A. (in press). Parental attachment, parental control and early development of alcohol use: A longitudinal study. Psychology of Addictive Behaviors.

Van Zundert, R. M. P., Van de Ven, M., Engels, R. C. M. E., Otten, R., \& Van den Eijnden, R. J. J. M. (submitted). The Role of Smoking Cessation-Specific Parenting in Adolescent Smoking-Specific Cognitions and Readiness to Quit. Journal of Child Psychology \& Psychiatry.

Vink, J. M., Willemsen, G., \& Boomsma, D. I. (2003). The association of current smoking behavior with the smoking behavior of parents, siblings, friends and spouses. Addiction, 98, 923-931.

Vink, J. M., Willemsen, G., \& Boomsma, D. I. (2005). Heritability of smoking initiation and nicotine dependence. Behavior Genetics, 35, 397-406.

Vroom, B. (1994). De tekst getest. Handleiding voor het pretesten van schriftelijk materiaal [The text tested. Manual for pretesting written material]. Assen, the Netherlands: Van Gorcum.

Wakefield, M., Flay, B., Nichter, M., \& Giovino, G. (2003). Role of the media in influencing 
trajectories of youth smoking. Addiction, 98 Suppl 1, 79-103.

Walls, T. A., \& Schafer, J. L. (2006). Models for intensive longitudinal data. New York: Oxford University Press.

Warren, C., Jones, N., Eriksen, M., \& Asma, S. (2006). Patterns of global tobacco use in young people and implications for future chronic disease burden in adults. The Lancet, 367, 749-753.

Watson, D., \& Clark, L. A. (1992). On traits and temperament: General and specific factors of emotional experience and their relation to the five-factor model. Journal of Personality, 60 , 441-476.

Watson, J. B. (1928). Psychological care of infant and child. New York: Norton.

Watson, J. B., \& Rayner, R. (1920). Conditioned emotional reactions. Journal of Experimental Psychology, 3, 1-14.

Webb, T. L., \& Sheeran, P. (2006). Does changing behavioral intentions engender behavior change? A meta-analysis of the experimental evidence. Psychological bulletin, 132, 249-268.

Weinstein, N. D. (1988). The precaution adoption process. Health Psychology, 7, 355-386.

WHO (1988). Guidelines for controlling and monitoring the Tobacco Epidemic. Geneva.

Wijatkowski, S., Forgays, D. G., Wrzesniewski, K., \& Gorski, T. (1990). Smoking behavior and personality characteristics in Polish adolescents. International Journal of the Addictions, 25, 363-373.

Wikipedia Encyclopedia (2006). Tobacco smoking. Retrieved March 12, 2006, from http:// en.wikipedia.org/wiki/Tobacco_smoking.

World Health Organization (2002). The Tobacco Atlas. London: The Hanway Press.

Wynder, E. L. (1956). Environmental causes of cancer in man. The Medical clinics of North America, 40, 629-645. 

Samenvatting 

Hoewel bekend is dat roken schadelijk is voor de gezondheid, beginnen adolescenten nog steeds met roken. Om dit te veranderen is het nodig een beter inzicht te krijgen in de factoren die het rookgedrag van adolescenten bepalen. Onderzoekers uit de hoek van de sociale cognitie hebben het rookgedrag van adolescenten uit interne cognitieve factoren verklaard en stellen dat adolescenten de grootste kans hebben om te roken wanneer ze een positieve attitude hebben ten aanzien van roken, sociale invloeden ervaren die positief zijn over roken en verwachten het roken moeilijk te kunnen laten. Onderzoekers uit een andere hoek hebben de invloed van de sociale omgeving nader onderzocht, bijvoorbeeld die van ouders en leeftijdsgenoten. De onderzoekers gaan er daarbij van uit dat gedrag van belangrijke anderen een sterke voorspeller is van het rookgedrag van adolescenten. Ofschoon de meeste studies uit deze laatste discipline zich hebben gericht op de invloed van leeftijdgenoten, is de invloed van ouders in dit opzicht van minstens even groot belang. Hoewel de relevantie van zowel cognitieve factoren als van sociale invloeden wordt erkend, zijn deze twee invalshoeken zelden geïntegreerd en is onduidelijk hoe rookgerelateerde cognities precies ontstaan. Het onderzoek dat in dit proefschrift wordt beschreven combineert deze twee benaderingen door te onderzoeken welke invloed ouders hebben op het ontwikkelen van rookcognities en -gedrag van adolescenten. Er werd onderzocht of aspecten van opvoeding konden worden geïntegreerd in een sociaal cognitief model, het I-Change Model, en of de persoonlijkheid van ouders aan hun opvoedstijl voorafgaat. Bovendien werden inconsistente effecten van rookspecifieke opvoeding op het rookgedrag van adolescenten uit eerdere studies aan de orde gesteld. De meest prominente bevindingen zijn uit Tabel 1 af te lezen.

\section{Deel I: Integratie van Opvoeding in het I-Change Model}

Deel I van dit proefschrift is gericht op het integreren van twee oorspronkelijk onafhankelijke benaderingen, door te onderzoeken of opvoeding kan worden beschouwd als een distale sociale factor in het I-Change Model. Volgens dit model wordt het rookgedrag 
van adolescenten verklaard uit rookgerelateerde cognities. Om te onderzoeken hoe deze cognities ontstaan en om de wijze te bestuderen waarop opvoeding het roken van adolescenten beïnvloedt, is onderzocht of effecten van opvoeding op het rookgedrag van adolescenten verloopt via rookgerelateerde cognities, namelijk attitude, waargenomen sociale invloeden en eigen-effectiviteitsverwachtingen. Dit wordt in hoofdstuk 2 en 3 onderzocht voor respectievelijk opvoedstijl en rookspecifieke opvoeding. Opvoedstijl wordt gedefinieerd als het globale emotionele klimaat waarin een familie functioneert, maar opvoeding kan ook meer inhoudelijke vormen aannemen, zoals met betrekking tot roken, waarbij rookspecifieke opvoedstrategieën alle aspecten van opvoeding omvatten die zijn gericht op het ontmoedigen van roken.

In hoofdstuk 2 wordt een cross-sectionele studie beschreven onder 482 adolescenten in de leeftijd van 12 tot 19 jaar, waarbij de relatie wordt onderzocht tussen opvoedstijlen (autoritatief, autoritair, permissief, afwijzend en verwaarlozend, gemeten door combinaties van onderliggende dimensies steun, strikte controle en psychologische controle) en rookcognities en -gedrag van adolescenten. De voornaamste bevindingen hielden in dat de mate waarin ouders steun boden niet samenhing met het wel of niet roken van adolescenten. Bovendien bleek strikte controle door de ouders van het gedrag van het kind samen te hangen met het rookgedrag van het kind. Dit effect bleek gedeeltelijk te verlopen via de attitude ten aanzien van roken en de intentie om te roken. Als ouders in hogere mate strikte controle uitoefenden, hadden adolescenten bijvoorbeeld een minder positieve attitude ten aanzien van roken en was het minder waarschijnlijk dat ze ooit gerookt hadden. Daarnaast bleek psychologische controle (pogingen van ouders om invloed uit te oefenen op de psychologische wereld van het kind) rechtstreeks samen te hangen met rookgedrag, in de zin dat adolescenten een verhoogde kans hadden ooit gerookt te hebben als hun ouders veel psychologische controle uitoefenden. Hogere niveaus van psychologische controle beïnvloedden de rookgerelateerde cognities niet en werden er niet door geïnternaliseerd. De specifieke opvoedstijlen zoals gecreëerd uit de onderliggende dimensies hingen niet samen met cognities of gedrag. 
De effecten van opvoeding op het rookgedrag verschilden niet voor vaders en moeders en waren hetzelfde voor jongens als meisjes. Bovendien waren de effecten van opvoeding op rookgedrag hetzelfde voor kinderen van rokende als van niet-rokende ouders. We concludeerden dat het IChange Model kon worden uitgebreid met aspecten van strikte controle door de ouders.

In hoofdstuk 3 wordt een studie beschreven waarin rookspecifieke opvoeding (reacties van ouders op roken, huisregels, frequentie en inhoud van communicatie over roken) wordt beschouwd als distale sociale factor in het I-Change Model. Onder een grote groep adolescenten van 13 jaar oud ten tijde van de basismeting en 15 jaar oud bij de tweede meting werd nagegaan of rookspecifieke opvoeding het rookgedrag via de rookgerelateerde cognities beïnvloedde. Op de leeftijd van 13 jaar werden relaties tussen aspecten van rookspecifieke opvoeding en het rookgedrag gemedieerd door cognities en deze effecten waren uitgesprokener toen de adolescenten twee jaar ouder waren. De prospectieve relaties tussen opvoeding en rookcognities en -gedrag werden ook bestudeerd. Adolescenten aan wie een beloning in het vooruitzicht was gesteld voor niet-roken, hadden twee jaar later een verhoogde kans te zijn gaan roken. Adolescenten hadden daarentegen een kleinere kans te zijn gaan roken als ouders met hen hadden gepraat over aandacht die op school aan roken besteed werd. Deze aspecten van opvoeding werkten rechtsreeks op gedrag, zonder via de cognities te verlopen zoals die hier gemeten werden. Effecten van opvoeding waren hetzelfde voor jongens als meisjes en het rookgedrag van ouders had geen invloed op de doeltreffendheid van rookspecifieke opvoedstrategieën. Er werd geconcludeerd dat rookspecifieke opvoeding een gunstig effect zou kunnen hebben op rookcognities en -gedrag van adolescenten, maar dat meer inzicht nodig was in de omstandigheden waaronder dit gold.

In hoofdstuk 4 wordt een studie beschreven waarin de persoonlijkheid van ouders aan hun opvoedstijl gerelateerd wordt. Eerdere studies naar determinanten van opvoeding beperkten zich veelal tot determinanten van inadequate opvoeding, opvoedkundige vaardigheden van ouders 
in groepen met verhoogd risico, of beperkten zich tot ouders van peuters. Omdat kenmerken van ouders van indirect belang kunnen zijn voor de ontwikkeling van kinderen, was er dus behoefte aan inzicht in determinanten van opvoeding voor normale ouders van adolescenten. De persoonlijkheid van ouders wordt verondersteld andere mogelijke determinanten van opvoedstijl te beïnvloeden en is daarmee een belangrijke eigenschap die van indirecte betekenis kan zijn voor het gezondheidsgedrag van adolescenten, zoals roken. In een cross-sectioneel onderzoek onder 688 ouders van adolescenten werd daarom onderzocht of de Big Five persoonlijkheidskenmerken (extraversie, nauwgezetheid, vriendelijkheid, emotionele stabiliteit en openheid voor nieuwe ervaringen) samenhingen met de autoritatieve, autoritaire, permissieve en verwaarlozende opvoedstijlen, die werden gemeten door de onderliggende dimensies van steun en strikte controle. Een van de voornaamste bevindingen was dat extraverte, vriendelijke, en minder emotioneel stabiele individuen het meest geneigd waren de autoritatieve opvoedstijl te hanteren die geassocieerd wordt met gunstig gezondheidsgedrag van adolescenten. Meer specifiek bleek dat ouders die hoog scoorden op interpersoonlijke interactie (doordat ze extravert en vriendelijk waren) meer steun boden en dat emotioneel stabiele ouders minder strikte controle uitoefenden. We redeneerden dat ouders die hoog scoorden op interpersoonlijke interactie prettigere ouders voor adolescenten zouden zijn en dat de affectieve component van de persoonlijkheid samenging met een affectieve component in de opvoeding. De bevinding dat emotioneel stabiele ouders minder controle uitoefenden was onverwacht, maar we suggereerden dat omdat emotioneel instabiele individuen sneller inadequaat reageren ze wellicht eerder hun toevlucht nemen tot het uitoefenen van controle. Emotionele instabiliteit kan zo in extreme mate resulteren in draconisch opvoeden. Nauwgezetheid en openheid hingen niet samen met opvoedstijl zoals hier gemeten, maar zijn misschien gerelateerd aan meer inhoudsspecifieke aspecten van opvoeding. Als het globale opvoedklimaat wordt gezien als een distale sociale factor in het I-Change Model die rookcognities en -gedrag van adolescenten beïnvloedt, dan kan de persoonlijkheid van ouders als een meer distale factor worden beschouwd. 


\section{Deel II: Over Inconsistente Verbanden tussen Rookspecifieke Opvoeding en Rookgedrag van Adolescenten}

In deel II van dit proefschrift worden eerder gerapporteerde inconsistente verbanden tussen rookspecifieke opvoeding en rookgedrag van adolescenten behandeld. Intuïtief gezien mag verwacht worden dat rookspecifieke opvoeding gunstige effecten kan hebben op het rookgedrag van adolescenten. Zo kan verwacht worden dat adolescenten die thuis niet mogen roken daadwerkelijk minder roken dan adolescenten bij wie het er thuis minder streng aan toegaat. En alhoewel sommige studies dit bevestigen, worden deze resultaten niet altijd gerepliceerd. Soms blijven effecten van rookspecifieke opvoeding uit of werkt het zelfs averechts. Er zijn verschillende verklaringen denkbaar, die afhangen van het gedrag van de ouders. Ten eerste kan het zo zijn dat de effectiviteit van rookspecifieke opvoeding afhangt van het rookgedrag van de ouders. Adolescenten zitten er misschien niet op te wachten dat hun rokende ouders boodschappen tegen het roken prediken. Een andere mogelijkheid is dat ouders die zelf roken pogingen hun kinderen van het roken af te houden achterwege laten omdat ze er niet aan hechten. Ook kan het zijn dat zij zich er minder goed toe in staat achten anti-roken boodschappen over te brengen en zich voelen alsof ze voor stoelen en banken preken. Het rookgedrag van ouders is dus een factor die niet over het hoofd gezien mag worden bij het interpreteren van effecten van rookspecifieke opvoeding. Ten tweede is opvoedstijl voorgesteld als een context waarin rookspecifieke opvoeding plaatsvindt en daarom moet deze wellicht in beschouwing genomen worden. De effectiviteit van rookspecifieke opvoedstrategieën zou kunnen afhangen van het opvoedklimaat waarin deze tot uitdrukking worden gebracht. Het socialiseren van adolescenten met betrekking tot niet-roken heeft wellicht alleen zin voor adolescenten die hun ouders als autoritatief ervaren. Ten derde is het leeuwendeel van het onderzoek naar de relatie tussen rookspecifieke opvoeding en het roken van adolescenten gebaseerd op cross-sectionele bevindingen, wat het moeilijk maakt uitspraken over causaliteit te doen. Gerapporteerde cross-sectionele relaties tussen rookspecifieke opvoedstrategieën en rookgedrag van adolescenten blijven uit in longitudinale analyses, wat 
erop kan duiden dat cross-sectionele verbanden verkeerd geïnterpreteerd zijn en dat kind-effecten over het hoofd gezien zijn. Volgens deze derde verklaring zouden ogenschijnlijk gunstige cross-sectionele effecten van bijvoorbeeld regels over niet-roken in huis uitblijven in longitudinale analyses als het niet de huisregels zijn die het rookgedrag van adolescenten beïnvloeden, maar als het rookgedrag de huisregels beïnvloedt.

Met betrekking tot de eerste verklaring voor de gerapporteerde tegenstrijdigheden tonen de bevindingen van hoofdstuk 3 en andere studies aan dat de effecten van rookspecifieke opvoeding niet afhangen van het rookgedrag van ouders. Dit sluit uit dat het rookgedrag van ouders de relatie tussen rookspecifieke opvoeding en roken van adolescent modereert. De andere twee verklaringen worden respectievelijk in hoofdstuk 5 en 6 aan de orde gesteld.

In de tweede verklaring verandert volgens Darling en Steinberg (1993) opvoedstijl de mogelijkheden van ouders om hun kinderen te socialiseren door de effectiviteit van rookspecifieke opvoeding te beïnvloeden. In hoofdstuk 5 wordt opvoedstijl dan ook beschouwd als een contextuele variabele die de relatie tussen rookspecifieke opvoeding en rookgedrag van adolescenten modereert. Onder de 12- tot 19-jarigen in de eerder genoemde steekproef werd een model getoetst waarbij rookspecifieke opvoedstrategieën (communicatie over roken, niet-roken huisregels, beschikbaarheid van tabaksproducten, afspraken om niet te roken) cross-sectioneel werden gerelateerd aan rookcognities en -gedrag van adolescenten. Communicatie over roken tussen ouders en jongeren hing samen met minder roken en verliep via de attitude ten aanzien van roken en de intentie om te roken. Het beschikbaar zijn van tabaksproducten hing samen met een positievere attitude ten opzichte van roken en een lagere inschatting van de eigen-effectiviteit om niet te roken, die beide weer samenhingen met de intentie om te gaan roken en het rookgedrag. Dit model werd vervolgens vergeleken voor adolescenten die opgroeiden in verschillende opvoedklimaten, namelijk bij hoge en lage niveaus van steun, strikte controle en psychologische controle. Hoewel verwacht werd dat de meest gunstige effecten van rookspecifieke opvoeding geboekt zouden worden voor adolescenten die opgroeiden in een 
autoritatief opvoedklimaat (veel steun, veel strikte controle en weinig psychologische controle) toonden de resultaten aan dat de effectiviteit van rookspecifieke opvoeding niet afhing van het opvoedklimaat waarin deze tot uitdrukking werd gebracht. Opvoedstijl diende dus niet als context voor rookspecifieke opvoeding zoals door Darling en Steinberg verondersteld werd, hetgeen suggereert dat opvoedstijl en rookspecifieke opvoeding onafhankelijk van elkaar met het roken van adolescenten samenhangen. De eerder gerapporteerde tegenstrijdige relaties tussen rookspecifieke opvoeding en roken van adolescenten konden dus niet worden toegeschreven aan het opvoedklimaat waarin deze gedragingen tot uitdrukking kwamen.

In hoofdstuk 6 wordt de derde verklaring voor deze inconsistenties onderzocht. Een longitudinaal cross-lagged model werd getoetst door rookspecifieke opvoeding (anti-roken huisregels en communicatie over roken) en het rookgedrag van jongeren op drie opeenvolgende tijdstippen te meten, om te bestuderen hoe ouders en adolescenten elkaar door de tijd beïnvloeden. De resultaten lieten zien dat jongeren het gedrag van ouders sterker beïnvloedden dan ouders het rookgedrag van jongeren. Hoewel de rookspecifieke opvoedstrategieën het rookgedrag nauwelijks beïnvloedden, reageerden ouders op het rookgedrag van hun kinderen door minder regels te stellen omtrent roken in huis en door meer met hun kinderen over roken te praten. De versoepeling van de huisregels was uitgesprokener als ouders zelf rookten en de communicatie nam sterker toe voor niet-rokende ouders. Deze bevindingen waren identiek voor jongens als meisjes. De resultaten suggereren derhalve dat opvoeding niet enkel als determinant van het rookgedrag van adolescenten moet worden beschouwd, maar ook als gevolg. De eerder gerapporteerde inconsistente effecten van rookspecifieke opvoeding lijken dus inderdaad te kunnen worden toegeschreven aan het feit dat kind-effecten buiten beschouwing zijn gelaten. Het buiten beschouwing laten van deze effecten bemoeilijkt de interpretatie van cross-sectionele bevindingen omdat onduidelijk blijft wie wie beïnvloedt. De resultaten duiden erop dat in toekomstig onderzoek naar de effectiviteit van opvoeding rekening gehouden moet worden met kind-effecten. 
In het afsluitende hoofdstuk worden de voornaamste bevindingen van de studies in dit proefschrift samengevat en worden implicaties besproken. Methodologische tekortkomingen worden aan de orde gesteld en er wordt een voorzet gedaan voor toekomstig onderzoek op het gebied van opvoeding en rookcognities en -gedrag van adolescenten. Geconcludeerd wordt tenslotte dat aspecten van opvoeding het rookgedrag van adolescenten via rookgerelateerde cognities beïnvloeden en dat het I-Change Model met deze aspecten uitgebreid kan worden. Ouders beïnvloeden niet alleen het rookgedrag van hun kinderen, maar zij passen zich minstens even sterk aan het gedrag van hun kinderen aan. Dat ouders boodschappen prediken tegen het roken is derhalve onvoldoende om adolescenten van het roken af te houden en ouders moeten de daad bij het woord voegen door zelf niet te roken.

Tabel 1

Samenvatting van de Belangrijkste Bevindingen van dit Proefschrift

Hoofdstuk

- Het I-Change Model kan worden uitgebreid met strikte controle van de zijde van de 2 ouders als distale sociale factor en psychologische controle werkt rechtstreeks op het rookgedrag van adolescenten zonder te worden geïnternaliseerd.

- Rookspecifieke opvoeding kan worden beschouwd als distale sociale factor in het IChange Model.

- Relaties tussen opvoeddimensies en het rookgedrag van adolescenten zijn onafhankelijk van het geslacht van ouder of kind.

- Relaties tussen rookspecifieke opvoeding en het rookgedrag van adolescenten zijn onafhankelijk van het geslacht van het kind.

- De persoonlijkheid van ouders is gerelateerd aan opvoedstijl en kan dus van indirect belang zijn voor rookcognities en -gedrag van adolescenten.

- Het rookgedrag van adolescenten hangt samen met dat van hun ouders en de effecten van opvoeding op rookcognities en -gedrag van adolescenten zijn hetzelfde voor rokende en niet-rokende ouders.

- Opvoedstijl kan niet beschouwd worden als context voor rookspecifieke opvoeding.

- Het rookgedrag van adolescenten is een sterkere voorspeller voor rookspecifieke opvoeding dan andersom. 



\section{Thanks to}

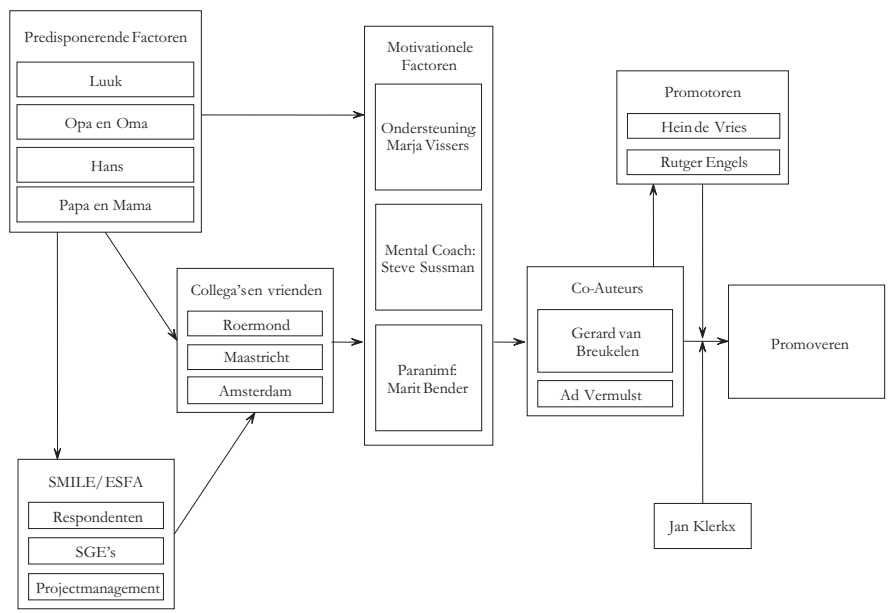





\section{About the author}

Rosemarie Huver was born in the Dutch town of Emmen on March 22, 1979. At age 9, she spent a year in New York with her brother and authoritative, nonsmoking parents. During her adolescence, parental anti-smoking socialization efforts affected neither cognitions nor behavior and she received her VWO diploma at the Stedelijk Lyceum in Roermond in 1997. In that same year, she started studying psychology at Maastricht University, where she graduated in 2001, having specialized in cognitive psychology.

After detouring into the world of the Inspectorate of Education, she returned to Maastricht University in October 2002 to work on a $\mathrm{PhD}$ project at the Department of Health Education and Health Promotion of the Faculty of Health Sciences. She studied the relation between parenting and adolescent smoking cognitions and behavior, which resulted in this thesis. In addition, she presented her research findings at several national and international conferences. In May 2006, she started working as a post-doc researcher at the Department of Private Law of the Vrije Universiteit in Amsterdam. 




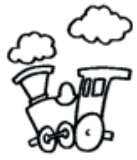

